Linköping Studies in Science and Technology

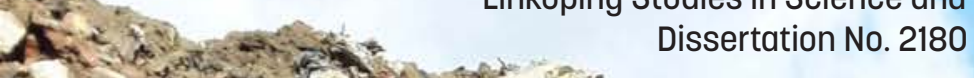

Q 35 .

(5)

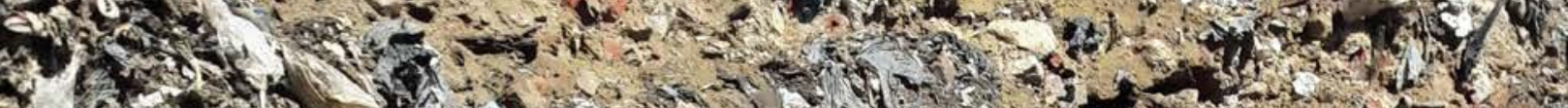

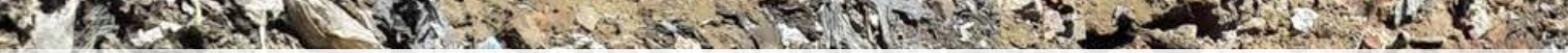

\title{
Developing strategies for improved economic performance and reduced climate impact of landfill mining in Europe John Laurence Esguerra
}

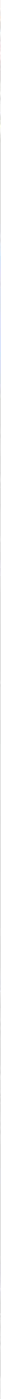





\section{Developing strategies for improved economic performance and reduced climate impact of landfill mining in Europe:}

\section{A generic and learning-oriented approach for assessing an emerging concept}

John Laurence Esguerra

Supervisors:

Joakim Krook (main)

Niclas Svensson

Steven Van Passel

Thesis submitted for the double degree of:

Doctor of Environmental Management and Engineering at Linköping University Doctor of Applied Economics at the University of Antwerp
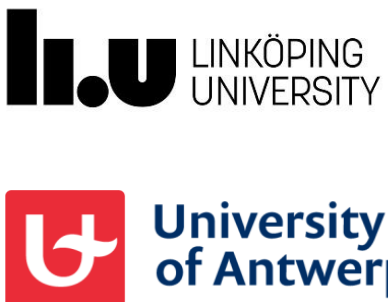

University of Antwerp
Division of Environmental Technology and Management Department of Management and Engineering Linköping University, SE-581 83 Linköping, Sweden

Faculty of Business and Economics, Department of Engineering Management University of Antwerp, BE-200o Antwerp, Belgium 
(c) EY This work is licensed under a Creative Commons Attribution 4.0 International License.

https://creativecommons.org/licenses/by/4.0/

(C) John Laurence Esguerra, 2021

Developing strategies for improved economic performance and reduced climate impact of landfill mining in Europe:

A generic and learning-oriented approach for assessing an emerging concept

Linköping Studies in Science and Technology

Dissertation No. 2180

ISBN 978-91-7929-056-6 (Print) ISBN 978-91-7929-055-9 (PDF)

ISSN 0345-7524

Printed in Sweden by LiU-Tryck, Linköping, 2021

Cover design:

John Laurence Esguerra

Photo taken at a landfill mining site in Mont-Saint-Guibert, Belgium

Distributed by:

Linköping University

Department of Management and Engineering

SE-581 83 Linköping, Sweden

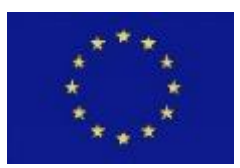

This study has received funding from the European Training Network for Resource Recovery through Enhanced Landfill Mining (NEW-MINE, Grant Agreement No 721185) under the European Union's EU Framework Programme for Research and Innovation Horizon 2020. 


\section{Abstract}

Landfill mining refers to the re-circulation of resources from the previously deposited wastes. It is an alternative approach for managing landfills that integrates resource recovery with site remediation. Several resources that can be recovered in landfills include scrap metals for recycling, combustibles for energy recovery, and inert materials for construction applications. In addition, land can be recovered for alternative uses, or landfill void space can be liberated for the deposition of future wastes. At present, landfill mining is still an emerging concept with few project implementations. Consequently, the assessments of its economic and climate implications are case study-specific, limiting the understanding of its potential in a wider geographical scope.

This thesis aims to assess the economic performance and climate impact of landfill mining in Europe towards the development of sound strategies for implementation. Different project setups are assessed in relation to varying factors at the site level such as waste composition and landfill settings, and at the system level such as policy and market conditions and background material and energy. In doing so, a factor-based method is developed and applied to generate multiple scenarios $(531,441$ scenarios per project setup) and determine the underlying important factors and their interrelations that drive the results. Such understanding is used to develop and discuss strategies for improvement by addressing relevant questions for specific stakeholders, including project investors (i.e., which landfill sites to prioritize?), landfill mining practitioners (i.e., how to set up such projects?), and policymakers (i.e., which policy instruments can effectively support such projects?).

Results show that landfill mining is preferable in terms of climate than economy. In general, about $50 \%$ of the scenarios are climate beneficial, while only about $20 \%$ of the scenarios are profitable. Possible economic and climate improvements are shown by employing internal thermal treatment of combustibles and extending fines residue utilization as construction aggregates. However, these require overarching conditions such that the choice of project setup must be in line with the selection of landfills for mining. Preferable site and system-level conditions are identified in general but it is also discussed that the plausibility of finding such conditions may be difficult at present. This steers the development of more tailored strategies on what can be done now by the landfill practitioners in terms of setting up projects under current policy and market conditions in specific regions, or what can be done by the policymakers in terms of implementing various policy instruments that can drive such changes at the system level. In this regard, the future of landfill mining research can be guided towards addressing key challenges and potential solutions for improvement elicited through a generic and learning-oriented assessment. Furthermore, this thesis highlights the role of assessment as a tool for learning and guiding the development of emerging concepts such as landfill mining. 


\section{Sammanfattning}

Landfill mining är en strategi som kombinerar sanering och resursutvinning av avfallsdeponier. Detta för att minimera de negativa miljö- och hälsoeffekter som dessa platser orsakar och samtidigt återvinna de värdefulla material och energiresurser som tidigare deponerats. Sådana projekt kan även genomföras för att frigöra mark för mer hållbara användningsområden eller för att skapa nytt utrymme för att deponera framtida avfallsflöden. Även om tidigare forskning har visat att landfill mining kan utgöra en viktig råmaterial- och miljöstrategi saknas fortfarande kunskap och erfarenhet om hur sådana projekt kan genomföras på ett lönsamt och miljömässigt motiverat sätt.

Den här avhandlingens mål är att analysera den ekonomiska prestandan och miljöpåverkan av landfill mining i ett europeiskt perspektiv och hur utfallet av sådana projekt i sin tur beror på olika plats-, projekt- och systemvillkor. Baserat på dessa studier utvecklas sedan strategier för implementering genom att tillämpa kunskapen om hur valet av deponi och projektupplägg påverkar prestandan av sådana projekt under olika policy- och marknadsvillkor.

Forskningen innefattar tillämpning av en miljösystemanalytisk metod som utvecklats speciellt för att analysera vilka plats-, projekt- och systemvillkor som tillsammans avgör den ekonomiska och miljömässiga prestandan av landfill mining i olika situationer och sammanhang. För att besvara målet med avhandlingen har ett stort antal scenarier analyserats, vilka täcker in den variation som kan förväntas vad gäller olika plats-, projekt- och systemvillkor för landfill mining i Europa.

Resultaten visar på en övergripande nivå att landfill mining presterar bättre med avseende på miljöprestanda än lönsamhet. Ca $50 \%$ av de analyserade scenarierna genererar klimatvinster medan endast 20\% är fördelaktiga ur ett ekonomiskt perspektiv. Det finns emellertid en stor potential att förbättra både den ekonomiska och miljömässiga prestandan genom att mer noggrant välja och koordinera valet av deponi och projektupplägg. En central slutsats från dessa analyser är att de omkringliggande, och till stor del regionalt betingade, systemvillkoren har en stor inverkan på utfallet av sådana projekt. I många fall inverkar dessa rådande policy och marknadsvillkor och bakgrundsystem för material och energiproduktion också negativt på den miljömässiga och ekonomiska prestandan. För att skapa bättre förutsättningar för landfill mining är det därför ofta nödvändigt att förändra och anpassa dessa systemvillkor. I avhandlingen analyseras potentialen av flera potentiella styrmedel för att stimulera och förbättra de ekonomiska villkoren för projekt som genererar tydliga klimatvinster. Sammantaget visar denna avhandling på hur miljösystemanalys av nya koncept som landfill mining kan användas som ett lärandeverktyg för att vägleda fortsatt kunskaps- och teknikutveckling inom området och ta fram strategier för implementering. 


\section{Acknowledgement}

This PhD thesis was done under the Sustainable Materials Management Research Unit at the Division of Environmental Technology and Management at Linköping University. A part of the research work was also done under the Environmental Economics Research Group at the Faculty of Business and Economics at University of Antwerp. The consortium was made possible under the Marie Skłodowska-Curie Action called Resource Recovery through Enhanced Landfill Mining, which has received funding from the EU Framework Programme for Research and Innovation Horizon 2020 (ETN NEW-MINE, Grant Agreement No. 721185). A broader research network was also coordinated with for more collection and dissemination of information that is the European Cooperation for Science and Technology - Mining the European Anthroposphere (COST-Action MINEA, Action No CA15115).

This $\mathrm{PhD}$ thesis marks the culmination of overcoming various challenges along my research journey, which will not be possible without the support of several people. I would like to extend my gratitude and appreciation to my supervisors Joakim, Niclas and Steven; my co-authors, especially David and Giovanna; my colleagues and friends; and of course my family.

John Laurence Esguerra

Linköping, December 2021 


\section{Table of contents}

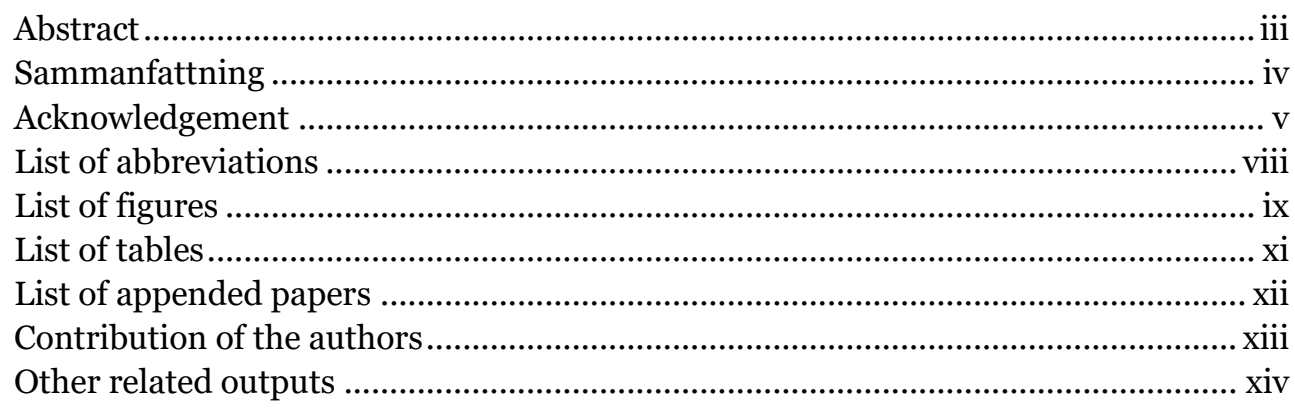

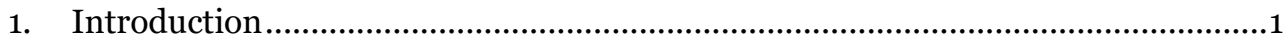

1.1 Background .......................................................................................... 2

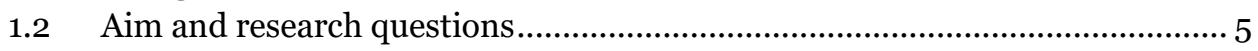

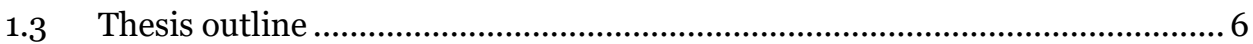

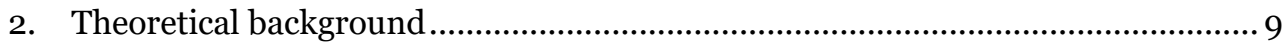

2.1 Landfill mining, the circular economy, and sustainability ......................... 10

2.2 Sustainability assessments and the ex-ante approach .................................12

2.3 Economic performance and climate impact assessment of landfill mining ...14

2.3.1 Identified drivers ...........................................................................14

2.3.2 Assessment challenges ................................................................... 17

$2.4 \quad$ Uncertainty and sensitivity analyses ......................................................19

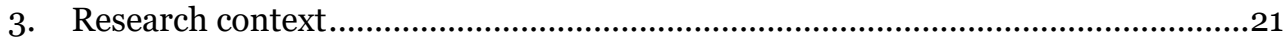

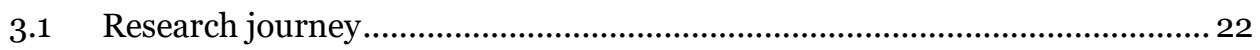

3.2 Overview of appended papers .............................................................. 24

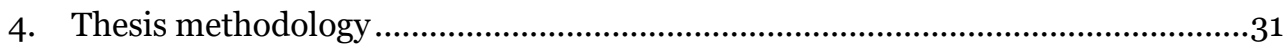

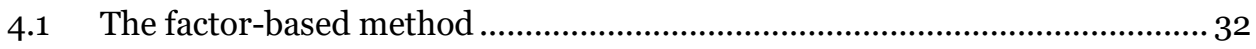

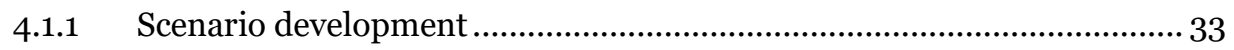

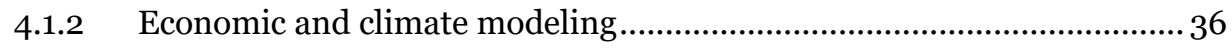

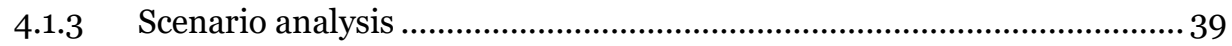

4.2 Synthesis of appended papers ….......................................................... 40

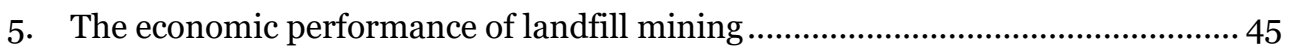

5.1 Net economic performance..................................................................... 46

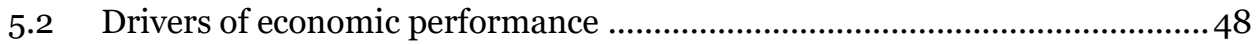

5.3 Interrelations among the drivers of economic performance .......................52 
6. The climate impact of landfill mining ……………….......................................... 55

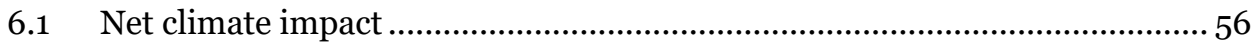

6.2 Drivers of climate impact.............................................................................. 56

6.3 Interrelations among the drivers of climate impact...................................... 58

7. Strategies for improved economic performance and reduced climate impact of landfill mining

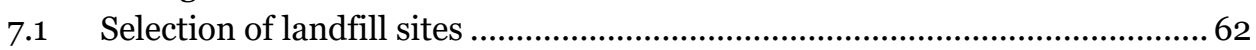

7.2 Tailored project setups for specific regional archetypes ....................................65

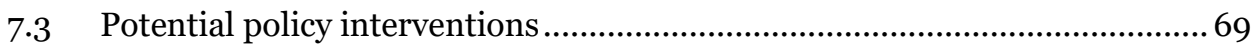

8. Contextualizing the methodological contributions of this thesis ........................... 73

8.1 Identified categories of assessment ................................................................ 74

8.2 Generic and learning-oriented assessment and the factor-based method .... 76

9. Recommendations and reflections on using a generic and learning-oriented

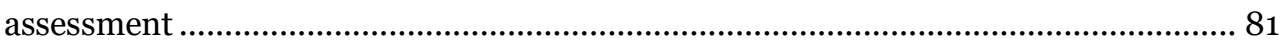

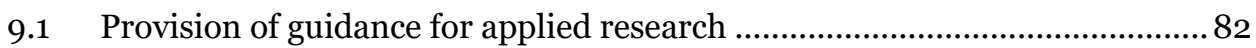

9.2 Limitations and possible improvements of the factor-based method ............ 83

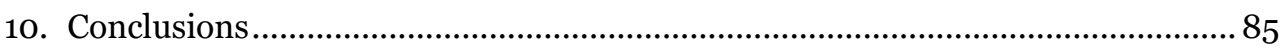

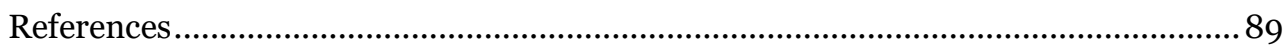

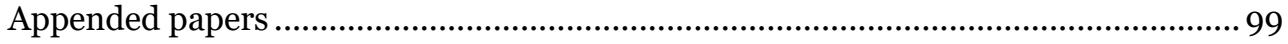




\section{List of abbreviations}

(E)LFM (enhanced) landfill mining, collective term for both LFM and ELFM

CML

COST-Action

MINEA

Institute of Environmental Sciences of Leiden University

CTUe

CTUh

Cooperation for Science and Technology - Mining the European

Anthroposphere

comparative toxicity units for ecosystems

comparative toxicity units for humans

ELFM

enhanced landfill mining

Fx

GWP

factor number

$\mathrm{H}_{2}$

global warming potential

IRR

hydrogen gas

internal rate of return

ISO International Organization for Standardization

$\mathrm{kg} \mathrm{CO}_{2}$ eq. kilogram of carbon dioxide equivalent

$\mathrm{kg}$ Sb eq. kilogram of antimony equivalent

LCA

life cycle assessment

LCC life cycle costing

LFM landfill mining

$\mathrm{Mg} \quad$ mega gram

mol H+ eq. mole of hydrogen ion equivalent

MSW

NEW-MINE

NPV

municipal solid waste

$\mathrm{Px}$

EU Training Network for Resource Recovery through ELFM net present value

$\mathrm{RDF}$

paper number

RQx

refuse-derived fuel

research question number

Shi

higher-order sensitivity index

$\mathrm{S}_{\mathrm{i}}$

first-order sensitivity index

$\mathrm{S}_{\mathrm{Ti}}$

WPx

total-order sensitivity index

work package number

WtE

waste-to-energy

WtM

waste-to-material 


\section{List of figures}

Figure 1. The simplified scheme of the landfill mining process chain with the corresponding sources of costs and revenues as well as climate savings and burdens.

Figure 2. The development of the appended papers (Ps) from the literature review of assessments of (E)LFM P5 (economic) and P6 (economic, environmental, and social), to the own method that was developed and applied for generic assessments with extended sustainability perspectives (economy and climate) and technological and organizational scopes (LFM and ELFM) in $\mathrm{P} 1$ to $\mathrm{P} 4$

Figure 3. Schematic illustration of the factor-based method developed to assess the importance of different factors for the economic performance and climate impact of (E)LFM

Figure 4. Summary of the system boundaries of the study. All processes from the excavation and sorting to the valorization of the thermal treatment residues are considered, together with the avoided production of recovered materials and energy. The highlighted processes (in gray) represent the additional processes considered from traditional LFM to ELFM.....

Figure 5. Illustration of the overall thesis structure, showing how each of the research questions ( $R Q 1$ to $R Q_{3}$ ) are addressed using the appended papers ( $P 1$ to $P 6)$ and the corresponding analyses. The reflection contextualizes the empirical and methodological contributions of this thesis by contrasting the type of results that can be generated using the factor-based method and the previous assessments on landfill mining. Further reflection on the role of assessments for guiding emerging concepts is discussed using the related literature on ex-ante assessments.

Figure 6. The cumulative net economic performance (in Euro/Mg waste) of the 531,441 (E)LFM generated scenarios per model with different technological and organizational setups. The four models differ primarily with external (P1) and internal ( $\mathrm{P}_{2} .1$ with incineration and $\mathrm{P} 3$ with plasma gasification) waste-to-energy (WtE) treatment and the utilization of fines residue as construction aggregates (P2.2).

Figure 7. The economic drivers of landfill mining in terms of the average cost (negative contribution) and revenue (positive contribution) items of the generated 531,441 LFM scenarios per model. The four models differ primarily with external (P1) and internal (P2.1 with incineration and $\mathrm{P}_{3}$ with plasma gasification) waste-to-energy (WtE) treatment and the utilization of fines residue as construction aggregates (P2.2).

Figure 8. Importance of variation of factors (in \%) for the net economic performance of landfill mining of the four models expressed by the total-order sensitivity index $\left(\mathrm{ST}_{\mathrm{i}}\right)$ of the variance-based sensitivity analysis. The four models differ primarily with external (P1) and internal (P2.1 with incineration and 
P3 with plasma gasification) waste-to-energy (WtE) treatment and the utilization of fines residue as construction aggregates (P2.2). .................50

Figure 9. Graphical analysis of the net economic performance (in Euro/Mg waste) of the generated 531,441 landfill mining scenarios with internal incineration (P2.1). The results are grouped according to the four most important identified factors, in order: waste handling costs (F9), reference case (F3), landfill settings (F1, colors), and market prices (F7, shapes).

Figure 10. Graphical analysis of the economic performance (in Euro/Mg waste) of the generated 531,441 ELFM scenarios with plasma gasification and valorization of syngas and slag ( $\left.\mathrm{P}_{3}\right)$. The results are grouped according to the identified four most important factors, in order: syngas valorization options (F6), market prices (F7), waste composition (F2, colors), and waste handling costs (F9, shapes).

Figure 11. The climate drivers of landfill mining in terms of average climate savings (negative contribution) and climate burdens (positive contribution) of various processes of the generated 531,441 landfill mining scenarios with internal plasma gasification ( $\left.\mathrm{P}_{3}\right)$. The negative contribution accounted for the avoided emissions due to substituted primary production from recovered materials and energy and avoided landfill gas emission from the landfill reference case, while the positive contribution accounted for the emissions from the primary production of materials and energy required for the processes and the landfill gas emission from re-landfilled waste. . 57

Figure 12. Importance of variation of factors (in \%) for the climate impact of landfill mining expressed in terms of total-order sensitivity index $\left(\mathrm{ST}_{\mathrm{i}}\right)$ of the variance-based sensitivity analysis. Enhanced landfill mining with plasma gasification and valorization of syngas and slag $\left(\mathrm{P}_{3}\right)$ is compared with traditional landfill mining with internal incineration (Laner et al., 2016). 58

Figure 13. Graphical analysis of the climate impact (in $\mathrm{kg} \mathrm{CO}_{2}$ eq./Mg waste) of the generated 531,441 ELFM scenarios in Europe ( $\left.\mathrm{P}_{3}\right)$. The results are grouped according to the four most important identified factors: syngas valorization options (F6), reference cases (F3), MSW waste composition (F2, colors), and background material and energy system (F9, shapes).

Figure 14. Trade-off analysis of the climate impact (vertical axis) and economic performance (horizontal axis) of the generated ELFM scenarios in Europe with plasma gasification and valorization of syngas and slag $\left(\mathrm{P}_{3}\right)$............ 65

Figure 15. Graphical analysis of the net economic performance (in Euro/Mg waste) of landfill mining (P2.2) in a European regional archetype with a high level of economic income and high waste management standards. The following factors are fixed to high datasets except for financial accounting (F11-1), as expected for more developed economies: variation in excavation \& sorting costs (Fo-3), the reference scenario (F3-3), costs of WtE technology (F6-3), markets for material and energy (F7-3), prices of reclaimed land or landfill void space (F8-3), and costs for waste treatment, disposal, and transport (F9-3). The 243 scenario results are grouped according to the four most 
critical factors under the influence of landfill practitioners, landfill settings (F1), excavation and sorting technology ( $\left.\mathrm{F}_{5}\right)$, project drivers ( $\left.\mathrm{F}_{4}\right)$, and landfill composition (F2).

Figure 16. Graphical analysis of the net economic performance (in Euro/Mg waste) of landfill mining (P2.2) in a European regional archetype with a low level of economic income and low waste management standards. The following factors are fixed to low datasets except for financial accounting (F11-3), as expected for less developed economies: variation in excavation \& sorting costs (Fo-1), the reference scenario (F3-1), costs of WtE technology (F6-1), markets for material and energy (F7-1), prices of reclaimed land or landfill void space (F8-1), and costs for waste treatment, disposal, and transport (F9-1). The 243 scenario results are grouped according to the four most critical factors under the influence of landfill practitioners such as landfill settings (F1), excavation and sorting technology ( $\left.\mathrm{F}_{5}\right)$, project drivers $\left(\mathrm{F}_{4}\right)$, and landfill composition (F2).

Figure 17. Explored policy instruments to support ELFM scenarios with net climate savings ( $\left.\mathrm{P}_{3}\right)$. The increase in the share of preferable scenarios in terms of both climate impact and economic performance is illustrated with respect to the increase in the value (10 points across the explored range) of individual policy instruments.

Figure 18. The categorization of assessments (Categories A-D) in terms of study object (case study-specific or generic) and extent of analysis (decisionoriented or learning-oriented). The factor-based method (highlighted in orange) is categorized as generic and learning-oriented (Category D). ..... 74

Figure 19. The net economic performance (in Euro/Mg waste) of landfill mining in Europe as presented in selected generic assessments with few scenarios (2 green triangles) in Van Vossen and Prent (2011) and multiple scenarios (531,441 orange circles) in P1 representing the use of the factor-based method in this thesis.

Figure 20. The economic drivers of landfill mining in terms of the main constituent costs and revenue items derived from the collective studies based on the systematic literature review $\left(\mathrm{P}_{5}\right)$.

\section{List of tables}

Table 1. Overview of appended papers.

Table 2. Summary of the factors and datasets used in the appended papers for the economic ( $P_{1}$ and $\left.P_{2}\right)$ and climate impact $\left(P_{3}\right)$ assessment of (E)LFM. 


\section{List of appended papers*}

1 Laner, D., Esguerra, J.L., Krook, J., Horttanainen, M., published Kriipsalu, M., Rosendal, R.M., Stanisavljević, N., 2019.

Systematic assessment of critical factors for the economic performance of landfill mining in Europe: What drives the economy of landfill mining? Waste Management 95, 674-686.

2 Esguerra, J.L., Laner, D., Krook, J., Svensson, N. 2021. published Landfill mining in Europe: Assessing the economic potential of value creation from generated combustibles and fines residue. Waste Management 126, 221-230.

3 Esguerra, J.L., Sauve G. Laner D., Krook J., Svensson, N., Van submitted Passel, S., Van Acker, K. 2021. Enhanced landfill mining in Europe: Assessment of critical factors for the climate impact and economic performance of extended resource recovery through valorization of syngas and slag from plasma gasification. Resources, Conservation and Recycling

4 Sauve, G., Esguerra, J.L., Laner, D., Krook, J., Svensson, N., Van Passel, S., Van Acker, K. 2021. Integrated early-stage environmental and economic assessment of emerging technologies: A case study of plasma gasification. Energy and Environmental Science

5 Esguerra, J.L., Krook, J., Svensson, N., Van Passel, S. 2019. published Assessing the economic potential of landfill mining: Review and recommendations. Detritus 8, 125-140.

6 Hernández Parrodi, J.C., Lucas, H., Gigantino, M., Sauve, G., published Esguerra, J.L., Einhäupl, P., Vollprecht, D., Pomberger, R., Friedrich, B., Van Acker, K., Krook, J., Svensson, N., Van Passel, S. 2019. Integration of resource recovery into current waste management through (Enhanced) Landfill Mining. Detritus 8, 141-156.

"The papers are arranged following the sequence of presentation in this thesis instead of the date of publication. 


\section{Contribution of the authors}

1 I took part in the model setup, collected the data, and wrote the original draft together with David Laner and Joakim Krook. I was also mainly responsible for the revision during the review process. The other co-authors provided comments during the entire process.

2 I revised the model from Paper 1, updated the relevant input data, analyzed the results, and wrote the original draft under the supervision of the co-authors. I was also mainly responsible for the revision during the review process.

3 Giovanna Sauve and I conceptualized the paper, selected and analyzed previous studies, analyzed the results, and wrote the original draft under the supervision of the co-authors.

4 Giovanna Sauve and I conceptualized the paper, selected and analyzed previous studies, analyzed the results, and wrote the original draft under the supervision of the co-authors.

5 I conceptualized the paper, selected and analyzed previous studies, and wrote the original draft under the supervision of the co-authors. I was also mainly responsible for the revision during the review process.

6 I contributed to the writing and revision of the section on multi-criteria assessment of landfill mining. 


\section{Other related outputs}

\section{Licentiate dissertation}

Esguerra, J.L. 2020. Economics of Landfill Mining: Usefulness and Validity of Different Economic Assessment Approaches. Licentiate Dissertation. Linköping University.

\section{Project reports}

Final report of Work Package 4: Multi-criteria assessment. European Training Network for Resource Recovery Through Enhanced Landfill Mining (NEW-MINE), EU Horizon 2020.

Landfill mining - creating resources and solving an environmental problem, NSR, Helsingborg, Energimyndigheten.

\section{Conference Papers and Abstracts}

Esguerra, J.L., Svensson, N., Krook, J., Van Passel, S., Van Acker, K. 2018. The economic and environmental performance of a landfill mining project from the viewpoint of an industrial landfill owner. 4th International Symposium on Enhanced landfill Mining, 5-6 February, Mechelen, Belgium, pp. 389-396.

Esguerra, J.L., Krook, J., Svensson, N., Van Passel, S. 2018. Is enhanced landfill mining profitable? International Solid Waste Association (ISWA) 2018 World Congress, 22-25 October, Kuala Lumpur, Malaysia, pp. 240-245.

Hernández Parrodi, J.C., Lucas, H., Gigantino, M., Sauve, G., Esguerra, J.L., Einhäupl, P. 2019. Strategies for landfill mining-Integrating resource recovery into current waste management. $17^{\text {th }}$ International Waste Management and Landfill Symposium, 30 September-4 October, Sardinia, Italy.

Sauve, G., Esguerra, J.L., Krook, J., Svensson, N., Van Passel, S., Van Acker, K. 2019. Integrated ex-ante environmental and economic assessment of plasma gasification for enhanced landfill mining. SETAC Europe 29th Annual Meeting, 2630 May, Helsinki, Finland.

Esguerra, J.L., Sauve, G., Krook, J., Svensson, N., Van Passel, S., Van Acker, K. 2019. A systematic method for ex-ante assessment of critical factors for the economic and environmental performance of emerging concepts. 10th International Conference on Industrial Ecology, 7-11 July, Beijing, China. 


\section{Introduction}




\subsection{Background}

Globally, continuous production and consumption have led to the accumulation of materials in the anthroposphere (Cossu and Williams, 2015; Zhang et al., 2019). These materials eventually turn into waste upon reaching their end of life, of which more than half is landfilled as such a disposal option is still considered cost-efficient in many parts of the world (Kaza et al., 2018). Within the European Union (EU), several countries have recently developed more advanced waste management and recycling systems, but landfilling remained important, and still, a quarter of the generated municipal waste in this region ends up in such deposits (Eurostat, 2019). Consequently, there are more than half a million landfills in Europe, most of them being old and non-sanitary deposits predating the EU Landfill Directive 1999/31/EC (Hogland et al., 2010). Such landfills are associated with several environmental and health hazards as well as land-use restrictions (El-Fadel et al., 1997; Porta et al., 2009). In addition, a higher risk of flooding due to climate change further aggravates these hazards in some regions (Laner et al., 2009; Wille, 2018). The proper management of landfills must be practiced to address such hazards, such as aftercare that involves collection and treatment of leachate and landfill gas, and remediation, which typically involves the excavation of waste and disposal to sanitary landfills (Brennan et al., 2016; Laner et al., 2012). Despite the recently amended EU Landfill Directive (2018/850), there is, however, still no coherent strategy for the management of these landfills, and the public funding for aftercare and remediation is often insufficient among the member states (Krook et al., 2018).

Apart from the perspective of hazard avoidance, another motivation to manage landfills is through the perspective of resource recovery, acknowledging landfills as resource reservoirs. Over time, massive amounts of metals, combustibles and minerals have been disposed of in such deposits (Frändegård et al., 2013; Kapur and Graedel, 2006; Müller et al., 2006). Several studies, therefore, proclaim that landfills should be considered as potential sources of secondary raw materials that can contribute significantly to the EU's material autonomy (Frändegård et al., 2013; Johansson et al., 2012; Jones et al., 2013). In line with this, an integrative landfill management approach called landfill mining has gained renewed attention. LFM extends traditional aftercare and remediation (Hogland et al., 2018; Johansson et al., 2012) with resources recovery, thereby accounting for a more exhaustive process chain including excavation, separation and sorting, thermal treatment, material recycling, and in some cases, also further valorization of subsequent residues (Burlakovs et al., 2017; Jones et al., 2013; Krook et al., 2012). Several resources from the landfilled wastes can potentially be recovered, including scrap metals for recycling (Burlakovs et al., 2018, 2016; Gutiérrez-Gutiérrez et al., 2015; Quaghebeur et al., 2013), combustibles for energy recovery (Bosmans et al., 2013; Rotheut and Quicker, 2017), and inert materials for construction applications (Hernández Parrodi et al., 2018). In addition, land can also be recovered for alternative purposes such as industrial and residential uses or landfill void space for deposition of future wastes (Damigos et al., 2016; Frändegård et al., 2013; Van Passel et al., 2013). By 
bringing such resources back into society and addressing the environmental and health hazards of such deposits, landfill mining is increasingly being acknowledged as a strategy to achieve a circular economy (Machiels et al., 2019; UN Economic Commission for Europe, 2018) and contribute to several sustainable development goals (Calderón Márquez et al., 2019).

In practice, landfill mining remains an emerging concept with few real-life and fullscale projects validating its feasibility (Calderón Márquez et al., 2019; Johansson et al., 2012). At present, the realization of such projects is subject to multi-faceted challenges in terms of several influencing technological, political, market, organizational, social, environmental, and economic conditions (Hermann et al., 2016; Johansson et al., 2017; Krook et al., 2015; Van Der Zee et al., 2004). These challenges are typical for emerging concepts and technologies since the incumbent conditions are not yet adapted for such unconventional practices (Hekkert et al., 2007). As a consequence of its emerging character, studies on where and how to implement landfill mining as well as its overall sustainability performance (i.e., economic, environmental, and social aspects) are limited. Such studies are necessary to earn the support of stakeholders towards its widespread adaptation as an alternative strategy for landfill management. In essence, further development of landfill mining relies on extensive research targeting the challenge of how such projects can be developed cost-efficiently and with clear environmental and societal benefits (Hermann et al., 2016; Johansson et al., 2017; Krook et al., 2015; Van Der Zee et al., 2004).

Several assessment studies are available on the economic performance and climate impact of landfill mining. However, most of them are case study-specific, and the applicability of their results is often limited to the specific conditions and settings of the studied project in question. In a way, this constitutes the state of current knowledge about the economic performance and climate impact being limited and incoherent. Some conclude that landfill mining is not profitable (Danthurebandara et al., 2015a, 2015b; Kieckhäfer et al., 2017; Winterstetter et al., 2015; Wolfsberger et al., 2016), while others present opposing results (Damigos et al., 2016; Van Passel et al., 2013; Wagner and Raymond, 2015; Zhou et al., 2015). Similarly, some conclude that landfill mining leads to climate savings (Danthurebandara et al., 2015c; Frändegård et al., 2013; Jain et al., 2014), while others presume it leads to climate burden (Danthurebandara et al., 2015a; Winterstetter et al., 2015). These contradictions are expected given that landfill mining can be realized in many different ways and settings involving different technical and organizational setups at the project level, different landfill settings at the site level, and different surrounding policy and market conditions at the system level, which are altogether interrelated influencing the economic performance and climate impact.

At the project level, landfill mining varies in terms of the extent and type of utilized processes and technologies. With the limited extent and use of conventional technologies, traditional landfill mining faces a major challenge for downcycling of 
extracted resources that generate disposal costs for the landfill mining practitioner and limits the potential environmental savings. Hence, recent developments extend the LFM process chain and utilize advanced technologies to promote upcycling towards a zero-waste process, which is coined as enhanced landfill mining (Burlakovs et al., 2017; Jones et al., 2013; Krook et al., 2012). For separation and sorting of excavated wastes, technologies are explored to recover resources from small-sized residue $(<60 \mathrm{~mm})$ or the fine fraction (Kieckhäfer et al., 2017; Mönkäre et al., 2019). For thermal treatment, instead of incineration, plasma gasification is considered a promising technology for maximizing the combined material and energy valorization of combustible fraction (Danthurebandara et al., 2014; Jones et al., 2013). Plasma gasification produces synthesis gas (syngas) that can potentially be valorized for combined heat and power production or used in the production of chemicals such as hydrogen and biofuels (Bosmans et al., 2013; Danthurebandara et al., 2015b; Rotheut and Quicker, 2017), while the residual slag can potentially be upcycled to produce inorganic polymers for construction applications, among others (Danthurebandara et al., 2015a; Machiels et al., 2016; Monich et al., 2018).

Similarly, wide variations can also be expected at the site and system levels that further highlight the limitations of case study-specific assessments. At the site level, waste composition, landfill size, and geometry and management alternatives can vary. Waste composition widely varies both within specific landfills and among different landfill sites depending on the type of deposited waste and age (Hernandez Parrodi et al., 2018; Hogland et al., 2018; Hölzle, 2019). The size and geometry of landfills also vary and influence the economy of scale for excavation, materials processing, internal logistics, and landfill management alternatives (Hogland et al., 2018; Hölzle, 2019). For landfill management alternatives such as aftercare or remediation, the choice is also influenced by the characteristics of the landfill, its content, and its surroundings (Brennan et al., 2016; Laner et al., 2012). At the system level, the landfill management alternative is also defined by specific process requirements that depend on national or regional regulations (Rosendal, 2015; Van Vossen and Prent, 2011). Also subject to regional variations are the marketability for recovered materials based on market quality requirements and fees for relandfilling and thermal treatment for process wastes based on imposed taxes and waste market conditions (Confederation of European Waste-to-Energy Plants, 2017). Furthermore, relevant for the climate assessment is the background material and energy system that can have different proportions of fossil and renewable share (Laner et al., 2016).

Considering that landfill mining can be implemented in many different ways and settings, there is a need to develop a more generic and systematic understanding of its economic performance and climate impact. In line with this, the ex-ante assessment literature recommends an exploratory scenario development, which means accounting for multiple scenario possibilities to cover the breadth of various paths for development (van der Giesen et al., 2020; Villares et al., 2017; Voinov et al., 2016). Moreover, to identify measures and strategies for improved performance, 
detailed knowledge about what the important factors are and how such factors interact influencing the overall performance is needed (Ferretti et al., 2016; Laner et al., 2016; Saltelli and Annoni, 2010). This learning-oriented assessment can lead to a sound understanding of the important factors and principles of performance that can allow the systematic development of measures and strategies for improvement. Such generic and learning-oriented knowledge can facilitate the development of economic and climate preferable landfill mining implementation in broader regions by giving insights on the importance of landfill site selection and policy and market conditions apart from the influence of different technological and organizational project setups.

\subsection{Aim and research questions}

This thesis aims to assess the economic performance and climate impact of landfill mining in Europe towards the development of sound strategies for implementation. Here, strategies refer to site selection, project setup, and policy interventions that correspond to the role of different stakeholders such as landfill investors, landfill practitioners, and policymakers, respectively. Different technological and organizational setups for landfill mining are assessed in relation to the different landfill site settings, policy and market conditions, and background material and energy systems expected within the European borders. In doing so, a generic and learning-oriented assessment method called the factor-based method is developed and applied, which accounts for broad scope and allows in-depth analysis. It offers an understanding from the overall results to the important underlying factors to the strategies for improving economic performance and climate impact. The following research questions ( $R Q s)$ are formulated to reach the thesis aim:

$R Q 1$ : How do the economic performance and climate impact of landfill mining vary within Europe?

This RQ aims to analyze the net economic and climate potential of multiple project possibilities of landfill mining in Europe. Such possibilities account for the influence of employing different technological and organizational setups on different landfill site settings and within different policy and market conditions and background material and energy systems. Here, technological variations refer to the different extents and advancements of technologies along the landfill mining process chain, while organizational variations refer to the accounting of certain processes as internal or external to such projects. This $R Q$ contributes to the aim by clarifying the different technological and organizational settings of landfill mining covered in this thesis and subsequently differentiating their implications on the overall results.

RQ2: What are the important factors and their interrelations that drive the economic performance and climate impact of landfill mining in Europe?

This $R Q$ aims to elicit granular information in terms of important factors and their interrelations that build up the corresponding overall economic performance and climate impact in $R Q 1$. To reiterate, important factors refer to the drivers and 
barriers or the factors that negatively or positively influence the overall results. It can be in terms of absolute contribution based on its share of the overall results or the relative contribution based on how much its variation influences the spread of the overall results. This $R Q$ contributes to the aim by showing a systematic approach to identifying important factors and their interrelations for the economic performance and climate impact of landfill mining in Europe.

RQ3: How can the economic performance and climate impact of landfill mining in Europe be improved?

This $R Q$ aims to develop and discuss strategies for improving the economic performance and reducing the climate impact of landfill mining. The strategies are based on the important factors and their interrelations derived from RQ2. Preferable factor combinations are identified to elicit strategies by addressing relevant questions for specific stakeholders, including project investors (i.e., which landfill sites to prioritize?), landfill mining practitioners (i.e., how to set up such projects?), and policymakers (i.e., which policy instruments can effectively support such projects?). This $R Q$ contributes to the aim by providing improvement strategies with respect to the roles of various stakeholders and tackling their respective plausibility in terms of practical implementation.

By addressing these $R Q s$, the empirical and methodological contributions of this thesis are highlighted and contextualized. The empirical contributions refer to the results of the $R Q s$ in relation to the findings from previous assessments on landfill mining. This is done to identify similarities and differences of the results when using the factor-based method and the synthesis of individual studies on landfill mining. The methodological contributions, on the other hand, refer to the learnings from developing and applying the factor-based method on landfill mining, acknowledging its emerging character. This is contrasted in relation to the methodological issues from previous assessments of landfill mining and in the broader literature on methods for assessing emerging concepts and technologies. Further reflection lies on the importance of using assessments as learning tools for the provision of strategies that can facilitate the development of landfill mining and other similar emerging concepts. These relate to the aim empirically through the identified knowledge gaps in the field of landfill mining and methodologically through the acknowledged issues faced when assessing emerging concepts like landfill mining.

\subsection{Thesis outline}

The proceeding sections are structured as follows: The broader scientific context on concepts and methods is presented in the theoretical background (Section 2). In the same section, the motivation for narrowing down the research scope is also stated. Then, the research context and journey (Section 3) explains the choices made in the project, the developed method, called the factor-based method, and an overview of the appended papers. This is followed by the thesis methodology (Section 4), which 
explains the developed factor-based method and synthesis of the appended papers in relation to the research questions. The results and discussion are divided into three parts: The separated analysis goes in-depth with the economic performance (Section 5) and climate impact of landfill mining (Section 6) with different technological and organizational settings. Subsequently, the developed strategies for landfill mining are presented (Section 7) for improved economic performance and reduced climate impact in terms of site selection, project setup, and policy instruments. Further discussion (Section 8) contextualizes the role of assessments for emerging concepts like landfill mining, done through presenting categories of assessments and contrasting the factor-based method and its results with related assessment studies as well as broader studies on ex-ante assessments. Finally, the recommendations (Section 9) and conclusions (Section 10) follow, which provide the next steps on expanding the research scope and provide direct answers to the research questions and research aim, respectively. 
2. Theoretical background 


\subsection{Landfill mining, the circular economy, and sustainability}

Landfills have long been considered as final waste deposits and are associated with environmental and health hazards as well as land-use restrictions, as landfills sometimes interfere with urban and regional development (El-Fadel et al., 1997; Laner et al., 2012; Johansson et al., 2012; Porta et al., 2009). Hence, appropriate landfill management is needed, such as traditional landfill aftercare where monitoring, collection, and treatment of leachate and landfill gas are assured, or remediation for malfunctioning sites wherein the waste is excavated and transferred to sanitary landfills. These landfill management alternatives obviously entail costs. Although revenues are expected for recovered land or landfill void space, additional sources of revenues can be integrated considering the potential for recovery of resources from landfilled waste. Several recoverable resources are found in such waste deposits, such as ferrous and non-ferrous metal scraps that can be recycled, combustibles that can be used as fuels for energy recovery (residue-derived fuel, RDF), and various inorganic materials that can be used as construction materials. This concept of integrated remediation and resource recovery that is called landfill mining has influenced the perception of landfills from final waste deposits to temporary material storages, which can be exploited to recover both materials, energy carriers, and land resources (Cossu and Williams, 2015; Johansson et al., 2012; Krook and Baas, 2013).

In this thesis, two different landfill mining concepts are used depending on the extent and type of utilized processes and technologies. Traditional landfill mining (LFM) differs from enhanced landfill mining (ELFM) by using advanced technologies to promote upcycling towards a zero-waste process (Burlakovs et al., 2017; Jones et al., 2013; Krook et al., 2012). In particular, plasma gasification is utilized instead of incineration that can maximize combined material and energy valorization of RDF (Danthurebandara et al., 2014; Jones et al., 2013). The syngas from plasma gasification can potentially be valorized for energy and chemical production (Bosmans et al., 2013; Danthurebandara et al., 2015b; Rotheut and Quicker, 2017), while the slag can potentially be valorized as functional inorganic polymers (Danthurebandara et al., 2015a; Machiels et al., 2016; Monich et al., 2018). This process is adapted in the EU Training Network for Resource Recovery through ELFM (NEW-MINE project), to which this research belongs. In the proceeding part of the thesis, (E)LFM is used when referring to both LFM and ELFM.

(E)LFM is tagged as the missing link to achieve a more comprehensive circular economy approach (Machiels et al., 2019). Rooted in the material perspective of industrial ecology (Saavedra et al., 2018), the circular economy concept addresses keeping the materials being used in society and minimizing waste (Ellen MacArthur Foundation, 2013). (E)LFM contributes to this concept by addressing the waste from the past, while the current focus of the circular economy is typically on the future waste streams. Some policy efforts have been initiated for supporting (E)LFM in the EU by directly linking it to the current attention on the circular economy. There is, for instance, an ongoing adaptation and inclusion of landfills as an anthropogenic stock of 
resources in the United Nations Framework Classification for Resources (UN Economic Commission for Europe, 2018). There was also a recent amendment of the EU Landfill Directive (2018/850) that aimed to include (E)LFM as one landfill management alternative, among others (European Parliament, 2018). Although this amendment was unsuccessful, as (E)LFM still only is a proof of concept with a lack of real-life applications, the revised directive does not directly prohibit (E)LFM implementation even at an industrial scale and scope (Jones et al., 2018). Nonetheless, the lack of overarching European legislation leaves member states with a variety of options to deal with (E)LFM and gives little room to address common challenges for its implementation (Einhäupl et a., 2019), such as to develop know-how and technologies for how to realize such projects (Danthurebandara et al., 2015c; R. Hermann et al., 2016; Hogland et al., 2018; Winterstetter et al., 2018).

With only about a hundred projects worldwide (Calderón Márquez et al., 2019), (E)LFM can be considered an emerging concept, especially when it comes to using extended and advanced technologies, as in ELFM. With promising recoverable material and energy, Jones et al. (2013) account for ELFM implementation to respect the sustainability criteria (i.e., economic, environmental, and social aspects). Hence, sustainability assessments are necessary to earn the support of stakeholders towards its widespread adaptation as an alternative strategy for landfill management. Studies on where and how to implement LFM from a broader sustainability perspective (i.e., economic, environmental, and social aspects) are scarce (Hermann et al., 2016; Pastre et al., 2018). In addition, these assessments only focus on single landfill projects, which means that their knowledge contribution to the general sustainability potential of (E)LFM is largely limited. At present, we thus know very little about the positive and negative sustainability consequences of (E)LFM. This situation underscores the policyrelevant question of how LFM should be evaluated-to pinpoint the need for conducting sound research that can guide further development of the area and set priorities on where and how to implement sustainable LFM projects (Hermann et al., 2014; Krook et al., 2018; Van Der Zee et al., 2004).

Furthermore, most of the sustainability assessments for (E)LFM address environmental impacts and economic performance, while societal impacts are typically not addressed (Krook et al., 2018). Since societal impacts are of a diverse and often complex nature, including welfare changes as well as health risks, no common assessment method for LFM projects exists (Einhäupl et al. 2019). Moreover, societal impacts are often strongly related to environmental and economic ones, as health risks are usually a consequence of environmental impacts, and taxes are accounted for as a private economic cost but also represent a societal income. Hence, it is difficult to define clear boundaries between the different dimensions of sustainability in (E)LFM, especially when considering causal relations between different impacts. In this regard, this thesis has also focused only on the economic and environmental aspects of sustainability to build further on relatively studied aspects. Above all, taking the context in which this research was part of the NEW-MINE project, economic and environmental assessments were the pre-defined objective. For the environmental 
aspect, climate impact was particularly the focus for comparability with the results from previous assessments of (E)LFM. Among other environmental impact categories, it is the climate impact that is highly linked to policy issues as it has a relevant contribution to global concerns for climate change mitigation.

\subsection{Sustainability assessments and the ex-ante approach}

Different sustainability assessment tools (Ahlroth et al., 2011; Finnveden and Moberg, 2005) have been widely used to enable structured assessments of various systems (e.g., products, services, projects, and policies). In general, these tools follow a common methodological framework that includes the definition of goal and scope, inventory of data, modeling and calculation, and interpretation of results (ISO, 2006a; Swarr et al., 2011). This framework is developed and standardized for the environmental assessment through life cycle assessment (LCA). Subsequently, in consideration of different sustainability perspectives (Purvis et al., 2019), the development of a methodological framework for economic (life cycle costing, LCC) and social (social LCA, SLCA) aspects are based on LCA to ensure compatibility for integrated sustainability assessment (Guinée, 2016; Hoogmartens et al., 2014; UNEP/SETAC Life Cycle Initiative, 2011).

Goal and scope definition sets the extent of the analysis and study object, in a way specifying the intended knowledge contribution of the assessment (Finnveden and Moberg, 2005; ISO, 2006a; Swarr et al., 2011). The choice of sustainability perspective is also decided in this step, and either an individual or integrated sustainability assessment can be chosen (Guinée, 2016; Hoogmartens et al., 2014; UNEP/SETAC Life Cycle Initiative, 2011). In terms of the extent of analysis, the assessment can be decision-oriented and aim to evaluate the net performance, which is typically done to support decisions for capital investments or marketing purposes. It can also be extended to a more learning-oriented approach that seeks a more in-depth understanding in terms of what builds up the net performance, which is common in optimization and design studies. The study object can be products, services, projects, or policies. For (E)LFM, the study object can either be case study-specific or more generic and cover multiple landfills on the regional, national, or global scales.

Data inventory refers to the collection of input data in which representativeness and transparency must be assured. The data sources must be noted in terms of whether they are primary data or, in the case of unavailability, secondary data or a combination of the two. Modeling and calculation include the actual numerical analysis to ensure mass and energy balance of input and output flows and the impact assessment based on environmental impact categories in LCA, different economic indicators in LCC, and different social impact categories in SLCA. Finally, the interpretation step serves as a check to ensure that the results are adequately supported by the data and the methods used and that the derived conclusion is well substantiated. This step also includes uncertainty and sensitivity analysis. 
For the economic assessment, private economics is chosen to support landfill owners and project managers, as they are at the forefront of adopting new alternatives for landfill management and, in doing so, must bear all the subsequent costs on their own. For the economic calculation step, several economic indicators are available for assessing the economic potential of different projects, such as payback time, net present value (NPV), and internal rate of return (IRR), among others. Frequently, these indicators are applied to verify whether investing in a project is worthwhile financially (Brealy et al., 2011). The payback time is determined as the time needed to cover the initial investment with the incoming direct cash flows. This method has the advantage of being generally known and easy to apply, but it does not take the time value of money into account. In addition, it does not provide information about the profit generated from the investment during the further lifetime of the project, that is, after the investment has been paid back. The NPV is calculated by subtracting the investment cost from the sum of the discounted cash flows and can be considered as the expected profit of the investment. Unlike the payback time, it takes the time value of money and all the relevant cash flow elements over a pre-defined period into account. The IRR, the discount rate at which the NPV is zero, gives an idea about the relative return of the investment but does not consider the scale of the project: while the IRR of two projects can be the same, the NPV of one project can be larger than the NPV of the other. On the other hand, the calculation of IRR does not require assumptions about the discount rate. As this thesis is concerned with economic assessments of different (E)LFM cases with different financing considerations and project durations, NPV is the preferred indicator of economic profitability. In a way, this indicator accounts for the way of budgeting that details the up-front investments as wells as the revenue cash flows that are distributed over the years (e.g., electricity and material sales), or only materialize in a distant future (e.g., avoided landfill aftercare and reclaimed land). Moreover, for the prospective and screening nature of this thesis, NPV is enough for comparability among the scenarios and with respect to other related studies, while accounting for the time value of money and the generated costs and revenues in the entire duration of the project, which are lacking in the other aforementioned indicators.

For the environmental assessment, similar system boundaries are considered as in the economic assessment. One major difference, though, is the exclusion of the impacts of the capital goods, while they are accounted for in the economic assessment as investment costs for different process technologies. This choice was made as it represents a common approach in previous studies (Arena et al., 2015; Danthurebandara et al., 2015b), and for comparability purposes, with the same studies. These considerations, coupled with the often lack of data on emerging systems, have further motivated the choice. Regarding the environmental assessment indicator, it can be midpoint and aggregated endpoint indicators. Midpoint indicators provide more insight on the nature of impact whether it is local, such as ecotoxicity (CTUe) and human toxicity (CTUh), or global such as acidification potential ( $\mathrm{mol} \mathrm{H}^{+}$eq.), resource depletion ( $\mathrm{kg} \mathrm{Sb}$ ), and climate change ( $\mathrm{kg} \mathrm{CO}_{2}$ eq.). As mentioned, climate change was selected as the only midpoint impact category for comparability with previous 
assessments of (E)LFM and given that climate impact is often relevant in wider policy discussions for climate change mitigation that is of global concern.

The recent development of sustainability assessment focuses on the concepts and technologies at an early stage of development like (E)LFM, and such studies are called ex-ante assessments (Cucurachi et al., 2018; Hetherington et al., 2014; van der Giesen et al., 2020; Villares et al., 2017). This is particularly timely and relevant due to the overwhelming rise of various innovative concepts and technologies. However, due to the lack of practical experiences and large-scale implementation, several empirical constraints and methodological challenges are apparent that bring large uncertainties into the assessments (Clavreul et al., 2012; Fleischer et al., 2005; Hellweg and Milà i Canals, 2014; Martinez-Sanchez et al., 2015). In contrast to assessing conventional technologies, insufficient data is expected as these technologies are often in the laboratory or pilot scale, if not completely hypothetical. Particularly, if the analysis is to be compared with conventional technologies, upscaling of data and scenario development must be done to ensure comparability (Hetherington et al., 2014; Villares et al., 2017). Scenario analysis based on such laboratory-scale processes must be done on a large scale to facilitate the assessment of the technologies at a similar scale. More explorative approaches to scenario development are recommended to scope in multiple possibilities with a wider degree of freedom (Voinov et al., 2016; Wender et al., 2014). That is, apart from the different upscaling possibilities of each process, the project setup of (E)LFM may also differ through multiple combinations of technology alternatives. Moreover, in the future, technological maturity, as well as the surrounding policy and market conditions, may also change. Consequently, these open up for further propagation of uncertainties that must be handled and understood in sustainability assessments. In this way, the future sustainability performance of emerging concepts and technologies can be assessed, which can provide guidance for further development and promotion of responsible innovation (Hetherington et al., 2014; Wender et al., 2014).

\subsection{Economic performance and climate impact assessment of landfill mining}

\subsubsection{Identified drivers}

A simplified scheme of a physical and economic flow is shown in Figure 1, providing an overview of processes that constitute the economic performance and climate impact of (E)LFM (Danthurebandara et al., 2015c; Van Passel et al., 2013). However, these processes are not necessarily part of all (E)LFM cases or accounted for in all studies. The objectives of (E)LFM, and thus what outputs and values are targeted, could vary between different projects. The main processes, such as excavation, transportation, processing, and treatment of materials and process wastes, account for the project costs and climate burden due to the impact of material and energy input. While the recovered materials, energy, and land resources account for the project revenues and climate savings due to the avoided impact of primary production. An indirect source of 
revenues and climate savings due to avoided landfill emission is accounted for from the alternative landfill management like aftercare or remediation.

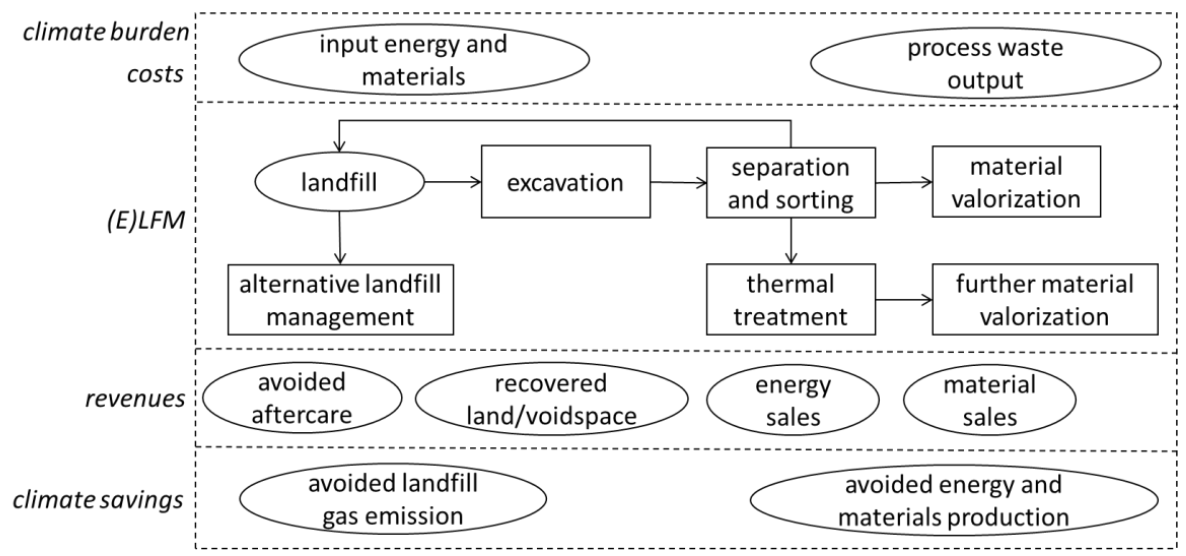

Figure 1. The simplified scheme of the landfill mining process chain with the corresponding sources of costs and revenues as well as climate savings and burdens.

Each of the processes in Figure 1 can be disaggregated into their constituent model parameters. For example, a particular landfill can be disaggregated into its characteristic waste composition, size, and geometry. In this thesis, the term "factor" is used for disaggregating the economy and climate impact of (E)LFM into different processes and model parameters (Laner et al., 2016; Van Der Zee et al., 2004). These factors can refer to both a whole process or its constituent model parameters and are generally classified into site, project, and system levels. Such classification is useful to pinpoint specific critical factors and identify which stakeholders can influence the economics and climate impact of (E)LFM.

At the site level, factors refer to the characteristics of a landfill in terms of its waste composition, landfill size and geometry, and management alternatives. Such sitespecific factors and local settings could be influenced by landfill owners and project managers, for instance, through the selection of landfills for mining. Knowledge about the waste composition of landfills is essential as it entails the potentially recoverable amounts of different resources, non-recoverable and hazardous materials in need of disposal and special treatment, and the landfill gas potential. The material composition of landfills varies widely depending on the type of deposited waste, such as municipal solid waste, industrial waste, or mixed waste. Also, the age and the region of the landfills influence their material constituents. It must be acknowledged that there are, in general, large uncertainties regarding the material composition of the deposited waste, both within specific landfills and among different landfill sites (Hernandez Parrodi et al., 2018; Hogland et al., 2018; Hölzle, 2019). The size and geometry of landfills are also of relevance because they influence the economy of scale for excavation, materials processing, internal logistics, and landfill management alternatives (Hogland et al., 2018; Hölzle, 2019). Moreover, for landfill management 
alternatives such as aftercare or remediation, the choice is also influenced by the characteristics of the landfill, its content, and its surroundings. In case of the need for land conversion, such as for industrial and residential use, remediation that typically involves the excavation of waste and disposal to other landfills is preferred over aftercare that only involves collection and treatment of leachate and landfill gas (Brennan et al., 2016; Laner et al., 2012).

At the project level, factors refer to the (E)LFM project setup, such as the choice of technologies, and organizational setup, such as if a certain process is done internally or externally to the project. Landfill owners and project managers primarily influence these project factors. The choice of sorting, upgrading, and recovery technologies is fundamental as it influences both the quantity and quality of different materials and energy carriers that can be recovered from the deposited waste. Technology setup can vary in terms of the advancement of technology used as well as the combination of technologies along the (E)LFM process chain. There are studies that account for variations and implications of employing different advancements of separation and sorting technologies (Kieckhäfer et al., 2017) and thermal treatment technologies (Danthurebandara et al., 2015b, 2015d; Winterstetter et al., 2016). In principle, more advanced technologies lead to higher recovery rates, but such improvements in processing efficiencies also come with higher costs and climate burden due to the resource requirement. For varying project organizational setup, such differences affect the distribution of costs and benefits in (E)LFM projects. For example, if thermal treatment is considered external, the gate fee for sending the combustibles to a waste incinerator is accounted for, while if the thermal treatment is done within the project organization, both waste-to-energy processing costs and revenues from the generated energy need to be considered. In terms of climate impact, the transport process accounts for the differences with varying organizational setup.

At the system level, policy and market conditions, as well as the background material and energy system, influence the economic and climate impact of most of the processes along the (E)LFM value chain. Relative to the factors at the site and project levels, system-level factors are more or less fixed as the incumbent background conditions. To some extent, policymakers can influence these conditions through various interventions, but they are, in general, regionally contingent and beyond the authority of any individual stakeholder to influence directly. For instance, apart from sitespecific factors, the choice of management for landfills is also defined by specific process requirements that depend on national or regional regulations. The required actions and costs for landfill closure, aftercare, and remediation can, therefore, vary widely between different regions (Rosendal, 2015; Van Vossen and Prent, 2011). Such variations among countries are also relevant regarding available treatment and recycling facilities, accessible markets, and current price settings for different materials extracted from landfills. Here, the lack of real-life projects that actually involved sales of recovered materials from waste deposits also displays large uncertainties regarding their marketability. In handling such uncertainties, different studies have employed different assumptions regarding both the marketability, 
potential revenues and thus avoided climate impact for production for the recovered and valorized materials. However, it is commonly assumed that the materials they plan to recover and valorize will be accepted by existing markets (Danthurebandara et al., 2015c; Van Passel et al., 2013; Winterstetter et al., 2015). Apart from marketable materials, an (E)LFM project also typically generates significant amounts of other materials (e.g., fines and combustibles) that are bound for disposal or further treatment (Hernández Parrodi et al., 2018). Consequently, the management expenditures for these waste fractions in terms of gate fees for landfilling and incineration can vary considerably among nations and regions due to their imposed taxes and waste market conditions (Confederation of European Waste-to-Energy Plants, 2017). Similarly, the climate impact varies due to the different background materials and energy systems that define both the climate burdens and savings in certain regions.

\subsubsection{Assessment challenges}

Our current knowledge about the economic performance and climate impact of (E)LFM is limited and incoherent. Previous assessments present contradictory conclusions regarding the overall economic performance and climate impact. Most of them conclude that (E)LFM is not profitable (Danthurebandara et al., 2015a, 2015c; Kieckhäfer et al., 2017; Winterstetter et al., 2015; Wolfsberger et al., 2016), while others have opposite conclusions (Damigos et al., 2016; Van Passel et al., 2013; Wagner and Raymond, 2015; Zhou et al., 2015). Similarly, some conclude that (E)LFM leads to climate savings (Danthurebandara et al., 2015c; Frändegård et al., 2013; Jain et al., 2014), while others lead to climate burden (Danthurebandara et al., 2015a; Winterstetter et al., 2015). Moreover, the reported critical factors that build up the net economic performance and climate impact are also inconclusive. These observations boil down to challenges that are related to the assessment of an emerging concept, or ex-ante assessment, with inherent knowledge deficits as well as the differences in applied assessment methods.

Firstly, large knowledge deficits about different processes along the (E)LFM process chain can be expected due to the absence of real-life and large-scale project implementation. For instance, because of the lack of large-scale processing of actual landfill waste, there is an apparent use of data from the processing of other waste in other situations like fresh municipal waste or direct use of laboratory-scale data (Ford et al., 2013; Van Vossen and Prent, 2011). The use of such proxy data and knowledge from neighboring fields is inevitable, but such empirical constraints also highlight the need to address the related uncertainties in an ex-ante assessment (Hetherington et al., 2014; van der Giesen et al., 2020). Otherwise, if left unaddressed, the validity of the presented results can be questioned.

Secondly, there is a lack of know-how when it comes to the implementation of (E)LFM and the identified drivers of the economic performance and climate impact. These drivers are often presented at different levels of aggregation, which relates to the differences in the level of specificity and complexity of the employed method. For 
instance, some studies provide aggregated information in terms of the process contributions (Kieckhäfer et al., 2017; Wolfsberger et al., 2016; Zhou et al., 2015), while other studies present more disaggregated results, such as how changes in specific parameter values influence the economic performance and climate impact (Danthurebandara et al., 2015c; Van Passel et al., 2013; Winterstetter et al., 2015). Such detailed information on critical factors for performance can facilitate the development of specific measures and strategies for improved economic performance and reduced climate impact. This pertains to the validity of the applied methods in previous assessments and to what extent they manage to systematically identify the critical factors of (E)LFM.

Lastly, when it comes to the usefulness of results in terms of applicability, most studies are case study specific with conclusions that are limited to a certain landfill and regional context. Variations of factors at the project level are thus often in focus while neglecting the influence of site selection, surrounding policy and market conditions, and background material and energy system. Some studies have also applied different modeling principles, and thus with varying (E)LFM processes (e.g., thermal treatment, avoided aftercare, the value of landfill void space or land) are accounted for. These individual considerations limit the understanding of what influences the overall economic performance and climate impact of (E)LFM in different situations and settings. There is a need to investigate all levels of factors and conditions influencing the economic performance and climate impact to develop useful strategies for implementation. It should be highlighted that these factors at the site, project, and system levels are interrelated. For instance, the choice of technical and organizational setup depends on the landfill and local settings in question as well as the surrounding policy and market environment. Such generic knowledge can be generated from the synthesis of results from previous studies or so-called meta-analyses (Glass, 1976; Lifset, 2012; Shelby and Vaske, 2008). At least in the field of sustainability, such metaanalysis is relatively new, and there are different employed methods. This displays a concern that such analysis can only provide a crude understanding and only serve as a hint for generic knowledge due to several harmonization challenges such as differences in case-specific considerations and lack of transparency, as well as variations in the applied modeling principles and assessment methods of individual studies (Brandão et al., 2012; Lifset, 2012). In this regard, more quantitative meta-analysis methods can offer a more systematic approach to synthesize the available information from different case studies (Shelby and Vaske, 2008). Several such sustainability assessments have recently been done to provide generic knowledge on the environmental performance of various systems (Brandão et al., 2012). Different studies on specific systems can be harmonized and integrated to elicit generic knowledge. In line with this, it can guide the explorative approach that is recommended for ex-ante assessment, which means accounting for multiple scenario possibilities in consideration of various paths for development as used in previous studies as well as with the aid of experts in the field (van der Giesen et al., 2020; Villares et al., 2017; Voinov et al., 2016). 
Such an explorative approach, both for an individual landfill in a case study-specific assessment or for multiple landfills in a generic assessment, accounts for extensive options for developing cost-efficient and climate-beneficial approaches that are actually addressed in previous assessments. The methodology developed by Laner et al. (2016) was used for analyzing the climate impact of LFM in Europe. Almost 3,000 LFM scenarios were generated and analyzed through a variance-based approach, accounting for different variations at the site, project, and system levels. Such an approach is rooted in the field of engineering called the statistical design of experiments, which is typically utilized for process improvement through the screening of alternatives (NIST/SEMATECH, 2012). In this thesis, this variance-based approach is also adopted for a generic assessment of economic performance and climate impact of (E)LFM in Europe. Through the variance-based approach, critical economic factors can be identified as well as their interrelations, which is necessary for the development of cost-efficient and climate-beneficial (E)LFM projects. In addition, several analyses are further developed in this thesis, such as trade-off analysis, regional archetype analysis, and policy analysis. See Section 4.1 for the details on the developed factorbased method.

\subsection{Uncertainty and sensitivity analyses}

From the previous sections, several sources of uncertainties are mentioned that may occur during scenario building, model development, and data gathering (Clavreul et al., 2012; Huijbregts et al., 2003). The nature of these uncertainties can be classified as either stochastic or epistemic (Clavreul et al., 2013; Saltelli et al., 2008). Stochastic uncertainty refers to the variability of data, for example, in time, space, and technology, which can be attributed to outcomes that for practical purposes cannot be predicted. Epistemic uncertainty, in contrast, refers to the lack of knowledge, for example, due to measurement errors, an insufficient number of measurements, or a lack of expertise. Uncertainties are inevitable, and for (E)LFM, it is highlighted that more epistemic uncertainties are expected as it is still an emerging concept with large empirical knowledge deficits.

To handle such wide uncertainties, the employment of uncertainty and sensitivity analysis methods is key (Ferretti et al., 2016; Saltelli and Annoni, 2010). Such methods explicitly account for the uncertainties, and it also enables fine-grained assessments of various factors and their interactions that jointly build up the net results. Uncertainty analysis accounts for the uncertainties of input parameters (i.e., range of values instead of an absolute value per parameter), which gives information about how much the output value could vary. Sensitivity analysis, on the other hand, apportions the variation of the output value to the input parameters. This could be done when input parameters are changed either one at a time, as in local sensitivity analysis, or simultaneously, as in global sensitivity analysis (Saltelli et al., 2008). The former is a classical approach to sensitivity analysis, and it is the most frequently used method. However, it is proven to be inefficient in revealing the underlying interactions, among other factors. Hence, global sensitivity analysis is instead recommended for a granular 
system understanding (Ferretti et al., 2016; Saltelli and Annoni, 2010). Through global sensitivity analysis, the variation in output is apportioned to the variation in each input factor over their entire range of value. A sensitivity analysis is considered to be global when all the input factors are varied simultaneously, and the sensitivity is evaluated over the entire range of each input factor.

Global sensitivity analysis methods can be classified into generalized sensitivity analysis methods, variance-based methods, globally aggregated measures of local sensitivities methods, density-based methods, and meta-modeling methods. These methods are based on different theories and principles, and as a result, have different efficiencies. Saltelli et al. (2008), Ciuffo et al. (2012), and Pianosi et al. (2016) provided a useful overview of these sensitivity analysis concepts, methods, and framework, with suggestions on how to choose specific methods. But often, the choice of method is largely research field-dependent. Variance-based methods are the most popular approaches for global sensitivity analysis (Saltelli et al., 2019). The main advantage of global sensitivity analysis is that it can compute the main effect and higher-order effect of factors, respectively, and make it distinguishable which factors have a strong influence on the output on their own and which factors have high interaction with others, respectively. These are particularly important to elicit an in-depth understanding of the factor importance, which significantly constitutes the economic performance and climate impact of (E)LFM. In this way, a systematic determination of critical factors can be derived, which can guide the development of cost-efficient and climate-beneficial (E)LFM projects and the identification of priority research areas to improve the current knowledge deficits. The previously mentioned methodology developed by Laner et al. (2016), used for analyzing the climate impact of LFM in Europe, employed variance-based global sensitivity analysis. Such features motivated the choice of adopting and developing a similar approach in this thesis for the assessment of economic performance and climate impact of (E)LFM. 
3. Research context 
This section provides details on the context of how the entire $\mathrm{PhD}$ research has unraveled from the funding project that it was part of and the development of the contents of individual papers.

\subsection{Research journey}

This research began as part of the NEW-MINE project or the EU Training Network for Resource Recovery through ELFM, a Marie Skłodowska-Curie Action under the EU Framework Programme for Research and Innovation Horizon 2020 (Grant Agreement No. 721185). NEW-MINE involved a consortium of higher education institutions and companies that mainly work with the development of ELFM technologies. In addition, civil society organization, governmental and non-governmental institutions were also involved as part of the advisory committee. In total, there were $15 \mathrm{PhD}$ students whose research topics were distributed into four Work Packages (WPs). Three of which were about the development of innovative technologies along the ELFM process chain in terms of exploration, excavation, and sorting (WP1), thermal treatment (WP2), and upgrading of residues from thermal treatment to high-added-value products such as geopolymers (WP3). In contrast, $\mathrm{WP}_{4}$, to which this research belonged, focused on the development and application of different sustainability assessment methods (environmental, economic, and social) for analyzing and comparing the impacts of different landfill mining and landfill management scenarios.

Under WP4, the pre-defined milestones for this research were to develop and apply (i) a generic economic assessment method that can address both the net economic performance of (E)LFM and the underlying critical factors and (ii) an extended economic assessment method for analyzing trade-offs between environmental and economic performance and evaluating the potential of policies and strategies for facilitating implementation. In this thesis, both milestones were achieved through the six appended papers ( $P 1$ to $P 6$ ). In particular, $P_{1}$ and $P 2$ focused on the economic assessment alone, while $P_{3}$ and $P_{4}$ extended the assessment with environmental aspects through climate impact assessment. The generic method employed in the aforementioned papers was based on the prior review of previous assessment studies of (E)LFM ( $P_{5}$ and P6). In contrary to the temporal sequence of the papers, the two literature reviews were numbered last in this thesis to aid in the wider discussion of the empirical contributions of $\mathrm{P}_{1}-\mathrm{P} 4$ in the field of (E)LFM and the method contributions and limitation with respect to related studies on ex-ante assessments for emerging concepts and technologies. The connections of $P 1$ to $P 6$ are illustrated in Figure 2. 


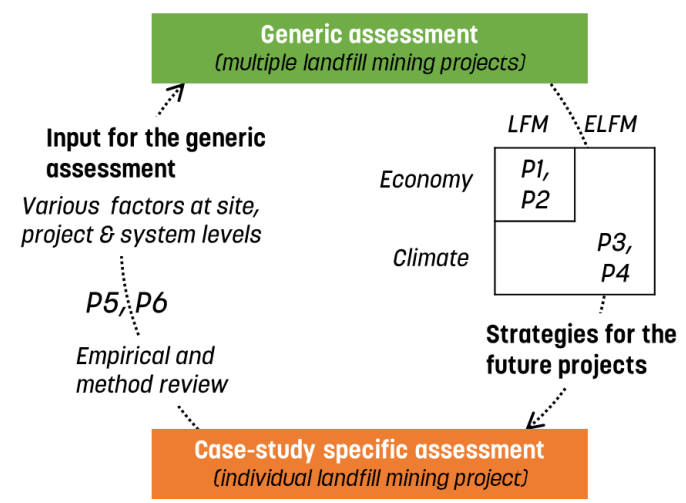

Figure 2. The development of the appended papers $(P s)$ from the literature review of assessments of (E)LFM P5 (economic) and P6 (economic, environmental, and social), to the own method that was developed and applied for generic assessments with extended sustainability perspectives (economy and climate) and technological and organizational scopes (LFM and ELFM) in P1 to P4.

It was necessary to do a literature review of the previous economic $\left(P_{5}\right)$ and environmental $\left(P_{5}\right)$ assessments of (E)LFM to perform a generic assessment. Acknowledgment of the different empirical and methodological contributions of previous studies, which were mainly case study-specific assessments, served as the basis for the development of a generic assessment method. In the review process, input data and presented results of different studies were collected, and various method features were noted. In the process, knowledge gaps were identified that includes the empirical (i.e., data along the (E)LFM value chain that are lacking or of limited availability) and methodological (i.e., physical, economic, and environmental modeling and uncertainty and sensitivity analyses) aspects, as well as the relevant knowledge for further (E)LFM development.

For the empirical aspect, additional data collection effort was made by taking advantage of the affiliation with the working group on LFM within the European Cooperation for Science and Technology - Mining the European Anthroposphere (COST-Action MINEA, Action No CA15115). Economic data on processes and price levels of relevance for (E)LFM were collected, as well as landfill management and waste management practices and policies in different European countries (i.e., Austria, Denmark, Estonia, Finland, Serbia, and Sweden). Additional material input and output for several advanced processes were collected from related assessments that dealt with fresh municipal solid waste and biological wastes as a proxy in case of unavailability for excavated landfill waste.

For the method aspect, the factor-based method was adapted and modified from Laner et al. (2016), which performed a generic climate impact assessment of traditional LFM that uses incineration. Such an approach is rooted in the field of engineering called the statistical design of experiments, which is typically utilized for process improvement through the screening of alternatives (NIST/SEMATECH, 2012). It accounts for the effect of the variation of different process input variables to the process output 
variables within the system boundaries considered. By doing so, the efficient planning of process experiments can maximize the amount of gathered information with respect to the amount of experimental effort. In this thesis, the factor-based method focuses on the full factorial design method relevant for performing generic assessments of (E)LFM. In particular, this can account for the expected wide variations in (E)LFM not just from the project level in terms of technological and organizational setups but also from the site level with varying landfill settings and waste composition, as well as from system level with varying policy and market conditions and background material and energy.

Following the set milestones, the first two assessments were only on the economics ( $P 1$ and $P 2$ ), while the other two were extended with environmental assessment through climate impact ( $P_{3}$ and $P_{4}$ ). From Laner et al. (2016), an economic counterpart was made, modifying the method for performing a generic economic assessment for traditional LFM with the external incineration process $(P 1)$. The proceeding paper explored strategies to improve the economics of traditional LFM by internalizing the incineration process with energy production $(P 2.1)$ and utilizing fines residue (P2.2), which otherwise count as costs. The proceeding paper was intended as a method paper to contextualize the method features with respect to available assessment methods for integrated economic and environmental assessment. For its application, the plasma gasification process with syngas to electricity valorization was chosen for exemplification (P4). With plasma gasification as the core of ELFM, based on NEWMINE, the final paper incorporated plasma gasification with various syngas and slag residue valorization in relation to other site and system-level settings and conditions for an overall economic and climate impact assessment of ELFM $\left(P_{3}\right)$. In addition, the inclusion of the climate aspect allowed the extension of analysis to guide and explore potential policies for improvement. In this thesis, the assessment of ELFM ( $\left.P_{3}\right)$ is numbered first to promote a continuous discussion that covers traditional LFM and ELFM, while plasma gasification (P4) is used for an additional discussion focusing on the specific process within the ELFM process chain.

The differences in scope in terms of sustainability (i.e., economy and climate) and technology perspectives (i.e., traditional LFM and ELFM) among the papers show the practical application and flexibility of the factor-based method. At the same time, the models from different papers are designed, as much as possible, to allow comparable results in various respects that will be highlighted in this thesis.

\subsection{Overview of appended papers}

The abstracts of each appended paper ( $P 1$ to $P 6)$ are provided below, followed by more detailed contents presented in terms of their aims, scopes, and highlights, as shown in Table 1. 
P1 - Systematic assessment of critical factors for the economic performance of landfill mining in Europe: What drives the economy of landfill mining?

Although several case study assessments on the economy of LFM exist, a broader understanding of the driving factors is still lacking. This study aims at identifying generically important factors for the economy of LFM in Europe and understanding their role in developing economically feasible projects in view of the different site, project, and system-level conditions. Therefore, a set-based modeling approach is used to establish a large number $(531,441)$ of LFM scenarios, evaluate their economic performance in terms of net present value (NPV), and analyze the relationships between input factors and economic outcome via global sensitivity analysis. The scenario results range from -139 Euro to +127 Euro/Mg of excavated waste, with $80 \%$ of the scenarios having negative NPVs. Variations in the costs for waste treatment and disposal and the avoided cost of alternative landfill management (i.e., if the landfill was not mined) have the strongest effect on the scenario NPVs, which illustrates the critical role of system-level factors for LFM economy and the potential of policy intervention to incentivize LFM. Consequently, system conditions should guide site selection and project development, which is exemplified in the study for two extreme regional archetypes in terms of income and waste management standards. Future work should further explore the developed model to provide decision support on LFM strategies in consideration of alternative purposes, stakeholders, and objectives.

P2 - Landfill mining in Europe: Assessing the economic potential of value creation from generated combustibles and fines residue

Previous studies showed that resources recovery through landfill mining (LFM) is generally challenging from an economic perspective and that a large share of project costs is related to the external treatment and disposal of bulk process wastes such as combustibles and fines residue. This study builds on these analyses and aims to explore the potential for improving the economy of LFM in Europe by creating value from these bulk process wastes. Specifically, the combustibles are treated through internal incineration with subsequent energy recovery, while fines residue is utilized as construction aggregates. These explored possibilities are investigated considering other varying factors at the site, project, and system levels that cover possible LFM project settings in Europe. A set-based modeling approach is adapted to generate multiple LFM scenarios $(531,441)$ and investigate the underlying critical factors that drive the economy of LFM through global sensitivity analysis. Results show that an additional $16 \%$ of LFM scenarios become net profitable, mainly driven by fines residue utilization. Avoided costs for re-landfilling are higher than the revenues from construction aggregates. By contrast, internal incineration is driven by the revenues from recovered energy rather than the avoided gate fee, which is substituted by the costs for building and operating own plants. Overall, the policy conditions remain critical to further improve the economy of LFM in Europe. Recommendations include an inclusive quality standard that relies on pollutant leachability rather than total concentration for higher-value application of fines residue and incentive rather than taxation for producing renewable energy from the combustibles. 
P3 - Enhanced landfill mining in Europe: Assessment of critical factors for the climate impact and economic performance of extended resource recovery through valorization of syngas and slag from plasma gasification

Plasma gasification has been proposed to maximize resource recovery within the concept of enhanced landfill mining (ELFM). However, the assessments of its economic and climate implications are case study-specific, limiting the understanding of its possible implementation in a wider geographical scope. This study aims to assess the climate impact and economic performance of extended resource recovery of ELFM in Europe. In particular, the valorization of syngas and slag from plasma gasification is assessed in relation to the wide variety of factors at the site, project, and system levels that cover possible ELFM settings in Europe. A set-based modeling approach is used with global sensitivity analysis to generate multiple scenarios $(531,441)$ and determine the underlying factors that drive the results. Results show that ELFM is preferable in terms of climate than economy. Specifically, $47 \%$ of the scenarios are climate beneficial ( $\mathrm{kg} \mathrm{CO} 2$ eq. $<0$ ), while only $17 \%$ of the scenarios are profitable (net present value $>0$ ). More than the slag valorization, the potential lies in the syngas valorization, especially in $\mathrm{H} 2$ production. However, to maximize the economic and climate benefits, the overarching condition depends on the combination of waste composition, policy and market conditions, and background systems for materials and energy. Integrated results show that only $9 \%$ of the scenarios are preferable in terms of both climate and economy. Through the explored policy instruments, the introduction of the lump-sum subsidy and green energy certificate has a significant role in supporting climatebeneficial projects to become profitable.

P4 - Integrated early-stage environmental and economic assessment of emerging technologies: A case study of plasma gasification

Economic and environmental impact assessments are increasingly being adopted to support decision-making in the design and implementation of emerging systems. However, current assessment approaches typically target environmental and economic hotspots of specific projects, with fixed design setups and operating conditions, thereby limiting the understanding of new technologies' performance under varying project and system conditions. This study presents an alternative approach for the integrated environmental and economic assessment of emerging systems. The aim of the approach is (i) to conduct an exploratory assessment of the systems under varying conditions and settings, (ii) to perform fine-grain analysis of the underlying mechanisms that drive the performance (iii), and to support decision-making by integrating economic and environmental results. The presented factor-based approach is based on a full factorial design method, which is extended and applied to a case study on plasma gasification in this study. The results of the study highlight the added value provided by the eco-efficiency indicators and the global sensitivity analysis in the identification of the driving factors for the integrated environmental and economic performance of emerging systems. At a technology level, the choice of gasifying agent and the slag management alternatives are significant factors for the integrated performance of the system, independently of the feedstock. This outcome is of great 
interest to the potential applicability of the technology for treating heterogeneous waste streams. Moreover, the results indicate the importance of system-level factors, such as market prices and substitution factors, in the system's integrated performance, stressing the importance of considering the variation of background processes and exogenous variables in the assessment of emerging systems.

$\mathrm{P}_{5}$ - Assessing the economic potential of landfill mining: Review and recommendations

As LFM gains public attention, the systematic assessment of its economic potential is deemed necessary. This review aims to critically analyze the usefulness and validity of previous economic assessments of LFM. Following the life cycle costing (LCC) framework, (i) the employed methods based on goal and scope, technical parameters and data inventory, and modeling choices were contrasted with respect to (ii) the synthesized main findings based on net profitability and economic performance drivers. Results showed that the selected studies $(n=15)$ are mostly case study-specific and concluded that LFM has a weak economic potential, hinting at the importance of favorable market and regulation settings. However, several method issues are apparent as costs and revenues are accounted for at different levels of aggregation, scope, and scale-from process to sub-process level, from private to societal economics, and from laboratory to pilot-scale, respectively. Moreover, despite the inherent large uncertainties, more than half of the studies did not perform any uncertainty or sensitivity analyses posing validity issues. Consequently, this also limits the usefulness of results as individual case studies and as a collective towards a generic understanding of LFM economics. Irrespective of case study-specific or generic aims, this review recommends that future assessments should be learning-oriented, that is, uncovering granular information about what builds up the net profitability of LFM to be able to systematically determine promising paths for the development of cost-efficient projects.

P6 - Integration of resource recovery into current waste management through (enhanced) landfill mining

Economic and environmental impact assessments are increasingly being adopted to support decision-making in the design and implementation of emerging systems. However, current assessment approaches typically target environmental and economic hotspots of specific projects, with fixed design setups and operating conditions, thereby limiting the understanding of new technologies' performance under varying project and system conditions. This study presents an alternative approach for the integrated environmental and economic assessment of emerging systems. The aim of the approach is (i) to conduct an exploratory assessment of the systems under varying conditions and settings, (ii) to perform fine-grain analysis of the underlying mechanisms that drive the performance (iii), and to support decision-making by integrating economic and environmental results. The presented factor-based approach is based on a full factorial design method, which is extended and applied to a case study on plasma gasification in this study. The results of the study highlight the added value provided by the eco-efficiency indicators and the global sensitivity analysis in the 
identification of the driving factors for the integrated environmental and economic performance of emerging systems. At a technology level, the choice of gasifying agent and the slag management alternatives are significant factors for the integrated performance of the system, independently of the feedstock. This outcome is of great interest to the potential applicability of the technology for treating heterogeneous waste streams. Moreover, the results indicate the importance of system-level factors, such as market prices and substitution factors, in the system's integrated performance, stressing the importance of considering the variation of background processes and exogenous variables in the assessment of emerging systems 


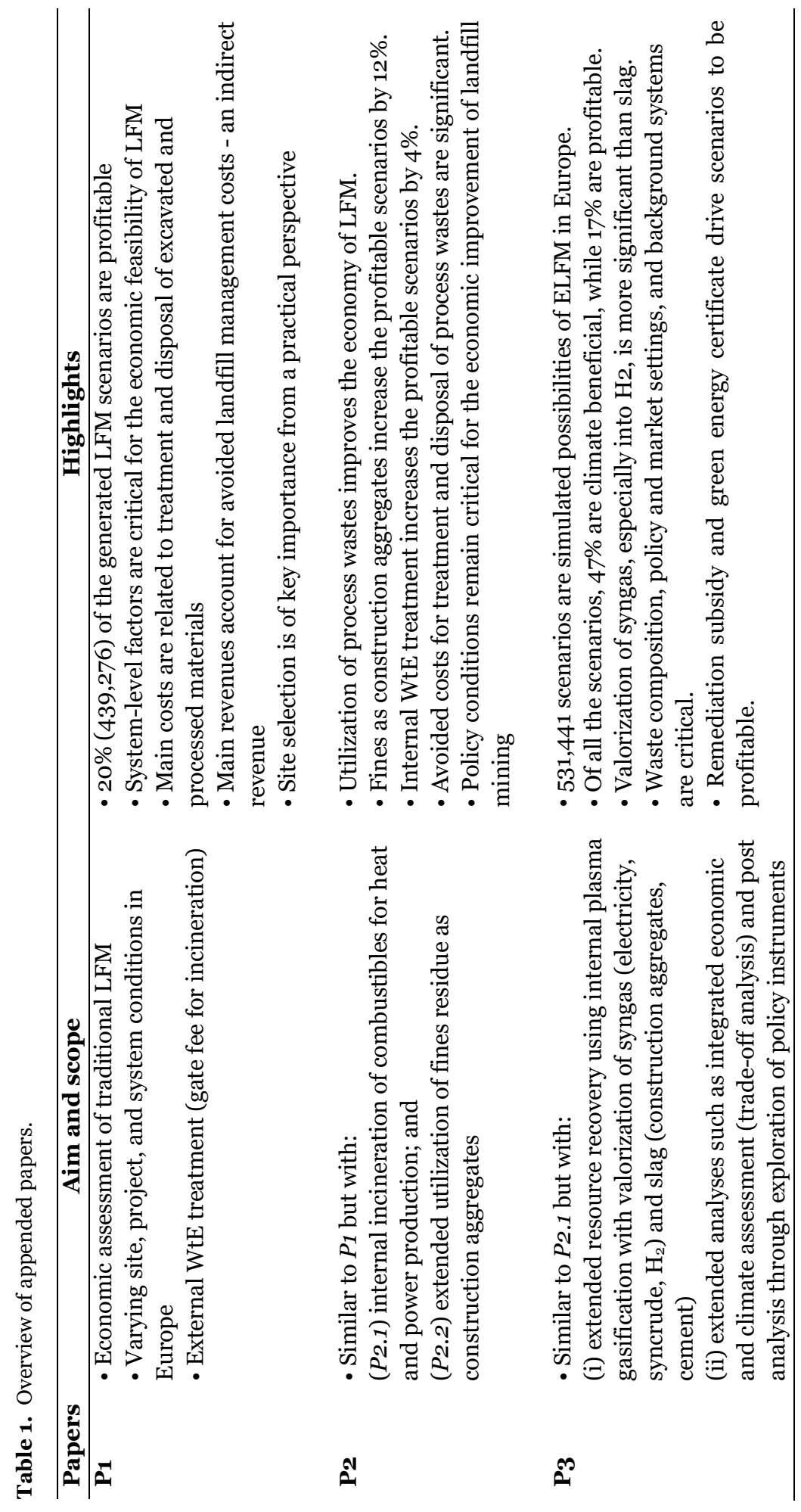




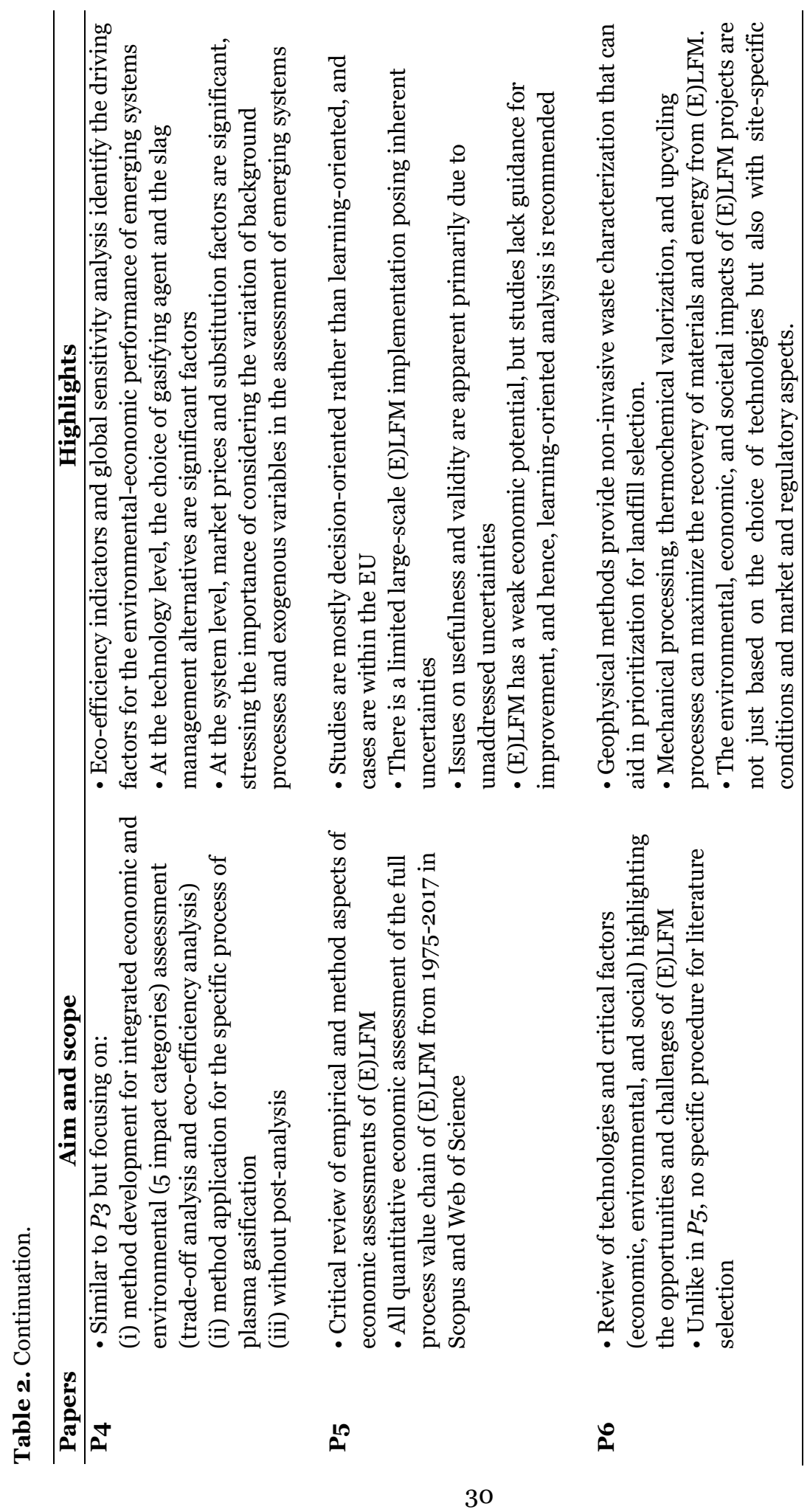


4. Thesis methodology 
This section provides details on the adapted and developed method called the factorbased method, which is the core method used in the appended papers ( $P_{1}$ to $\left.P_{4}\right)$. In addition, the synthesis of the contributions of each appended paper ( $P 1$ to $P 6)$ is presented here showing how it is utilized to address the three research questions (RQ1 to RQ3), and thus the thesis aim.

\subsection{The factor-based method}

The factor-based method is divided into three steps that include (i) a full factorial combination to generate multiple (E)LFM scenarios, (ii) a material and energy balance to serve as the basis for economic performance and climate impact assessment of each scenario, and (iii) a scenario analysis for an in-depth understanding of what and how the net performances are build up by different site, project and system factors (Figure 3). MATLAB ${ }^{\circledR}$ was used for all the modeling procedures. Only the general approach is presented here; refer to the appended papers for specific details and operationalization.
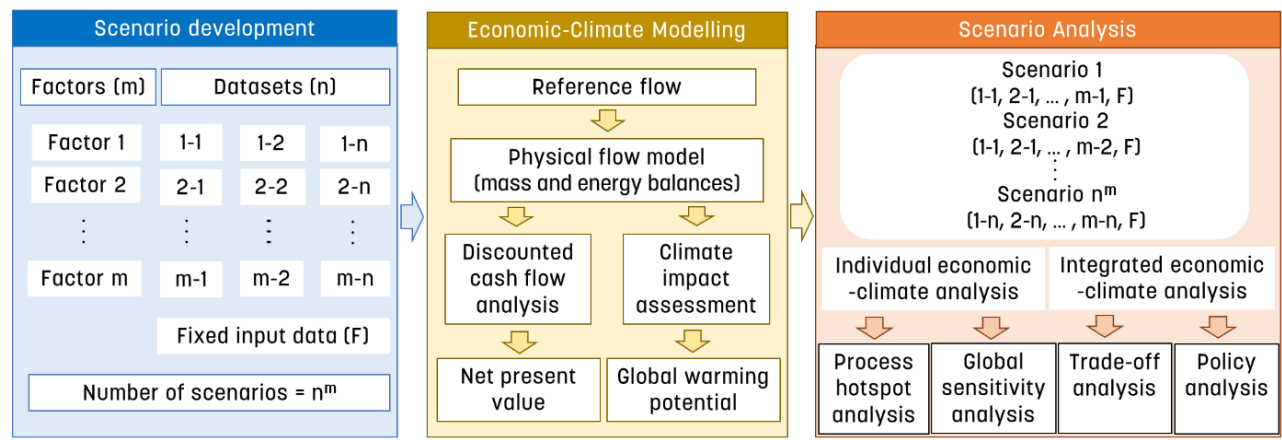

Figure 3. Schematic illustration of the factor-based method developed to assess the importance of different factors for the economic performance and climate impact of (E)LFM.

In relation to the factor-based method used in Laner et al. (2016), the novelty on how it was used in the appended papers lies in the adaptation and modification for performing separate $\left(P_{1}\right.$ and $\left.P 2\right)$ and integrated $\left(P_{2}\right.$ and $\left.P_{4}\right)$ economic performance and climate impact assessment and in the subsequent scenario analysis. In addition to the global sensitivity analysis, this final step included process hotspot analysis to understand the main contributing processes to the overall impacts ( $P_{1}$ to $\left.P_{4}\right)$ and trade-off analysis to compare scenario results from the economic and climate perspectives ( $P_{3}$ and $\left.P_{4}\right)$.

The full factorial combination allows exploratory scenario development enabling the determination of (E)LFM project possibilities that are preferable in terms of economy and climate. However, it is also a limitation that certain combinations may be of questionable plausibility considering the current circumstances. Acknowledging the difficulty on checking the plausibility of full factorial combinations, post processing and analysis of the scenarios were also performed. Regional archetypes were simulated based on income level and waste management standards by fixing related system-level 
factors to narrow down the factor combinations and elicit more specific insights on site selection and project setup ( $P_{1}$ and $\left.P 2\right)$ for improved economic results. For specific insights on potential policy instruments, policy analysis were done integrating economic and climate results $\left(P_{3}\right)$ to develop preferable ELFM projects in both sustainability perspectives.

\subsubsection{Scenario development}

A systematic scenario development was performed by selecting relevant factors (m) and data sets (n) according to the goal and scope of the study (Table 2). For each of the models in $P_{1}$ to $P_{3}, 12$ factors were considered, each with 3 alternative datasets that generated 531,441 $\left(3^{12}\right)$ unique (E)LFM scenarios. Factors (m) refer to the selected variables that are relevant for the economic and climate assessments of (E)LFM in Europe covering different factors at the site (i.e., waste composition and landfill settings), project (i.e., technology choices and organization), and system levels (i.e., policy and market conditions and background material and energy systems). Datasets (n), in contrast, refer to several possible alternatives that define each factor that corresponds to the variations that can be encountered within the European borders. These are represented as the discrete choices such as minimum, average, and maximum possibilities, as determined based on the literature review including case studies, company reports, and existing models, and were iteratively developed with the knowledge from various experts such as the (E)LFM experts within COST-Action MINEA, as previously mentioned. In the same manner, fixed factors were also determined, whose variation is considered as not critical for the assessment based on the goal and scope of the study, literature review, and from various experts or such factors are physical constants such as calorific values and landfill gas potential of different waste fractions. 


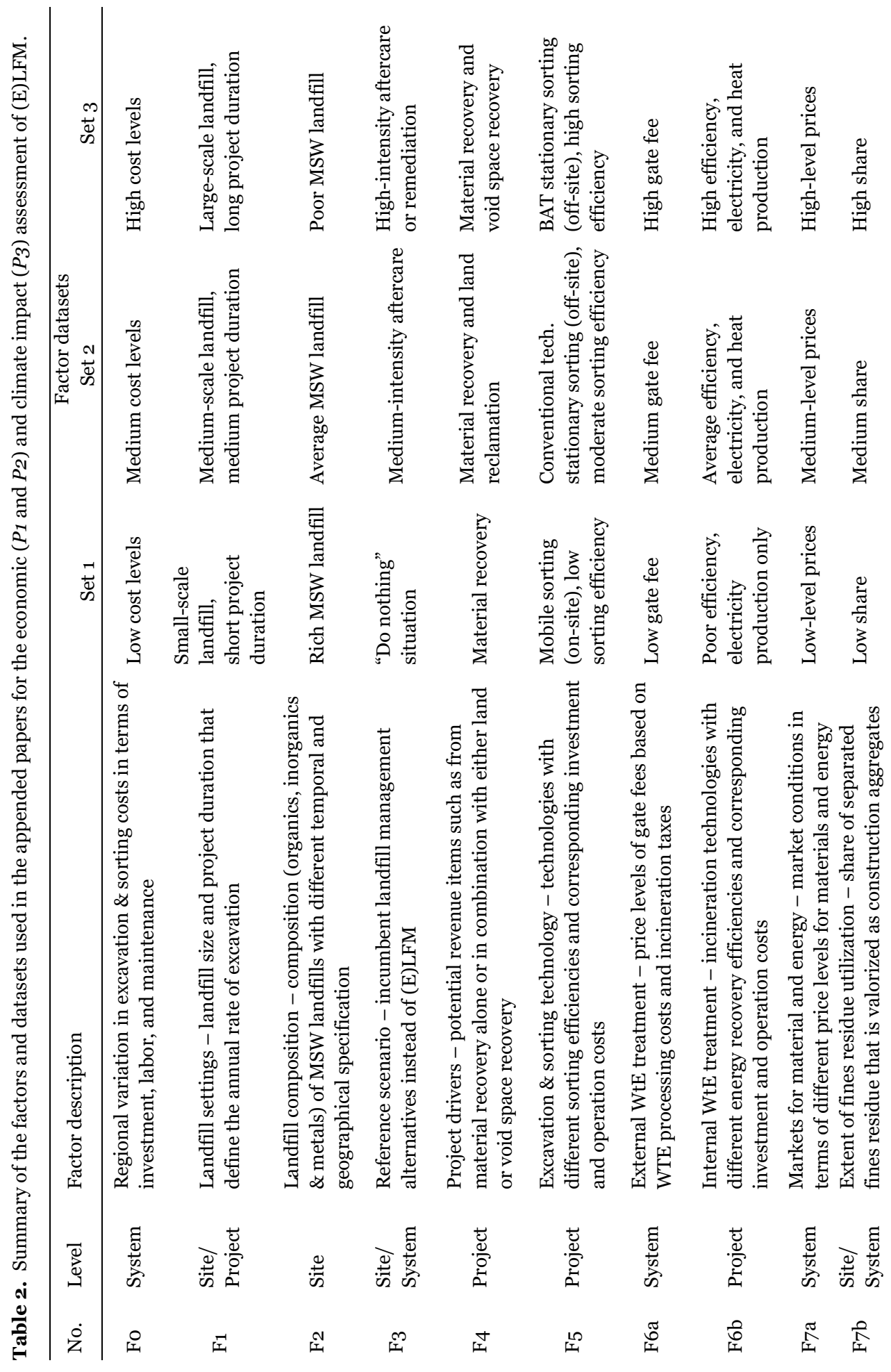




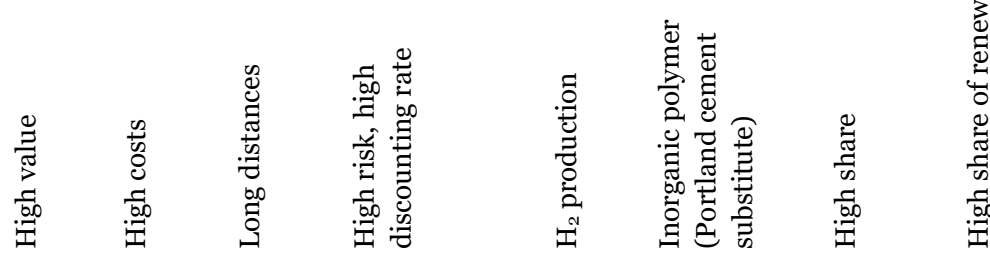

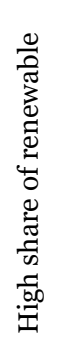

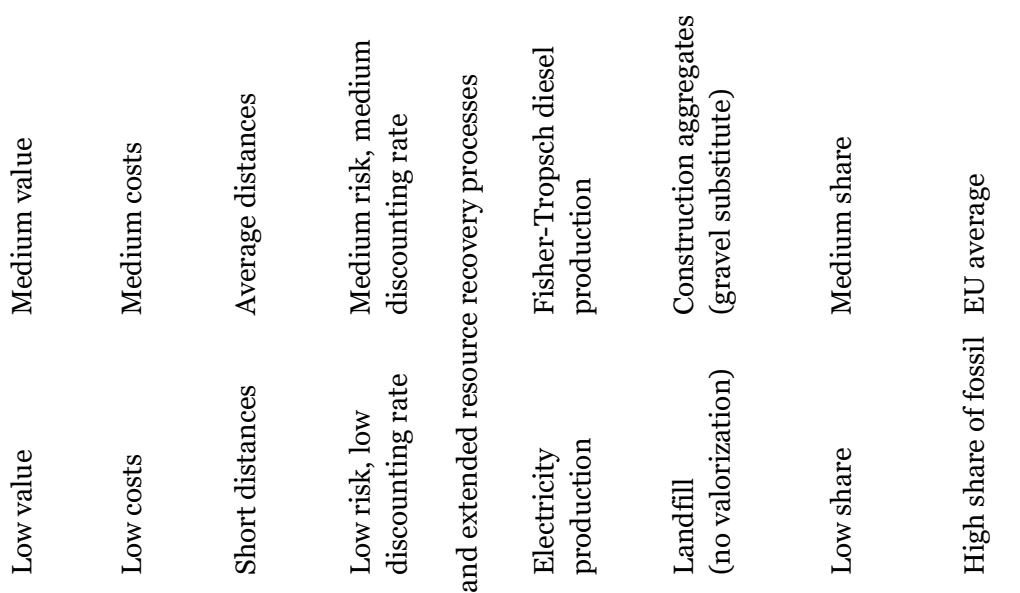

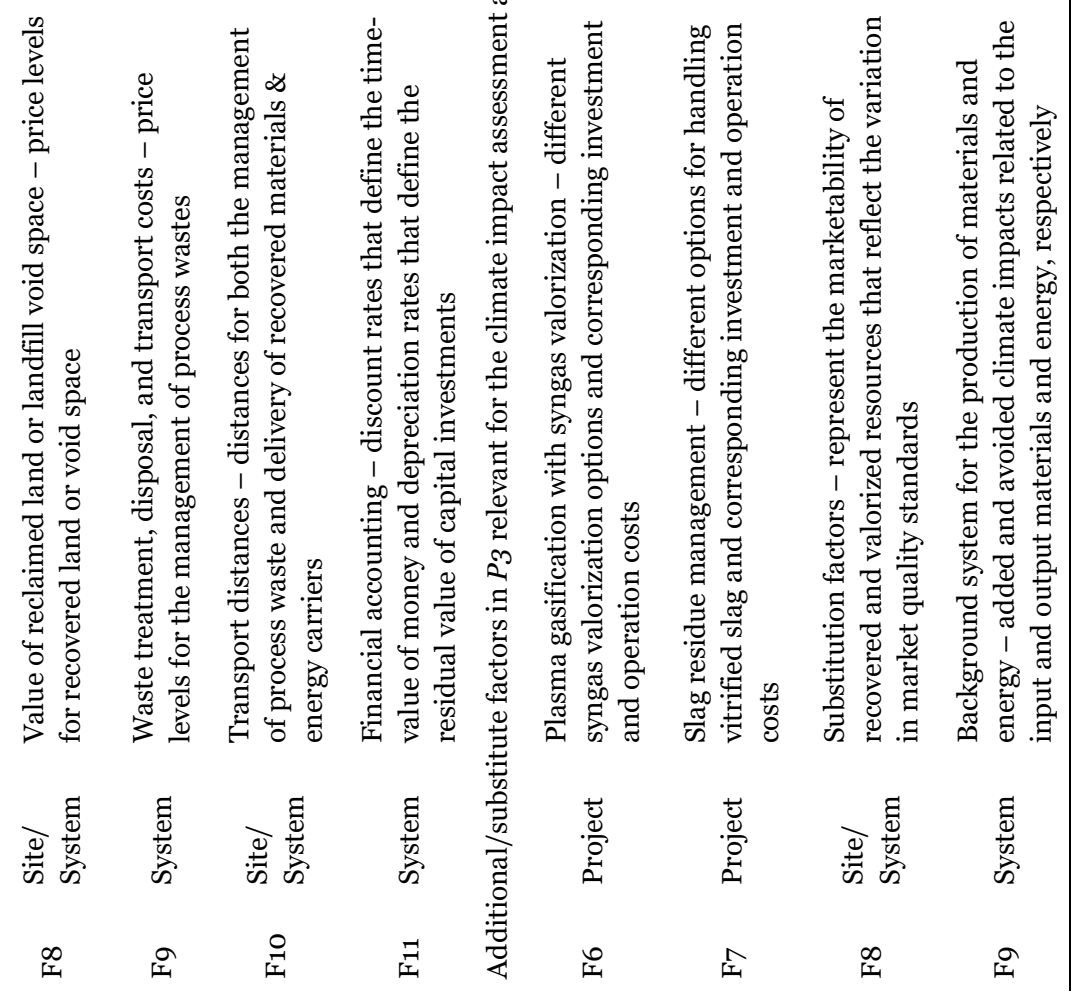




\subsubsection{Economic and climate modeling}

The economic and climate modeling is based on a balanced material and energy flow accounting for the fate of each material fraction and their properties as they transfer from each process step. The process chain from traditional LFM to ELFM is shown in Figure 4. The mathematical relations among the factors for material and energy flow, the corresponding economic performance and climate impact, and the fixed factors constitute the overall modeling approach to assess the generated multiple (E)LFM scenarios.

Different landfill settings (F1) in terms of landfill size and, therefore, the amount of waste and length of the project are considered. The landfills with different waste compositions (F2) are excavated and sorted (F5), and the valorized products are directed to material recycling, including metal scraps, plastics, and construction aggregates. The process residues are either re-deposited internally or externally, depending on the project driver $\left(\mathrm{F}_{4}\right)$, apart from the material recovery that is either void space recovery or land reclamation, respectively. The combustibles are input to plasma gasification with different syngas valorization (F6), and the resulting vitrified slag is also valorized (F7). A fraction of the output products is considered to get into the market and substitute the primary production through a substitution factor (F8) that reflects the quality standards. All of these processes and material and energy flows are associated with certain economic costs or revenues and climate burdens or savings. Apart from processing costs, disposal and transport of materials and processing waste (F11) are accounted for at different transport distances (F12). The associated benefits refer to revenues for the recovered materials, energy, land, or void space (F10), as well as to avoided costs for the reference case (F3). The associated climate burden from the aforementioned process and climate savings from the subsequent products are dependent on the background material and energy system (F9).

The economic performance assessment accounted for costs that corresponded to the processing and transporting of materials and revenues that corresponded to both direct revenues, such as valorization of materials and recovered value of land or void space, as well as indirect revenues from avoided management costs in the reference case. The net present value (NPV) of the overall project was calculated for $1 \mathrm{Mg}$ of excavated waste using discounted cash flow analysis over the respective project duration. Similarly, climate impact assessment accounted for climate burden from the required input materials and energy from the processing and transporting of materials and climate savings from the avoided production of valorized products and avoided direct emission from the landfill reference case. The climate impact was calculated based on environmental data available from related literature or derived from available databases, mainly Ecoinvent v.3 or Gabi thinkstep. For direct emissions, characterization factors were directly used to assess the impacts. In particular, direct emissions for the landfill reference case were estimated based on the landfill gas potential of the waste fractions and calculated based on the IPCC model (Laner et al., 2016; Pipatti et al., 2006). The same approach was also used for the estimation of the 
emissions from the re-landfilling of the non-recoverable waste streams. For this thesis, climate change is the highlighted midpoint impact category with global warming potential as the indicator (kg CO2 eq.). It was assessed based on the CML2001 method for comparability with previous studies, especially with Laner et al. (2016). 

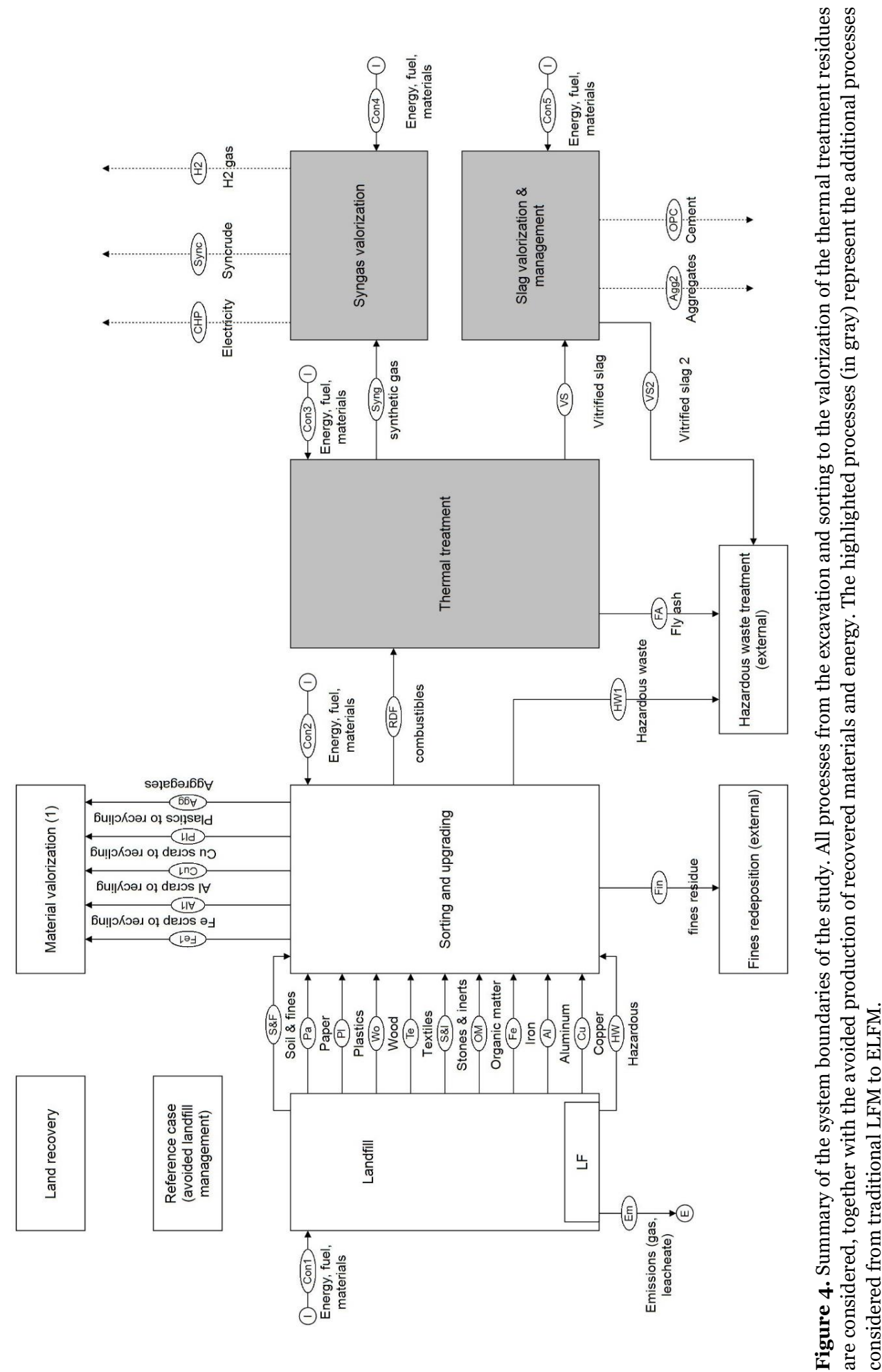


\subsubsection{Scenario analysis}

Scenario analysis was conducted, including the process hotspot analysis and global sensitivity analysis for individual economic and climate impact results, and trade-off analysis and policy analysis for integrated results. These analyses were applied to different extents in the appended papers, with $P_{3}$ as the latest spin-off for method development.

Hotspot analysis provides information on which processes contribute most in absolute terms to the overall scenario results (Clavreul et al., 2012), while the global sensitivity analysis, particularly variance-based sensitivity analysis, assesses the relative importance of the addressed factors to the total variance of the scenario results (Laner et al., 2019; Laner et al., 2016; Saltelli et al., 2008). Although hotspot analysis provides knowledge of pinpointing important contributing processes, it fails to capture the reason behind the wide range of results as they are analyzed on average and is unable to determine the underlying factors that drive the economic performance that global sensitivity analysis can show. In essence, global sensitivity analysis, which is the core of the approach proposed by Laner et al. (2016), allows a deeper understanding than hotspot analysis about what and how the factors drive the economic performance and climate impact of (E)LFM.

Variance-based sensitivity analysis is measured through sensitivity indices, which are used to express the criticality of specific factors on their own through the first-order sensitivity index $\left(\mathrm{S}_{\mathrm{i}}\right)$, in combination with other factors through the higher-order sensitivity index $\left(\mathrm{S}_{\mathrm{Hi}}\right)$, or both through the total-order sensitivity index $\left(\mathrm{S}_{\mathrm{Ti}}\right) . \mathrm{Si}$, calculated according to Equation 1, represents the main effect contribution of the input factor to the output. In Equation 1, $F_{i}$ is the $i^{\text {th }}$ factor, $F_{\sim i}$ are all factors but $F_{i}, Y$ is the model output, and $\mathrm{E}_{\mathrm{F} \sim \mathrm{i}}$ is the mean value of $\mathrm{Y}$ over all possible values of $\mathrm{F}_{\sim \mathrm{i}}$ while keeping $F_{i}$ fixed. $V_{F i}$ is the variance of the mean values over the different sets of $F_{i}$, which is divided by the total variance of the output.

$$
S_{i}=\frac{V_{F_{i}}\left(E_{F_{\sim i}}\left(Y \mid F_{i}\right)\right)}{V(Y)}
$$

(Equation 1)

$\mathrm{S}_{\mathrm{Ti}}$, calculated according to Equation 2, represents the main and higher-order effects of factor $F_{i}$. In Equation 2, the numerator is the first-order effect of $F_{\sim i}$, so that $V(Y)$ minus this term gives the contribution in the variance decomposition of all terms containing $\mathrm{F}_{\mathrm{i}}$ (Saltelli et al., 2010).

$$
S_{T_{i}}=1-\frac{V_{F_{\sim i}}\left(E_{F_{i}}\left(Y \mid F_{\sim i}\right)\right)}{V(Y)}
$$

(Equation 2)

While $S_{i}$ measures the main effect of factor variation on the output variation, $\mathrm{STi}_{\mathrm{T}}$ provides the overall importance of a factor for the output variation, including interactions with other factors. These interaction-related effects are expressed by $\mathrm{SHi}_{\mathrm{Hi}}$ which is given by $\mathrm{S}_{\mathrm{Ti}}$ minus $\mathrm{S}_{\mathrm{i}}$, as in Equation 3 .

$$
S_{H_{i}}=S_{T_{i}}-S_{i}
$$

(Equation 3) 
For integrated analysis, a trade-off analysis was performed to compare scenario results from the economic and climate perspectives $\left(P_{3}\right.$ and $\left.P_{4}\right)$. Here, the specific factor datasets and combinations were identified that both influence economic performance and climate impact. This was done by plotting the total scenario results in terms of economic performance (horizontal axis) and climate impact (vertical axis). This allows a graphical understanding of the distribution of the scenarios within the four quadrants of the graph: Quadrant I with economically preferable scenarios, Quadrant II with economically and climate preferable scenarios, Quadrant III with climate-preferable scenarios, and Quadrant IV with no preferable scenarios. Then, the frequency of factor datasets was determined to identify what constitutes the scenarios in each quadrant. In $P_{3}$, it was used to identify important factor datasets for identifying economically and environmentally preferable scenarios for ELFM, while in $P 4$, it was used for the specific plasma gasification process alone.

Post-processing and analysis of the scenarios were also performed to address the difficulty regarding the plausibility of full factorial combinations. Analysis of regional archetypes was performed to narrow down the factor combinations and elicit more specific insights. By fixing related system-level factors, two regional archetypes were simulated, such as a region with a high income and high waste management standards and its counterpart with a low income and low waste management standards. Hence, factors at the site and project levels were allowed to vary, making it possible to gain insights on site selection and project setup $\left(P_{1}\right.$ and $\left.P 2\right)$ for improved economic results. For specific insights on potential policy instruments, policy analysis was done integrating economic and climate results $\left(P_{3}\right)$ to develop preferable ELFM projects in both sustainability perspectives. Two policy instruments are based directly on the economic aspect, such as the lump-sum subsidy (Euro/Mg excavated waste) and landfill tax reduction (\% reduction), while the other two are based on the environmental aspect, such as green certificate (Euro/MWh eq.) and climate subsidy (Euro/Mg CO2 eq.). Emphasis is given to those with net climate savings (i.e., Quadrant III) that are further investigated to avoid supporting ELFM scenarios with a net climate burden (i.e., Quadrants I and IV).

\subsection{Synthesis of appended papers}

The six appended papers ( $P 1$ to $P 6$ ) were utilized to address the three research questions ( $R Q 1$ to $R Q 3)$, and thus the thesis aim through the synthesis of their contributions. The overall thesis structure is shown in Figure 5, which illustrates the connections between the research questions and the appended papers, as well as the subsequent analysis and reflection. The structure of the thesis is designed to provide an aggregated to granular understanding from the overall results $(R Q 1)$, the important factors that constitute such results (RQ2), and the strategies for improvement (RQ3) while highlighting the specific contributions of the appended papers, noted with a checkmark and detailed in the preceding text. In particular, the contributions of $P 1$ to $P_{4}$ differ in scope in terms of sustainability perspective (i.e., economy and climate) and technology used (i.e., LFM and ELFM) while using the developed assessment method, 
that is, the factor-based method. These papers provide various dimensions on addressing the $R Q s$ with respect to varying technological and organizational setups assessed in relation to the varying site and system conditions and settings in Europe. $P_{5}$ and P6, together with other ex-ante assessment studies, were then used to contextualize both the empirical and methodological contributions of the aforementioned studies using the factor-based method as well as its limitations and potential developments for assessing emerging concepts such as (E)LFM. 


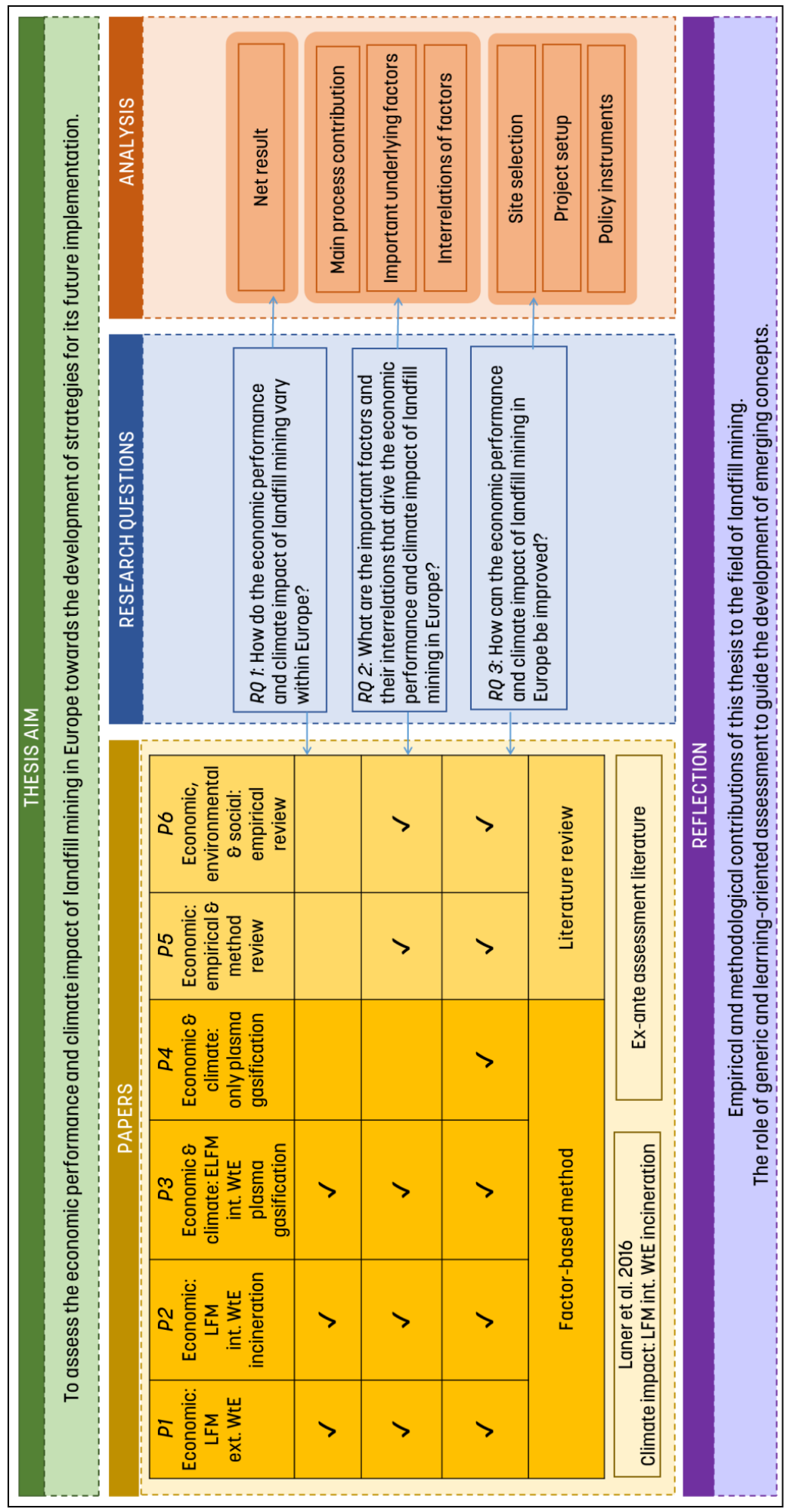

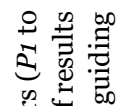

뉼 पै

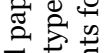

웡

है

完.

吾苛

oo $80 \%$

需合

.

प्य छ

.马

흃

㟧

कิ

言

욜

¿

:

웁웅

항

동

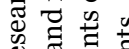

즐 छ

\&. 대

廿ै

동 च्वे

ॠ $\Xi ّ$

उ 0

$00:$

.

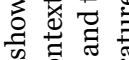

ब

코웡

过

部要 要

氙造

矛

ठ췀

\& ते 50

苍: 可.

두요요.

क्ष

告

1.

เง $\mp 0$

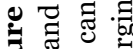
क 
RQ1 aims to analyze the net result in terms of economy and climate of (E)LFM with multiple project possibilities, considering both technological and organizational variations in relation to various site and system conditions that are expected in Europe. The net result refers to the typical aggregated assessment result that is either net profit or net deficit from the economic perspective, and either net savings or net burden from the climate perspective. $P 1$ provided an economic assessment of traditional LFM in which RDF is sent for external incineration. $P 2$ explored the internal incineration of RDF with energy recovery and increase in the utilization of fines residue as construction aggregates. From $P_{1}$ to $P 2$, the influence on the net economic performance of different organizational setups for traditional LFM was determined (i.e., Can internal incineration of RDF and extended utilization of fines improve the economy of traditional LFM?). Furthermore, the influence of advanced technologies for ELFM, such as plasma gasification with the valorization of syngas and slag, was determined with $P_{3}$ (i.e., Can advanced technologies for treating RDF and upcycling improve the economy of ELFM?). Apart from the net economic performance, $P_{3}$ also addressed the climate impact of ELFM. The results of climate impact for traditional LFM by Laner et al. 2016 were used (i.e., Can advanced technologies for treating RDF and upcycling improve the climate impact of ELFM?) to balance the discussion.

$R Q 2$ aims to elicit more granular information in terms of important factors and their interrelations that build up the corresponding net economic performance and climate impact in $R Q 1$. Here, two levels of granular information are shown through contribution analysis and global sensitivity analysis. Contribution analysis determines the important processes in terms of absolute process contribution to the net result. On the other hand, global sensitivity analysis determines the importance of the underlying factors in terms of relative variation between the net results and the constituent factors. $P 1$ provided the important cost and revenue items as well as the underlying factors that drive the net economic performance of traditional LFM with external incineration of RDF. With internal incineration and utilization of fines residue in P2, the corresponding changes in important cost and revenue items and the underlying factors were revealed (i.e., Which cost and revenue items are influenced by the internalization of incineration and extended utilization of fines residue? What are corresponding factors that become important for the economy of traditional LFM?). Similar changes in cost and revenue items and the underlying factors were revealed with advanced technologies and upcycling for ELFM in $P_{3}$ (i.e., What are the main cost and revenue items when using advanced technologies and upcycling for ELFM? What are the important factors that drive the economic performance of ELFM?) as well as for the extended climate impact (i.e., What are the main processes that contribute to climate savings and climate burden when using advanced technologies and upcycling for ELFM? What are the important factors that drive the climate impact of ELFM?). Based on the four most important factors, the dataset combinations that build up profitable or non-profitable (E)LFM scenarios are visualized in an ordered plot through graphical analysis. Since the important factors of the three models of traditional LFM are similar, traditional LFM with internal incineration is used here. In particular, $P 2$ for economics and Laner et al., 2016 for climate impact are presented to be compared with ELFM 
with plasma gasification in $P_{3}$, thereby highlighting the differences due to the type of employed WtE process.

RQ3 aims to develop and discuss generic strategies for improving the economic performance and climate impact of (E)LFM. The strategies are derived from the interrelations among the factor datasets from $R Q 2$. These strategies correspond to the role of specific stakeholders, such as landfill investors on prioritizing landfill sites suitable for mining, landfill practitioners on setting up (E)LFM projects in specific regional settings, and policymakers on potential policy instruments for implementation. For site selection, the overarching site and system conditions for traditional LFM in $P_{1}$ and $P_{2}$ and ELFM in $P_{3}$ are contrasted. Further discussion lies in the plausibility among the scenarios considering the incumbent policy and market conditions that are regionally contingent. Hence, for project setups, the designing of projects in defined regional archetypes was analyzed, that is, in terms of income level and waste management standards (i.e., How does project setup differ in specific regions where there is a high/low income level and high/low waste management standards?). In particular, results for traditional LFM with internal incineration in P2 are presented. A similar discussion is presented for the climate impact of traditional LFM in Laner et al. (2016) and ELFM in $P_{3}$. Subsequently, trade-off analysis between the economic performance and climate impact highlights the need for policy intervention. Several policy instruments are qualitatively discussed both in $P_{1}$ and $P_{2}$, while in $P_{3}$, quantitative analysis is performed showing how effective such instruments can be in supporting the development of economically profitable and climatebeneficial ELFM projects.

Moreover, the presented results from $P_{1}$ to $P_{3}$ are put into context to highlight the empirical contribution of this thesis by comparing the results with respect to the previous assessment of (E)LFM. In particular, these are synthesized in the literature review for economic $\left(P_{5}\right)$ and environmental assessments (P6) of (E)LFM. In essence, the difference in results when using the factor-based method and the synthesis of individual studies on landfill mining is emphasized. In addition, the methodological contributions of this thesis are also highlighted by discussing how the factor-based method aids in eliciting generic knowledge both in considering a particular process such as plasma gasification $\left(P_{4}\right)$ and in the entire (E)LFM chain ( $P_{1}$ to $\left.P_{3}\right)$. The results for (E)LFM are discussed in contrast with the synthesis of findings from individual assessments of case studies (P5). In this way, methodological issues for assessing emerging concepts are addressed both through the literature related to (E)LFM and to the broader literature on methods for ex-ante assessments. Furthermore, the importance of using generic and learning-oriented assessments, such as through the factor-based method, is discussed to emphasize the importance of identifying knowledge gaps and opportunities for improvement, especially for concepts and technologies at the early stage of development like (E)LFM. 
5. The economic performance of landfill mining 
In this section, the economic performance of (E)LFM with varying technological and organizational setups are analyzed in relation to the varying site and system conditions in Europe. The results are presented in terms of net profitability and its constituent factors and interrelations, offering an understanding of how the economic performance of (E)LFM in Europe is built up. Here, the varying technological and organizational setups refer to the four models of (E)LFM in Appended Papers 1, 2, and 3 . The models differ in terms of external $\left(P_{1}\right)$ and internal waste-to-energy treatment ( $P 2.1$ with incineration and $P_{3}$ with plasma gasification) and the utilization of fines residue as construction aggregates $(P 2.2)$.

\subsection{Net economic performance}

In general, the net economic results reveal that (E)LFM in Europe is a challenging business venture. Among the four models with different technological and organizational setups, the share of scenarios that are net profitable (NPV $>0$ Euro/Mg) is only between $17 \%$ and $35 \%$, with all the average results showing net deficits from 30 to -10 Euro/Mg (Figure 6). It is also notable that all the scenario results display wide ranges, from net deficits to net profits. This implies that the economic performance of the different technological and organizational setups is largely dependent on specific site and system conditions.

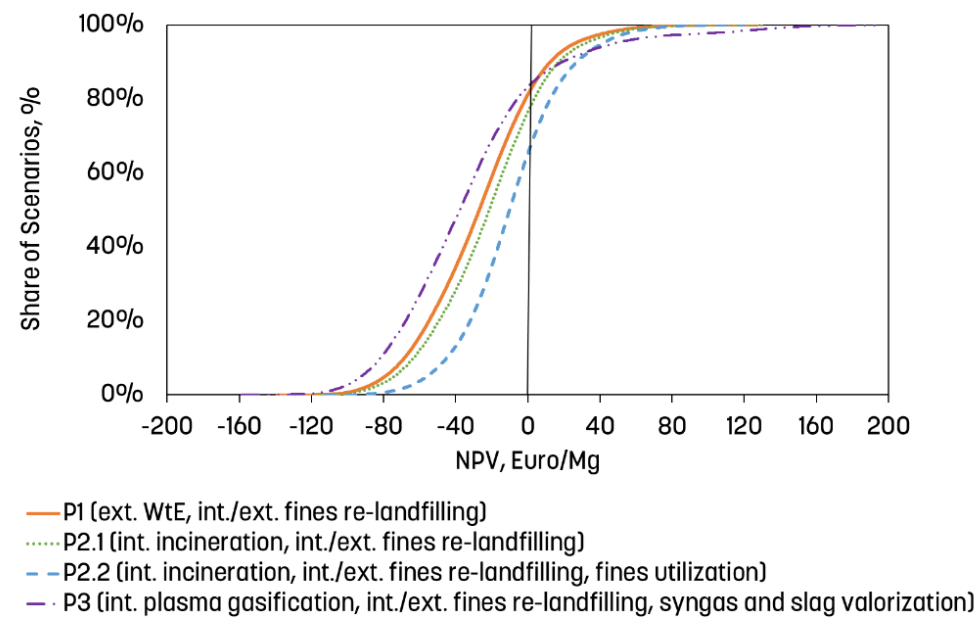

Figure 6. The cumulative net economic performance (in Euro/Mg waste) of the 531,441 (E)LFM generated scenarios per model with different technological and organizational setups. The four models differ primarily with external $\left(P_{1}\right)$ and internal ( $P_{2} .1$ with incineration and $P_{3}$ with plasma gasification) waste-to-energy (WtE) treatment and the utilization of fines residue as construction aggregates (P2.2).

For traditional LFM, the model with external incineration of RDF has the least share of profitable scenarios and the lowest average NPV (19\%, -27 Euro/Mg). External incineration of $\mathrm{RDF}$ requires costs in terms of gate fees, while the potential revenues from the recovered energy heat and electricity belong to other actors beyond the project organization. Similarly, fines residue requires costs for re-landfilling either internally or externally, while the potential revenues rely on its utilization rate as construction 
aggregates. Apart from the potential revenues, the avoidance of costs for managing these bulk fractions highlights the crucial role of internalizing WtE treatment of RDF and enabling a high utilization rate for fines residue to attain better profitability. From external incineration of RDF, the net results improved with internal incineration and energy recovery $(23 \%,-22$ Euro/Mg) and even more when this is combined with extended utilization of fines residue as construction aggregates (35\%, -10 Euro/ Mg).

Among the four models, ELFM with advanced processing of RDF in terms of plasma gasification and valorization of syngas and slag has the worst net economic performance (17\%, -30 Euro/Mg). However, it is notable that the range of scenario results is also the widest, implying that the use of advanced technologies can either improve or worsen the economic performance, depending on how much the obtained revenues from recovered resources can compensate the expensive processing costs. In comparison to traditional LFM, ELFM also shows the highest potential net profit. At its best, $28 \%$ of the profitable scenarios of ELFM have profits beyond 50 Euro/Mg of waste, while the corresponding figure for traditional LFM is less than $10 \%$.

In sum, considerations at the project level in terms of varying technological and organizational setups for dealing with RDF and fines residue are important and can both significantly improve and worsen the net economic performance of (E)LFM in Europe. However, the presented results only provide aggregated information regarding the net profitability, while other possible sources of costs and revenues and the influence of varying site and system conditions are left uncovered. Hence, the subsequent analyses provide granular information on the underlying processes and constituent factors and their interrelations that drive such net results. 


\subsection{Drivers of economic performance}

The scenario results are divided into main cost and revenue items through contribution analysis (Figure 7) to illustrate which main processes actually build up the economy of (E)LFM. In general, the differences among the process contributions depend on how the bulk fractions such as RDF and fines residue are handled.

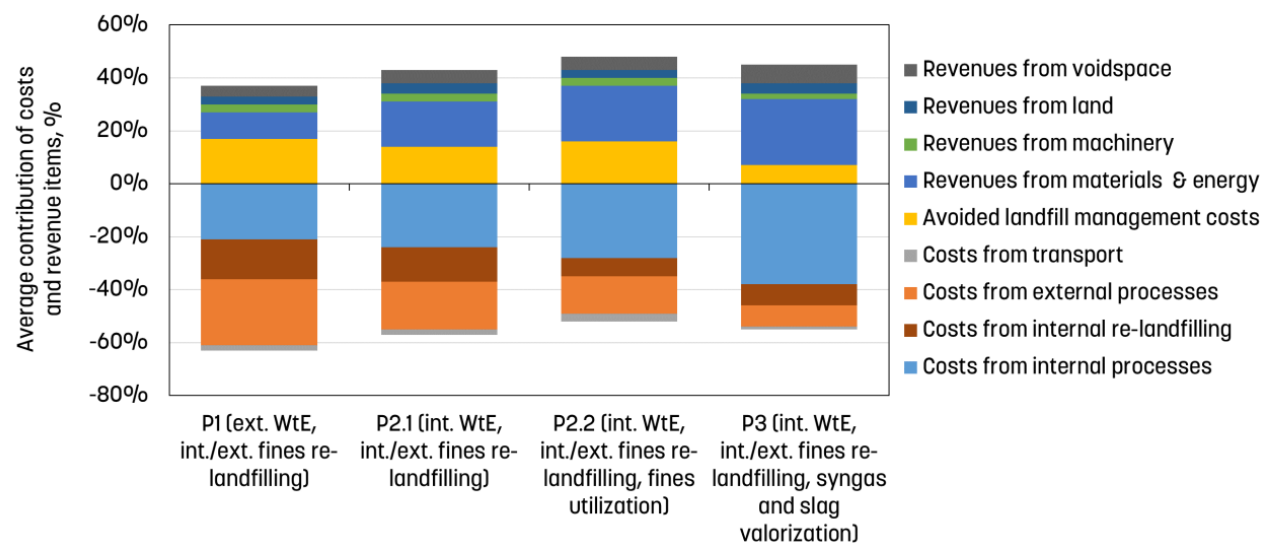

Figure 7. The economic drivers of landfill mining in terms of the average cost (negative contribution) and revenue (positive contribution) items of the generated 531,441 LFM scenarios per model. The four models differ primarily with external $\left(P_{1}\right)$ and internal ( $P_{2.1}$ with incineration and $P_{3}$ with plasma gasification) waste-to-energy (WtE) treatment and the utilization of fines residue as construction aggregates (P2.2).

In terms of costs, the major contributions come from external waste handling and internal waste processing. As previously mentioned, the associated costs for external waste handling include gate fees for incineration and re-landfilling, while the costs for internal processes include different capital and operational expenditures related to excavation, sorting, and treatment of the exhumed materials. It follows that for traditional LFM with external incineration of RDF, the costs for external waste handling have the highest contribution. However, the costs for internal processes become the highest contributor when WtE is internal due to the associated capital and operational expenditures. This becomes increasingly apparent in ELFM, where the costs for internal processes are almost doubled compared to traditional LFM with external incineration. In addition to internal WtE, the utilization of fines residue as construction aggregates further decreases the importance of external waste handling costs by avoiding gate fees for re-landfilling.

At the expense of increased costs for internal processes, the internalization of WtE also results in higher revenues from the recovered resources. These include energy sales from electricity and heat in addition to the sales of recovered materials such as metals (e.g., steel, aluminum, and copper), plastics, and construction aggregates. For traditional LFM, the internalization of WtE increases the contribution of revenues from recovered resources at $17 \%$ and even more at $21 \%$ when combined with an 
extended utilization of fines residue as construction aggregates. When it comes to ELFM, such revenues obtained from the recovered resources are clearly the most important source of income. Here, the valorization of syngas into electricity, syncrude, and $\mathrm{H}_{2}$ has the highest contribution to these revenues, while the valorization of slag into construction aggregates and cement substitutes is less important. Another major revenue item is the avoided costs for the reference case, which is an indirect revenue as it is otherwise spent to comply with the incumbent landfill management and aftercare regulations. It has the highest contribution for traditional LFM with external incineration of RDF and re-landfilling of fines residue since no revenues can be expected from these bulk waste fractions. Apart from the recovered materials and energy and the avoided landfill management, other sources of revenues include reclaimed void space and land, as well as the residual value of machinery at the end of the project. Altogether, these different types of revenues highlight the importance of multiple resource recovery as an approach to facilitate the economic conditions for investment-intensive projects such as (E)LFM.

Although these results from the contribution analysis provide some guidance on important cost and revenue items of (E)LFM, they fail to capture the reason behind the wide range of results as they are analyzed on average, and the underlying factors that drive the net economic performance are still left uncovered. These factors can be economic, such as regulatory costs and market prices, or physical and related to different material and energy flows, such as the waste composition and subsequent processing. Here, global sensitivity analysis serves to understand the reasons behind the variation in the results by assessing the influence of individual factors and a combination of factors on the scenario results. Such granular information is particularly relevant for understanding what and how different factors constitute the economy of (E)LFM in Europe (Figure 8). 


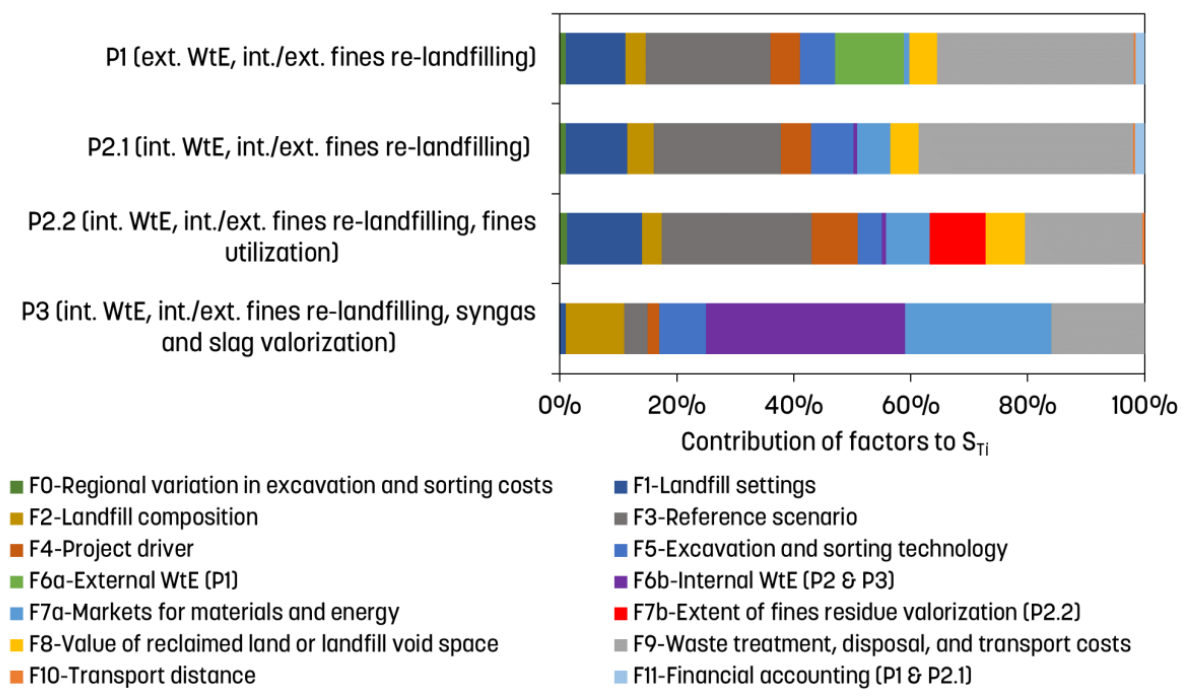

Figure 8. Importance of variation of factors (in \%) for the net economic performance of landfill mining of the four models expressed by the total-order sensitivity index $\left(\mathrm{ST}_{\mathrm{i}}\right)$ of the variance-based sensitivity analysis. The four models differ primarily with external $\left(P_{1}\right)$ and internal $\left(P_{2.1}\right.$ with incineration and $P_{3}$ with plasma gasification) waste-to-energy (WtE) treatment and the utilization of fines residue as construction aggregates (P2.2).

For all the models of traditional LFM, the conducted global sensitivity analyses reveal that the two most important factors, that is, the costs for waste treatment, disposal, transport (F9), and the reference landfill management (F3), explain around $50 \%$ of the variations in the scenario results. These factors address the system level and involve regionally contingent variations in terms of varying regulatory and market conditions influencing the costs and taxes for the re-landfilling of generated residues and the required landfill management and aftercare, respectively. Both of them primarily affect the variation of the scenario results in a first-order $\left(\mathrm{S}_{\mathrm{i}}\right)$ manner. That is, the wide range of results is directly influenced by the variation in the datasets of the individual factors, and only to a minor extent due to combination effects with other factors (i.e., higherorder effects, $\mathrm{S}_{\mathrm{Hi}}$ ). The dominance of first-order effects can be explained by the fact that both these system-level factors refer to different costs and prices, and thereby their variation has a direct influence on the scenario results.

Another important factor for all the models of traditional LFM is the landfill settings (F1) that have higher-order effects $\left(\mathrm{S}_{\mathrm{Hi}}\right)$. Landfill settings pertain to the amount of deposited waste and landfill geometry, which in turn dictate the processing capacity, project duration, avoided aftercare costs, and obtained revenues from reclaimed land and landfill void space. It interacts with several other factors, influencing the physical flows of materials and valorization potentials throughout the entire LFM process chain. This means that apart from the landfill settings, the amount of materials to be processed, disposed of, further treated, and sold depends on the realization of other datasets, such as landfill composition (F2), determining the gross amount of 
potentially recoverable materials, project drivers $\left(\mathrm{F}_{4}\right)$, deciding what is recovered and whether the generated residues are re-deposited internally or externally, and finally the employed technology for excavation and sorting (F5), influencing the separation efficiency of materials and RDF.

The remaining important factors differ among the models of traditional LFM in relation to whether the $\mathrm{WtE}$ treatment is external or internal to the project. In general, the net economic performance is more sensitive to varying policy instruments such as WtE taxation across Europe than to variations in terms of technological choices for incineration, from conventional to best-available technology. For external incineration of RDF, the amount of gate fee (F6a) is a highly important factor due to the wide variation of incineration taxes in different regions. However, by internalizing $\mathrm{WtE}$ treatment of RDF, the incineration process (F6b) becomes less important despite the differences between the technology-specific datasets for the recovery efficiencies for electricity and heat, as well as the capital and operation costs. Moreover, when WtE is internalized, the importance of market prices (F7a) increases as additional revenues from electricity and heat are generated. Although sales of fines residue as construction aggregates (F7b) also contribute to the importance increases in market prices (F7a), this factor primarily decreases the importance of the costs for waste handling (F9). That an extended utilization of fines residue primarily avoids costs rather than generates revenues is because the market prices considered for sales of construction aggregates are lower than the avoided gate fee for its re-landfilling.

In contrast, the use of plasma gasification in ELFM shifts the most important factor at the project level, followed by a factor at the system level. The variation of the syngas valorization process into electricity, syncrude, or $\mathrm{H}_{2}(\mathrm{~F} 6 \mathrm{~b})$ and the variation in market prices $\left(\mathrm{F}_{7}\right)$ explain around $50 \%$ of the variations observed in the net scenario results. It implies that the economic performance of ELFM is, in contrast to traditional LFM, more dependent on the revenues from the sales of output products, especially so given the high costs for the advanced processing of RDF. This is also further supported by the increased importance of the landfill waste composition (F2) and its higher-order effects as it determines the amount of recoverable resources such as RDF. However, also in ELFM, significant amounts of the excavated waste still need to be re-landfilled, and hence the costs for waste handling $(\mathrm{Fg}$ ) remain an important factor.

In sum, the performed global sensitivity analyses display the important factors for the economic performance of both traditional LFM and ELFM, as well as how they influence the net results in terms of first-order or higher-order effects. However, the interrelations among the factor datasets that build up profitable or non-profitable (E)LFM scenarios cannot be derived directly at this point. In this regard, graphical analysis is used to visualize these scenarios and the underlying combinations of factor datasets. 


\subsection{Interrelations among the drivers of economic performance}

Based on the four most important factors identified through the global sensitivity analyses, the dataset combinations that build up profitable or non-profitable (E)LFM scenarios are visualized in an ordered plot through graphical analysis (Figure 9 and Figure 10). Since the important factors of the three models of traditional LFM are similar, traditional LFM with internal incineration is here chosen to be compared with ELFM with plasma gasification for highlighting differences due to the type of the employed WtE process.

For traditional LFM, the promising scenarios are defined by low costs for waste handling (F9-1), high costs for the reference landfill management (F3-3), and high market prices (F7-3) (Figure 9). For these system-level factors, determining the preferable combinations of datasets is more or less straightforward due to their firstorder effects, as previously explained. On the contrary, it is less obvious for landfill settings (F1) that have higher-order effects. The graphical analysis reveals that the importance of this factor primarily depends on its interrelation with the reference case for landfill management (F3). For instance, the setting with small-scale landfills and short project durations (F1-1, yellow) is clearly preferable for scenarios with standard aftercare (F3-2) and intensive aftercare or remediation (F3-3), while such setting is more or less insignificant in the case of the low-cost reference scenario such as "do nothing" (F3-1). The main reason for this combined effect is that simply performing aftercare or remediation is more expensive in small-scale settings compared to largescale, thereby leading to higher avoided costs or indirect revenues. These economicscale effects are reflected in this study by increasing average deposition heights for larger landfills, which results in a greater amount of waste being processed or managed per unit area from small-scale to large-scale landfill settings.

For ELFM with plasma gasification, the promising scenarios are with $\mathrm{H}_{2}$ production as the syngas valorization option (F6-3) and with high market prices (F7-3) (Figure 1o). For $\mathrm{H}_{2}$ production, maximum net profitability is shown in combination with rich MSW landfill compositions (F2-1, yellow); however, it also shows a wide spread in results from net deficit to net profit. This implies that the valorized resources do not always compensate the costs for the extensive WtE process, which is largely influenced by regionally contingent policy and market conditions. Similar to that of traditional LFM with internal incineration, these conditions dictate the marketability and price settings for the input process consumables and the output of valorized resources. Waste handling costs for residues also show importance but to a lower extent than the aforementioned system condition related to the WtE process. For instance, $\mathrm{H}_{2}$ production (F6-3) in combination with high market prices (F7-3) shows less reliance on the costs for waste treatment and disposal than other syngas valorization options and market settings. Given that such system conditions vary considerably between regions, so could the economic implications of the technology choices. 


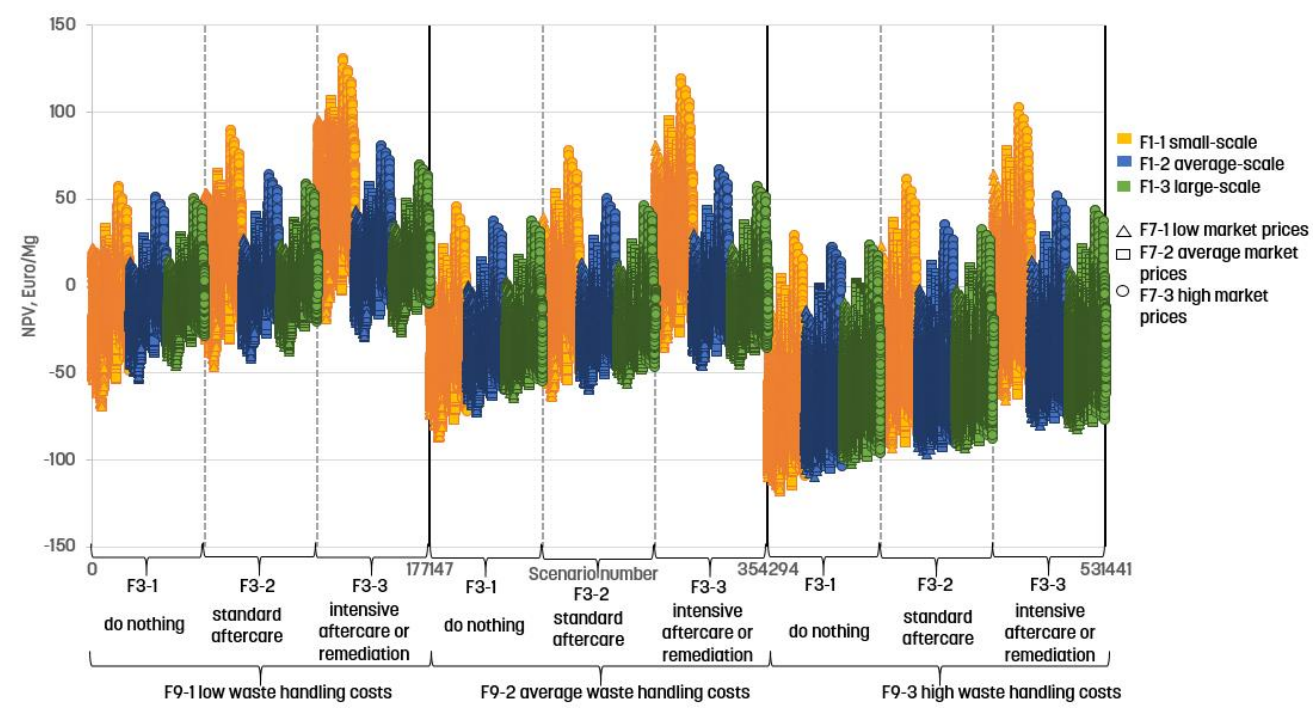

Figure 9. Graphical analysis of the net economic performance (in Euro/Mg waste) of the generated 531,441 landfill mining scenarios with internal incineration $(P 2.1)$. The results are grouped according to the four most important identified factors, in order: waste handling costs (F9), reference case (F3), landfill settings ( $\mathrm{F} 1$, colors), and market prices ( $\mathrm{F} 7$, shapes).

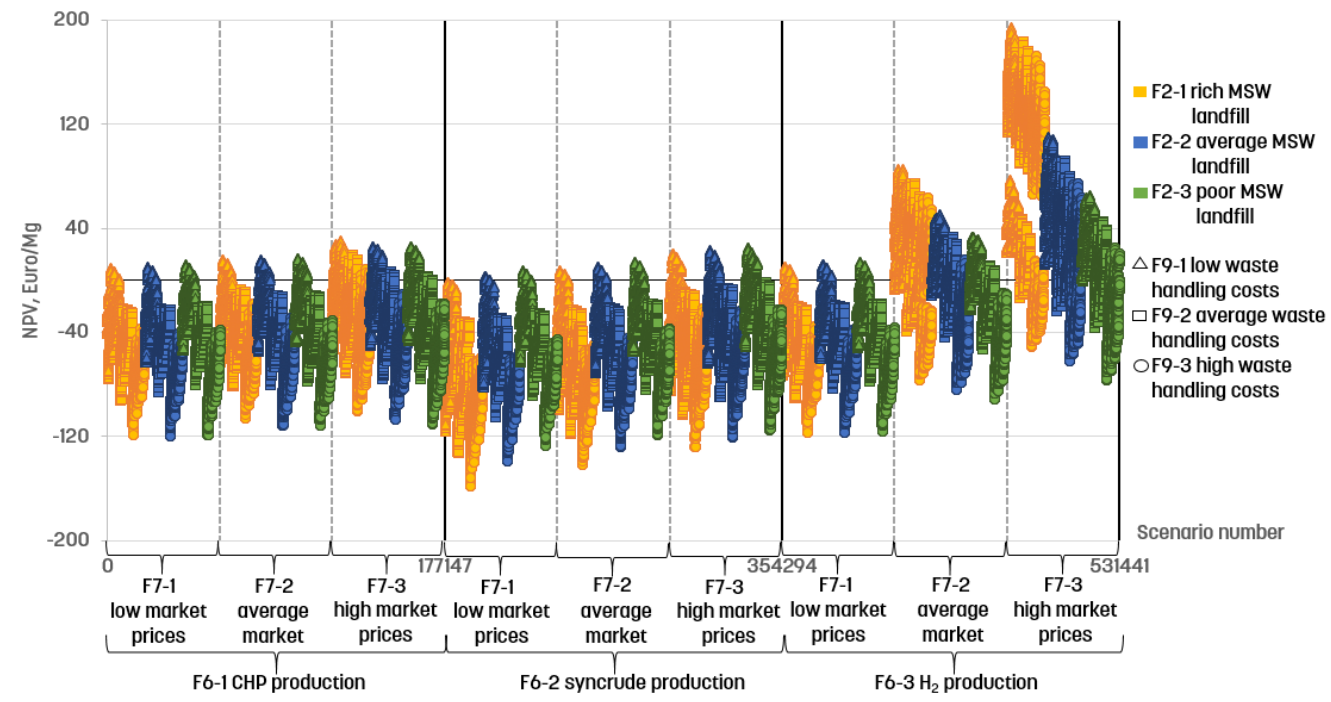

Figure 10. Graphical analysis of the economic performance (in Euro/Mg waste) of the generated 531,441 ELFM scenarios with plasma gasification and valorization of syngas and slag $\left(P_{3}\right)$. The results are grouped according to the identified four most important factors, in order: syngas valorization options (F6), market prices (F7), waste composition (F2, colors), and waste handling costs (F9, shapes). 


\section{The climate impact of landfill mining}


In this section, the climate impact of (E)LFM with varying technological and organizational setups are analyzed in relation to the varying site and system conditions in Europe. The results are presented in terms of net climate impact and its constituent factors and interrelations, offering an understanding of how the climate impact of (E)LFM in Europe is built up. The results presented here are mainly from the climate impact assessment of ELFM with plasma gasification ( $\left.P_{3}\right)$, which is developed to complement the already-existing assessment on traditional LFM with external incineration (Laner et al., 2016). In this way, the similarities and differences between the two can be identified in terms of net performance and underlying critical factors.

\subsection{Net climate impact}

Contrary to the net economic performance, the net climate impact of (E)LFM is generally better in terms of the share of scenarios that are net climate-beneficial $(<0$ $\mathrm{kg} \mathrm{CO} 2 \mathrm{eq} . / \mathrm{Mg}$ ) and the average results showing net climate savings. The conducted climate assessment of ELFM with plasma gasification ( $\left.P_{3}\right)$ shows that $47 \%$ of the scenarios have net climate savings ranging from -1010 to $605 \mathrm{~kg} \mathrm{CO} 2 \mathrm{eq} . / \mathrm{Mg}$ waste with an average of $-60 \mathrm{~kg} \mathrm{CO} 2 \mathrm{eq}$. $/ \mathrm{Mg}$ waste. This is quite similar to the climate impacts of traditional LFM (Laner et al., 2016), where about $50 \%$ of scenario results involved net climate savings with a range from -1550 to $640 \mathrm{~kg} \mathrm{CO} 2$ eq./ $\mathrm{Mg}$ waste and an average of $-81 \mathrm{~kg} \mathrm{CO} 2 \mathrm{eq} . / \mathrm{Mg}$ waste. Given that $P_{3}$ builds on that of Laner et al. (2016) with similar factors at site and system levels, the slight differences in the net climate impact are attributed to the factors that refer to plasma gasification and the subsequent syngas valorization options and slag management. In general, it still shows that both ELFM and traditional LFM could potentially be a better option in comparison to the reference landfill management that entails climate burdens due to the direct emission of landfill gas.

\subsection{Drivers of climate impact}

The contribution analysis shows that the avoided climate burdens from the reference case due to direct emission of landfill gas account for the largest share (29\%) of climate savings for ELFM (Figure 11). The remaining share of climate savings is due to the substituted primary production of recovered resources. While material recovery from sorting and slag valorization shows relatively small contributions to climate savings (2\%), the production of energy and fuels through plasma gasification with the syngas valorization process is significant (25\%). However, the same process is also responsible for the largest share of the climate burdens due to direct emissions related to process requirements such as input materials and energy (30\%). Other important processes for the generated climate burdens of ELFM are emissions caused by re-landfilling (11\%) of bulk waste materials such as fines residue and, to a lower extent, by the excavation and sorting process (3\%). 


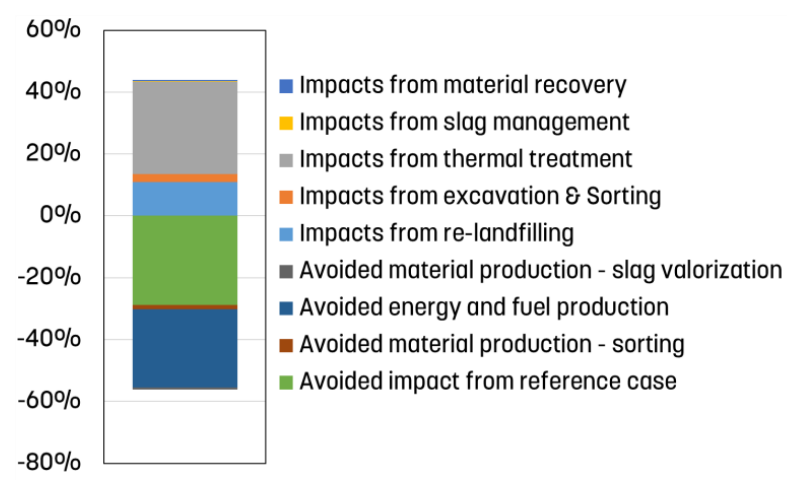

Figure 11. The climate drivers of landfill mining in terms of average climate savings (negative contribution) and climate burdens (positive contribution) of various processes of the generated 531,441 landfill mining scenarios with internal plasma gasification $\left(P_{3}\right)$. The negative contribution accounted for the avoided emissions due to substituted primary production from recovered materials and energy and avoided landfill gas emission from the landfill reference case, while the positive contribution accounted for the emissions from the primary production of materials and energy required for the processes and the landfill gas emission from re-landfilled waste.

In line with the contribution analysis, global sensitivity analysis reveals the importance of underlying factors such as the variation of reference landfill management (F3) and syngas valorization options (F6). Moreover, it also reveals the importance of related factors such as input waste composition (F2) and the background material and energy system (F9) (Figure 12). Overall, these four factors define 95\% of the variance of the overall climate impact of ELFM, which means that the specific combinations among the factor alternatives more or less fully explain the wide variation of scenario results. The reference landfill management varies mainly on the collection and treatment of landfill gas, from leaving it as it is to utilizing it for electricity production, while syngas valorization options vary, including the production of $\mathrm{CHP}$, syncrude, or $\mathrm{H}_{2}$. Moreover, the landfill waste composition determines the amounts of potentially recoverable resources (e.g., metals and RDF) as well as of fines and other residues in need of relandfilling. In addition, the presence of anaerobically degradable organic materials is of particular relevance because it is directly related to the landfill gas potential and thus the climate burdens of the reference landfill management that can be avoided by ELFM. The extent of climate impact is further dependent on the background material and energy system (i.e., high-fossil share, EU average, and high-renewable share), which defines both the climate burdens and climate savings from the resources used and produced within (E)LFM. 


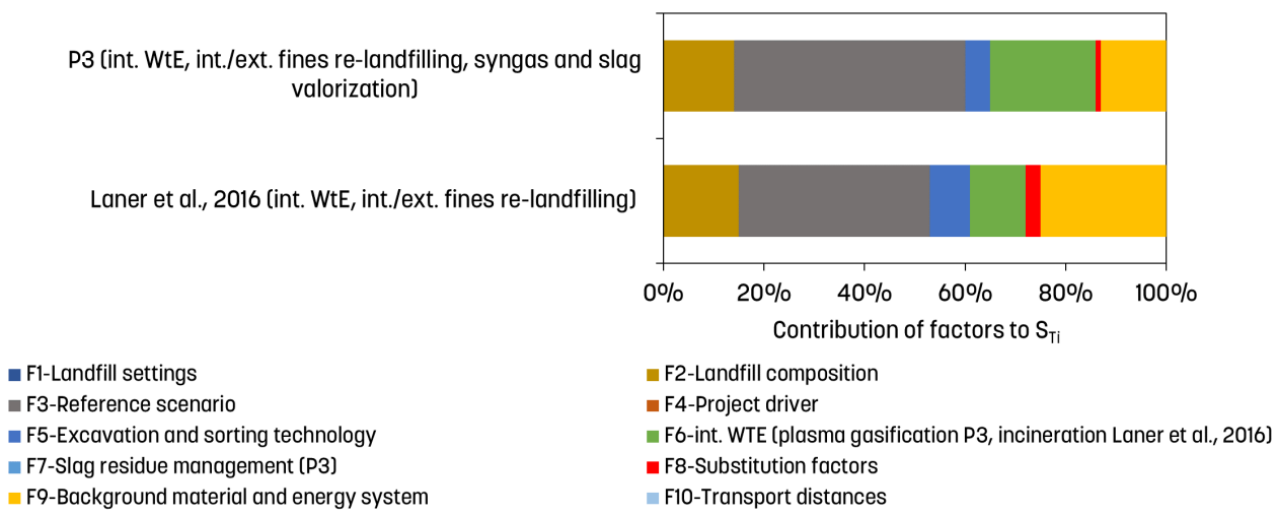

Figure 12. Importance of variation of factors (in \%) for the climate impact of landfill mining expressed in terms of total-order sensitivity index $\left(\mathrm{ST}_{\mathrm{i}}\right)$ of the variance-based sensitivity analysis. Enhanced landfill mining with plasma gasification and valorization of syngas and slag $\left(P_{3}\right)$ is compared with traditional landfill mining with internal incineration (Laner et al., 2016).

Similar top four factors were identified for traditional LFM (Laner et al., 2016). While the reference landfill management $\left(F_{3}\right)$ remains the most important factor, the difference is reflected in the relative importance of the remaining factors. When comparing the two $\mathrm{WtE}$ technologies, plasma gasification has wider variation in terms of the different syngas valorization routes compared to incineration with variation only in terms of efficiency for energy recovery. Plasma gasification has more interaction effects with other factors compared to incineration; hence, WtE is more important for ELFM than in traditional LFM, respectively. Consequently, WtE becomes the least important following the background energy system (F9) and waste composition (F2).

\subsection{Interrelations among the drivers of climate impact}

For ELFM with plasma gasification, the reference case shows a dominant effect on the spread of the scenario results (Figure 13), highlighting landfills with no gas collection as a particularly good condition for obtaining avoided climate burdens. With the "do nothing" reference case (F3-1), all the scenarios have net climate savings due to avoided landfill gas emission, irrespective of the syngas valorization option, waste composition, and background material and energy system. This is of similar importance for traditional LFM, in which the avoided direct emissions of landfill gas set the overall climate benefits of such projects rather than the climate savings that can be obtained from the recovery of materials and energy. 


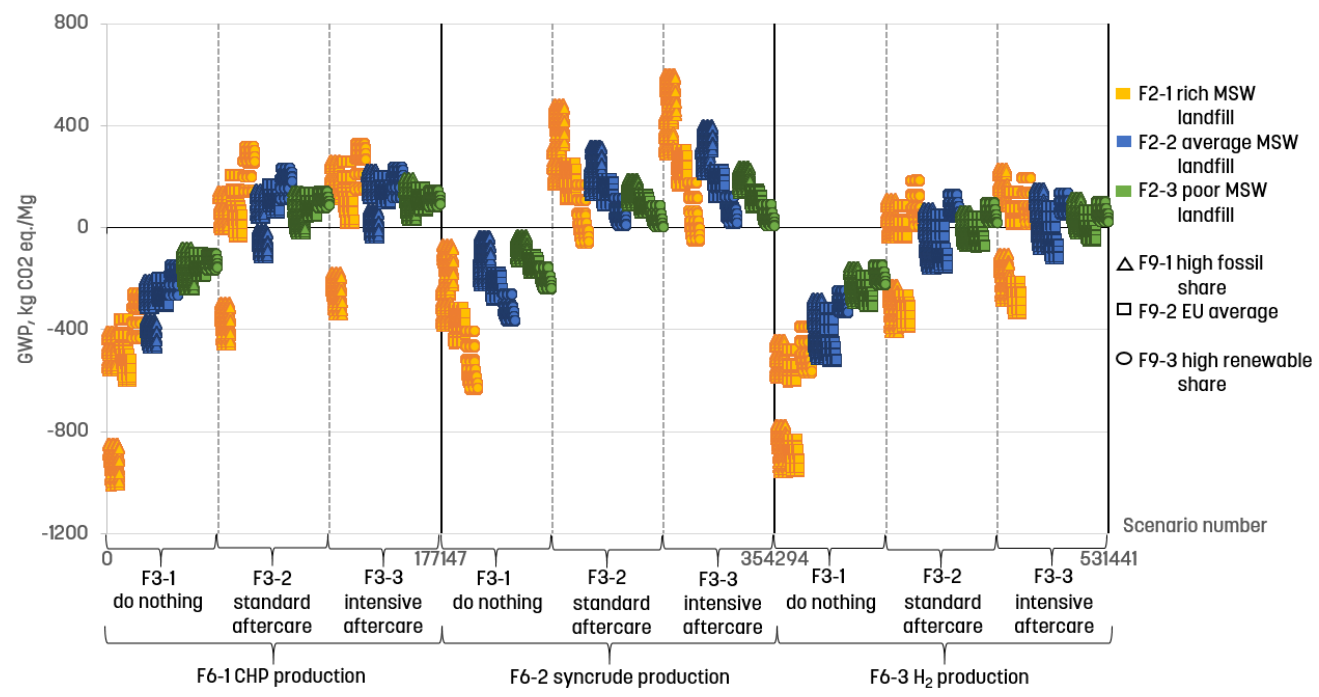

Figure 13. Graphical analysis of the climate impact (in $\mathrm{kg} \mathrm{CO}_{2}$ eq./Mg waste) of the generated 531,441 ELFM scenarios in Europe ( $\left.\mathrm{P}_{3}\right)$. The results are grouped according to the four most important identified factors: syngas valorization options (F6), reference cases (F3), MSW waste composition (F2, colors), and background material and energy system (F9, shapes).

In contrast with traditional LFM (Laner et al., 2016) that implies going for high energy conversion efficiency for incineration, ELFM has a more dynamic factor data set combination for different syngas valorization into $\mathrm{CHP}$, syncrude, and $\mathrm{H}_{2}$. For syngas valorization, $\mathrm{H}_{2}$ production (F6-3) shows the best option and is closely followed by CHP production (F6-1), while syncrude production (F6-2) shows the worst. Then, the subsequent consideration for reduced climate impact is about how much the climate burden from required resources can be compensated for by the avoided primary production from recovered resources. These, however, are not straightforward with respect to the type of syngas valorization option.

For the input waste composition, rich MSW composition (F2-1, yellow) is generally preferred, but it also leads to a high spread in results in comparison to average (F2-2, blue) and poor composition (F2-3, green). In particular, rich waste composition leads to the highest climate savings when the recoverable materials and energy carrier are under the preferable background material and energy system, which dictates the extent of avoided climate burden of production. A high-fossil share (F9-1, triangle) is generally preferred for CHP production, while $\mathrm{H}_{2}$ production also includes the average EU mix (F9-2, square). The climate burden for $\mathrm{H}_{2}$ production is better compensated by a dirty background system, that is, higher avoided material and energy production that leads to higher climate savings. Conversely, a high renewable share (F9-3) is preferred for syncrude production. While $\mathrm{CHP}$ and $\mathrm{H}_{2}$ productions are about maximizing the avoided production (i.e., output-focused), syncrude production is about minimizing the direct emissions (i.e., input-focused) as the output product does not compensate for the direct emissions of the process input. 
7. Strategies for improved economic performance and reduced climate impact of landfill mining 
The development of strategies for improved economic performance and reduced climate impact of (E)LFM requires a holistic perspective and consideration of the interrelations between various site, project, and system conditions. Such an understanding is elicited in this thesis through the factor-based method ( $P_{1}$ to $P_{3}$ ), which is used here to discuss strategies by addressing relevant questions for specific stakeholders, including project investors (i.e., which landfill sites to prioritize?), landfill mining practitioners (i.e., how to set up such projects?), and policymakers (i.e., which policy instruments can effectively support such projects?). The discussion involves contrasting the elicited strategies with the findings of previous assessments of (E)LFM ( $P_{5}$ and $\left.P 6\right)$ ).as well as tackling their respective plausibility in terms of practical implementation, thereby highlighting the empirical contributions of this thesis.

\subsection{Selection of landfill sites}

Given that previous research on (E)LFM typically has involved case study-specific assessments, the importance of the landfills in question and how their various site and local settings influence the outcome of such projects have so far not been addressed $\left(P_{5}\right)$. This thesis clearly demonstrates the importance of this research gap as the selection of landfills for mining has been found to have an overarching influence on both the economic performance and climate impact of (E)LFM (P1 to P3).

The importance of the selection of landfill sites for mining has been suggested earlier by van der Zee et al. (2004). It is a general framework for narrowing down the landfills that are most suitable for mining in a region depending on market opportunities. However, the framework did not provide details regarding what specific site and local settings actually constitute suitable landfills for mining. By taking a step further, this thesis provides details on which site and local settings are most important for economic performance and climate impact, hence specifying what data and information should be gathered about different landfills to enable well-grounded choices on whether a certain site is worth pursuing.

In general, the findings of this thesis show that a promising landfill site for mining is where multiple resource recovery options are assured ( $P_{1}$ to $\left.P_{3}\right)$. This includes economic and climate benefits that are both direct from the recovered materials and energy as well as the reclaimed land and landfill void space and indirect in terms of avoided costs and landfill gas emissions from the reference landfill management, respectively. Moreover, this thesis also differentiates the varying importance of such benefits for selecting promising sites when considering either economic or climate aspects and either traditional LFM or ELFM with the further valorization of RDF.

In terms of economic performance, promising sites are primarily defined by high avoided costs for reference landfill management and low costs for waste treatment and disposal $\left(P_{1}\right.$ to $\left.P_{3}\right)$. Avoided costs for reference landfill management depend on the incumbent regional regulations as well as the specific site conditions. For instance, high avoided costs are expected when stringent regulations are in place requiring 
management of landfill gas emissions and leachate and aftercare, or even remediation in the case of non-sanitary landfills or sites that pose high risks of failure. In many countries such as Sweden and Belgium, there are landfill surveys that can be used to identify such high-risk landfills in need of extensive aftercare or remediation due to failure of containment system (Frändegård et al., 2015) or flooding, especially in lowlying areas (Laner et al., 2009; Wille, 2018; Winterstetter et al., 2018). In contrast, incumbent regional regulations alone are accountable for waste treatment and disposal costs of bulk fractions such as fines residue and RDF, especially for traditional LFM with external WtE treatment $(P 1)$. For instance, low costs are expected when low WtE treatment and re-landfilling taxes are in place, respectively.

However, there are also other possibilities to have low costs for handling fines residue and RDF that depend on the site selection (Paper 2). A higher utilization rate of fines residue as construction aggregates is possible when the chosen landfill has a waste composition that passes the regulatory limits for heavy metals, soluble salts, and (residual) organics and is located in a region where the legislation requires less stringent testing procedures that are easier to comply with. The former highlights the importance of pre-testing the contamination of the fines residue in the landfill before large-scale (E)LFM operations, while the latter emphasizes the differences that occur among regions both regarding allowable contamination levels and whether they are measured in total or leaching concentrations, as stated in Article 6 of the EU Waste Framework Directive (2008/98/EC) and in several local legislations (Saveyn et al., 2014). For fines residue, as well as for other similar residues (Blasenbauer et al., 2020), leaching concentrations are much easier to fulfill, even if they are strict, since they typically contain high total concentrations, but these elements are tightly bound to the material and thereby difficult to leach out (Hernández Parrodi et al., 2019). For RDF, lower WtE treatment costs can be achieved through shared use of the facility in regional LFM initiatives involving multiple landfill sites. For instance, clustering of small sites in Flanders, Belgium, is considered to make different small projects financially profitable (Van Passel et al. 2013). Another possibility is selecting landfills in an area with already-existing WtE treatment plants in the proximity of (E)LFM projects, which run in overcapacity and need additional fuel to secure a full working load (Frändegård et al., 2015). In such cases, the RDF recovered from landfills can be considered a valuable supplementary feed to the WtE company, which then might accept to buy it or at least take it for free without charging any gate fee.

These site selection characteristics with high avoided costs for reference landfill management and low costs for waste treatment and disposal are particularly relevant for traditional LFM with external handling of RDF, in which expected revenues from recovered materials and RDF are limited. However, for sites in regions with high market prices, internal WtE treatment of RDF makes sense as the additional revenues from the valorized materials and energy products can offer better compensation for the additional processing costs. In this regard, maximization of direct revenues pinpoints the importance of selecting a landfill with rich MSW composition in terms of recoverable materials as well as RDF for further valorization as in ELFM (P3). This 
finding is challenging from a practical point of view because, in contrast to the environmental risks and needs for aftercare and remediation of landfills, there is a large knowledge deficit about the material composition of individual landfills in Europe. In this regard, a platform for homogeneous data collection was initiated under the SMART GROUND project to enhance the availability and accessibility of data and information in the EU on secondary raw materials from landfills (Dino et al., 2016). However, it remains a challenge to encourage different landfill owners to participate and respond to the platform.

In terms of climate impact, poor reference landfill management and background material and energy systems with high fossil share primarily define promising sites for mining. Altogether, these site selection characteristics are relevant for both traditional LFM and ELFM with the further valorization of RDF. Landfills with poor management of landfill gas should be prioritized for the associated net climate savings due to avoided emissions when (E)LFM is performed. This is a safety measure as the results from $P_{3}$ and from Laner et al. (2016) clearly show that in such cases, (E)LFM is virtually always beneficial. For sites with an installed collection and treatment system for landfill gas, net climate savings are also expected in many cases, but primarily in regions with an energy system that has a high fossil share. Otherwise, the net climate burden is probable for an energy system that has a high renewable share, especially for landfills rich in plastics. The same goes for the background material system, in which more avoided climate emissions are expected when the avoided primary production is with a high fossil share. In this case, the climate benefits of selecting landfills with rich MSW composition in terms of recoverable materials, including RDF, are maximized.

However, considering both the economic performance and climate impact of (E)LFM reveals an important trade-off for site selection based on the reference landfill management. As previously mentioned, the preference for the poor reference case is good for the climate with high avoided landfill gas emissions but bad for the economics with low avoided costs. This trade-off is a critical consideration as the reference case is an important driver of both the economic performance and climate impact. Hence, this makes it challenging when it comes to the selection of which landfills are suitable for mining. The trade-off analysis for ELFM in $P_{3}$ (Figure 14) shows that the poor reference landfill management is one of the most frequent factor datasets for scenarios that result in net climate savings, but also for scenarios that result in a net deficit. In particular, $47 \%$ of the scenarios have net climate savings, but $38 \%$ are in net deficit. These are the scenarios that lie in Quadrant III (-NPV, -GWP). However, the remaining $9 \%$ of the climate-beneficial scenarios that lie in Quadrant II (+NPV, -GWP) show that net profitability is achievable even with the poor reference case. From the analysis of the frequently occurring datasets in these scenarios, the low avoided costs from the poor reference case are compensated for by low costs for waste handling, high market prices for energy, materials, and land, and rich MSW landfill compositions that set up the preferable economic conditions for ELFM. 


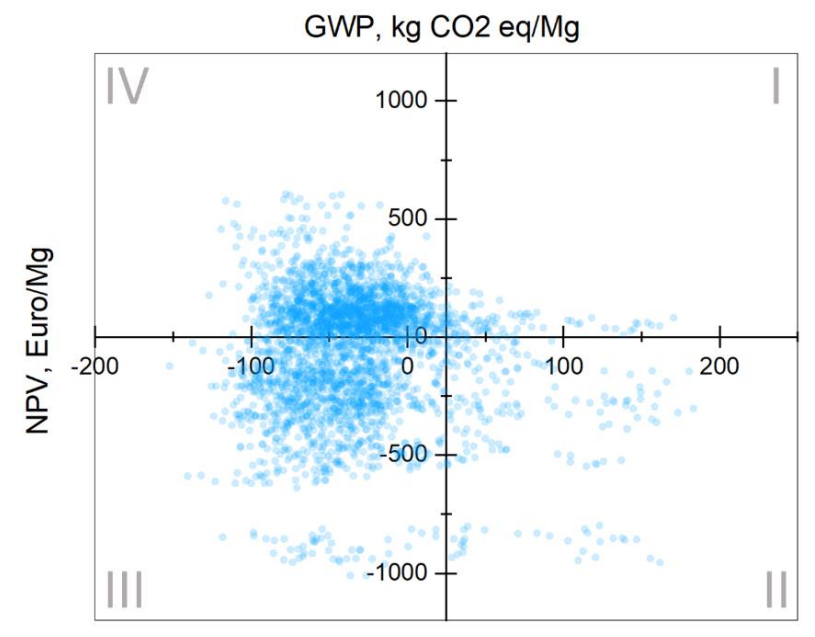

Figure 14. Trade-off analysis of the climate impact (vertical axis) and economic performance (horizontal axis) of the generated ELFM scenarios in Europe with plasma gasification and valorization of syngas and slag $\left(P_{3}\right)$.

The use of the factor-based method with full factorial combination is advantageous in determining the abovementioned preferable combinations of datasets to achieve costefficient and climate-beneficial (E)LFM projects. However, it is also a limitation that certain combinations of factors (i.e., low costs for waste handling, high avoided costs for the reference case, high market prices) may be difficult to find under current policy and market conditions. Hence, these combinations should be interpreted as ideal system conditions for (E)LFM, implying the need for changes through policy and market interventions. This steers the proceeding sections on what can be done now by the landfill practitioners in terms of setting up projects under current policy and market conditions in specific regions, or what can be done by the policymakers in terms of implementing various policy instruments that can drive such changes at the system level.

\subsection{Tailored project setups for specific regional archetypes}

Apart from considering only one landfill site, previous assessments of (E)LFM typically only account for one specific separation process and type of WtE treatment plant, and they often do so without any clear motivation $\left(P_{5}\right)$. Thereby, the interrelation of the project setup with respect to the landfill site settings and the surrounding policy and market conditions remains unknown. This highlights an important contribution of this thesis, where several project setups are assessed with respect to the varying site and system conditions and how such interrelations influence the outcome of (E)LFM projects.

In general, it is known that the internalization of WtE for RDF (incineration in $P 2$ and plasma gasification in $P_{3}$ ) and utilization of fines residue as construction aggregates 
(P2) offer improvements in economic and climate benefits compared to external handling and landfilling of these bulk fractions, respectively $\left(P_{1}\right)$. However, the choice of such project setup must be made in coordination with other related and important factors occurring on the site (i.e., landfill waste composition, landfill settings) and system (i.e., reference case, market prices, waste disposal and treatment costs, and background material and energy) levels to maximize such benefits.

In the perspective of landfill mining practitioners, consideration of performing (E)LFM is subject to specific regional settings with fixed policy and market conditions. As previously mentioned, these regionally contingent settings determine the overarching condition influencing the economic performance and climate impact of (E)LFM. Given that landfill mining practitioners hardly can influence such system-level conditions, the development of such projects, therefore, needs to be done in accordance with the prevailing policy and market conditions in the region. Strategies for setting up traditional LFM projects with internal incineration (P2) were simulated for two different regional archetypes that vary in terms of income and waste management standards to exemplify the importance of carefully considering such interrelations.

For the regional archetype with high income and high waste management standards, a promising strategy for obtaining profitable LFM projects involves the selection of small-scale landfills with short project duration (F1-1) and a rich MSW composition (F2-1), the employment of highly advanced excavation and sorting technology (F5-3), and the realization of project aims that target both resource recovery and land reclamation (F4-2) (Figure 15). This indicates that in such settings with high market values, revenues from reclaimed land can compensate for high costs for excavation and processing, WtE treatment, and disposal of residues. In addition, the preference for advanced excavation and sorting technology in such regions is primarily beneficial because it reduces the external costs for disposal of residues rather than increases the revenues for recovered materials and energy. For medium and large-scale landfill settings $(\mathrm{F} 1-2,3)$, there is a major drop in the NPV. This signifies the importance of the reference case because, for these larger landfills, significantly lower indirect revenues from avoided costs for landfill management are expected due to economic scale effects. For the same reason, project aims that target resource recovery and reclamation of landfill void space (F4-3) are also preferred for larger landfills. With a landfill geometry that also increases in height, a proportionally larger amount of fines residue is generated per landfill area. That means that the associated costs for external relandfilling become more expensive, and the value of land ( $\left.\mathrm{F}_{4}-2\right)$ can then often not compensate for these higher external re-landfilling costs. Hence, internal re-landfilling is preferable as it is cheaper in combination with void space recovery (F4-3). 


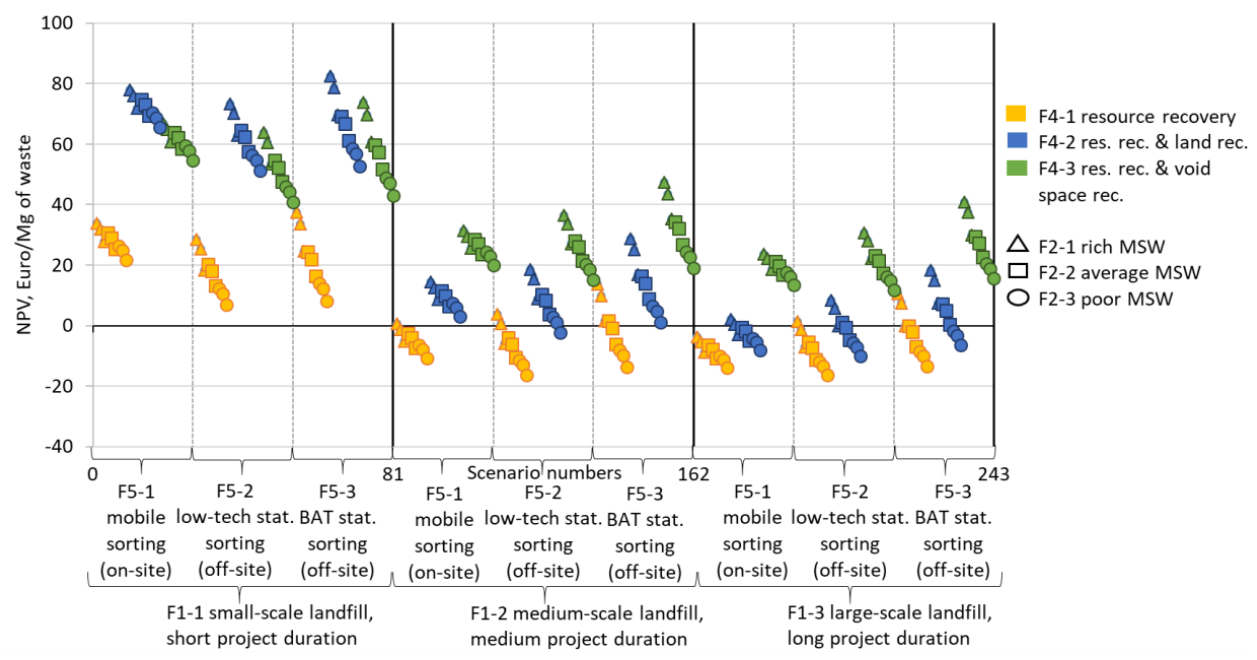

Figure 15. Graphical analysis of the net economic performance (in Euro/Mg waste) of landfill mining $(P 2.2)$ in a European regional archetype with a high level of economic income and high waste management standards. The following factors are fixed to high datasets except for financial accounting (F11-1), as expected for more developed economies: variation in excavation \& sorting costs (Fo-3), the reference scenario (F3-3), costs of WtE technology (F6-3), markets for material and energy (F7-3), prices of reclaimed land or landfill void space (F8-3), and costs for waste treatment, disposal, and transport (F9-3). The 243 scenario results are grouped according to the four most critical factors under the influence of landfill practitioners, landfill settings ( $\left.\mathrm{F}_{1}\right)$, excavation and sorting technology ( $\mathrm{F}_{5}$ ), project drivers (F4), and landfill composition (F2).

For regional archetype with low income and low waste management standards, all the scenarios are in net deficit (Figure 16). Overall, the (very low) avoided costs for poor reference landfill management in such regions set a highly challenging condition for obtaining profitable scenarios as it is typically a major source of indirect revenue for traditional LFM. Moreover, although there are low costs for excavation and processing, WtE treatment, and disposal of residues, these cannot be compensated by the low revenues due to the set low market prices for recovered materials and energy in this region. For the currently unprofitable scenarios, several observations for improved cost-efficiency can still be made. For instance, the least net deficit among the scenarios is characterized by a large-scale landfill setting with long project duration (F1-3), mainly due to more discounted costs distributed throughout the project. The preference for the selection of sites with poor MSW composition (F2-3) and the employment of conventional mobile sorting technology ( $\left.\mathrm{F}_{5}-3\right)$ is mainly because this lowers the processing costs for internal incineration of RDF and material recovery. The revenues from respective products cannot compensate given low market prices, even if rich MSW landfills are mined (F2-1). There is also an indifference among different project drivers $(\mathrm{F} 4)$ because of low values for land and void space that cannot compensate the costs for external and internal re-landfilling of residues, respectively. 


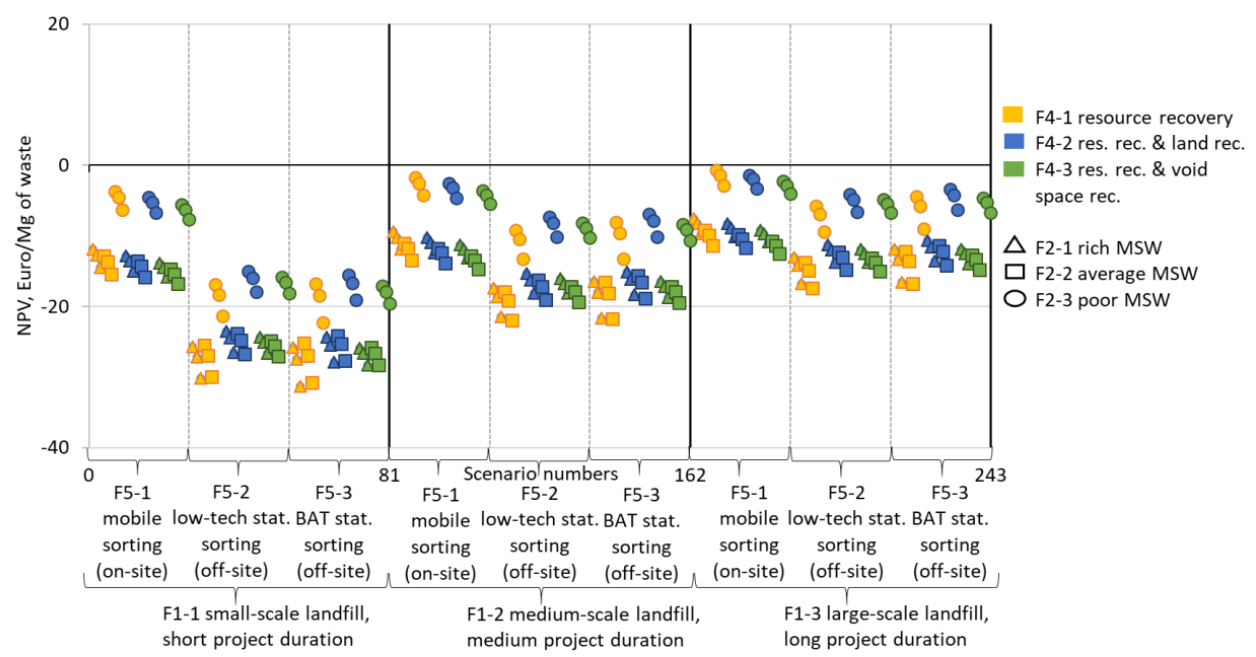

Figure 16. Graphical analysis of the net economic performance (in Euro/Mg waste) of landfill mining $(P 2.2)$ in a European regional archetype with a low level of economic income and low waste management standards. The following factors are fixed to low datasets except for financial accounting (F11-3), as expected for less developed economies: variation in excavation \& sorting costs (Fo-1), the reference scenario (F3-1), costs of WtE technology (F6-1), markets for material and energy (F7-1), prices of reclaimed land or landfill void space (F8-1), and costs for waste treatment, disposal, and transport (F91). The 243 scenario results are grouped according to the four most critical factors under the influence of landfill practitioners such as landfill settings (F1), excavation and sorting technology (F5), project drivers (F4), and landfill composition ( $\left.\mathrm{F}_{2}\right)$.

In addition to the discussion of regional archetypes based on income level and waste management standards, the background material and energy system can also be included that is relevant for the assessment of climate impact. For instance, in regions with high income and high waste management standards, a high share of renewables is more likely as the background material and energy system. On the contrary, in regions with low income and low waste management standards, a high-fossil share is more likely the background material and energy system. However, irrespective of the regional archetypes, the generic project setup for (E)LFM should maximize the potential for climate savings from material and energy recovery. That means employing an advanced separation and sorting process to increase the rate of material recovery, including RDF as feed for energy recovery. In relation, the choice of landfill composition with rich waste composition is preferred. With regard to the maximization of WtE treatment, $P_{3}$ gave insight on the choice of syngas valorization: that it only applies for $\mathrm{CHP}$ and $\mathrm{H}_{2}$ productions but not for syncrude production. The latter relies on minimizing the direct emissions as the syncrude product does not compensate for the direct emissions of processing. On the other hand, Laner et al. (2016) gave insight into the importance of specific waste fractions that undergo WtE; that is, the mean impact of separating both wood and plastic into RDF results in net burdens. In particular, it is challenging for regions with an energy system with a high share of renewables. As otherwise, leaving them in the landfills keeps the carbon intact in the concept of carbon storage. 
Again, considering both the economic performance and climate impact of (E)LFM extends the trade-off analysis understanding the constituent factor datasets that build up both aspects. The combination of high waste management standards (i.e., low avoided landfill gas emission) and a high share of renewables (i.e., low avoided emission from primary production) sets a challenging condition for climate-beneficial (E)LFM projects. In addition, for economics, high waste management standards mean high avoided costs for reference landfill management but also high costs for waste processing and disposal. For ELFM that relies more on the processing costs and the revenues from materials, these system conditions set challenging conditions for economics. In fact, the combination of the factor datasets for the regional settings with high income, high waste management standards, and a high share of renewables defines the majority of ELFM scenarios that are not preferable in both climate and economy under Quadrant IV (-NPV, +GWP) of the trade-off plot (Figure 14). Conversely, regions with low income, low waste management standards, and a high share of fossils define ELFM scenarios that are only preferable in terms of climate under Quadrant III (-NPV, +GWP) of the trade-off plot (Figure 14). For such a regional archetype, the development of (E)LFM can only be motivated by the potential climate savings and not in terms of economy considering the incumbent system condition.

\subsection{Potential policy interventions}

As highlighted in the preceding sections, factors at the system level set up the overarching conditions that influence both the economic performance and climate impact of (E)LFM in Europe. Moreover, as argued in different regional archetypes, the incumbent policy and market conditions make it particularly difficult to develop economically beneficial (E)LFM projects. However, changes at the system level are also possible, considering the influence of policymakers. The potential of such policy interventions has been a common topic in previous research, but few studies have so far assessed to what extent such instruments would actually influence the performance of different (E)LFM projects ( $P_{5}$ and $\left.P 6\right)$.

Several policy instruments raised in previous studies are relevant to achieving favorable system-level conditions. The costs for handling the bulk fractions such as $\mathrm{RDF}$ and fines residue can, for instance, be lowered by decreasing the gate fees for incineration (Frändegård et al., 2015) and lifting the taxes for re-landfilling (Rosendal, 2015). In terms of motivating resource recovery, the internal WtE of RDF can further benefit from subsidies for producing energy from renewable resources (Ford et al., 2013; Van Passel et al., 2013). Similarly, higher utilization rates of fines residue can be achieved by implementing more inclusive market quality standards for secondary material use (Blasenbauer et al., 2020). When it comes to potential climate benefits, additional revenues can be obtained through monetary valuation based on emission trading schemes (Van Passel et al., 2013; Winterstetter et al., 2015).

However, the suggested policy instruments in previous studies are discussed in relation to a single case. Hence, the knowledge of the influence of policy instruments on the 
economics of (E)LFM projects remains unknown for a broader regional scope. In addition, the policy instruments are often separately explored in previous studies. Hence, a comparison among different options is not done, making it difficult to identify the most effective ones. Furthermore, it should be emphasized that not all the (E)LFM scenarios are climate beneficial. In this regard, an extended climate assessment should be used to complement the development of not just profitable but also climatebeneficial (E)LFM projects. That is, the implementation of policy instruments should be limited only to projects with potential climate savings. Otherwise, without such restriction, even the projects with net climate burden will be unreasonably incentivized.

The economic and climate assessment of ELFM in Paper 3 allowed the exploration of a number of policy instruments to determine their potential in supporting scenarios with net climate savings. As mentioned earlier, a more significant share (38\%) of the ELFM scenarios is only climate-beneficial, while a minor share (9\%) is preferable in terms of both economy and climate. In this policy analysis, the resulting increase in the share of preferable scenarios in terms of climate and economy is observed in the effect of four different policy instruments (Figure 17).

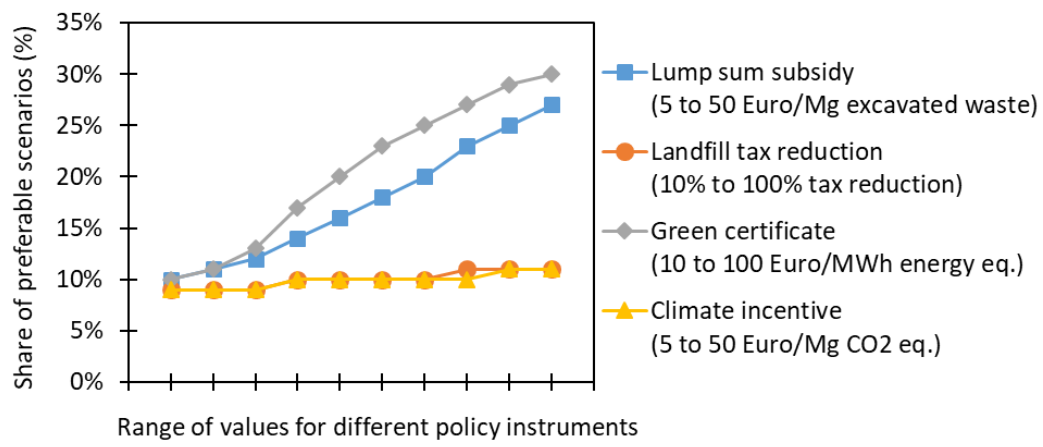

Figure 17. Explored policy instruments to support ELFM scenarios with net climate savings $\left(P_{3}\right)$. The increase in the share of preferable scenarios in terms of both climate impact and economic performance is illustrated with respect to the increase in the value (10 points across the explored range) of individual policy instruments.

The climate savings incentive and landfill tax reduction barely influence the results with a maximum increase of up to $2 \%$ for each instrument. The climate savings incentive is ineffective as the magnitude of reduced $\mathrm{CO}_{2}$ eq. emissions from ELFM is low as well as its monetary valuation even with a maximum of 50 Euro/ $\mathrm{Mg}$ of $\mathrm{CO}_{2}$ eq. This is in relation to the low avoided costs from the reference landfill case that sets the climate benefits but also the economic deficits. With a generic approach, this result gives a perspective on the influence of valuating $\mathrm{CO}_{2}$ eq. only for climate-beneficial projects. In previous case-specific studies that dealt with the same landfill site, different modeling considerations (i.e., background energy mix and extent of material recovery) result in a contrasting conclusion about the importance of valuating $\mathrm{CO}_{2}$ eq. as either significant (Danthurebandara et al., 2015) or insignificant (Winterstetter et al., 2015). 
Similarly, landfill tax reduction is also shown to be ineffective for improving the economic performance of climate-beneficial projects. One reason is that for ELFM, the costs for the re-landfilling of residues are significantly less important than for traditional LFM due to high investment and processing costs for RDF and slag valorization. So for ELFM, landfill tax reduction is not enough to compensate for the high processing costs as well as the above-mentioned low avoided costs of the poor reference case. Again, this brings up the trade-off for choosing landfills with poor reference cases, which is good for the climate due to the avoided landfill gas emission but bad for economics with low avoided costs. In this regard, a better policy instrument is to implement a more stringent requirement for managing landfills in general, thereby increasing the avoided costs. In line with this, a refund for landfill tax has also been proposed (Rosendal, 2015), considering that it has already been paid before.

On the contrary, the green energy certificate and lump-sum subsidy are shown to be effective with a maximum increase in the share of preferable scenarios of up to $21 \%$ and $18 \%$, respectively. These policy instruments are both forms of subsidies that could directly reduce or compensate for the high processing costs involved in ELFM projects. The green certificate subsidizes the production of CHP, syncrude, and $\mathrm{H}_{2}$, provided that the RDF from the excavated landfill waste is considered as a renewable source. Such considerations are assumed in the previous economic assessments of (E)LFM in countries with existing green certificates, including Scotland at 40 Euro/MWh (Ford et al., 2013) and Belgium at about 100 Euro/MWh (Van Passel et al., 2013). However, there are differences between these studies when considering RDF as a renewable source of energy. Ford et al. (2013) considered the entire RDF as renewable, while Van Passel et al. (2013) considered only the biomass fractions.

The lump-sum subsidy is comparable to the remediation subsidy that is implemented to address the sanitation of contaminated sites or so-called brownfields. However, in this regard, motivation in terms of climate impact may not be enough, and complementary local risk assessment may be needed. For instance, depending on the site condition, such local risks can be exacerbated by the failure of landfill containment systems due to age (Frändegård et al., 2015) or flooding, especially in low-lying areas (Laner et al., 2009; Wille, 2018; Winterstetter et al., 2018). Other motivations include the fact that several landfills are in the proximity of growing urban settlements and that such landfill areas can be converted to more productive purposes.

Notably, the analysis presented here is limited to the effects of the individual policy instruments. However, it is also a possibility for these instruments to be implemented in a combination that can further result in favorable system conditions for developing both economically and climate-beneficial (E)LFM projects. For instance, the implementation of both the green energy certificate and lump-sum subsidy can result in a significant increase in the share of preferable ELFM scenarios. This quantitative policy analysis shown in this thesis highlights the significant influence of changing the overarching system conditions to promote (E)LFM projects in Europe. It supports the previous studies that call for the recognition and institutionalization of (E)LFM as an alternative strategy for landfill management (Machiels et al., 2019; Johansson et al., 2017; Krook et al., 2018). Without such recognition among policymakers, the current system conditions will continue to make it hard for landfill mining investors and practitioners to develop both economic and climate-beneficial (E)LFM projects. 
8. Contextualizing the methodological contributions of this thesis 
All the presented results are based on the factor-based method designed to perform a generic and learning-oriented assessment, which covers wide variations of factors at the site, project, and system levels expected for (E)LFM scenarios in Europe, followed by in-depth analyses to understand the important factors and their combinations to guide the development of strategies for improvement. In this section, the difference of this category of assessment is contextualized with respect to other elicited categories from the literature review of related studies. It is followed by contrasting how the type of results from using the factor-based method ( $P_{1}$ to $P_{3}$ ) differ from other assessment studies and their implications. The main parts of this section are based on the literature review of economic assessment studies $\left(P_{5}\right)$ and is extended to cover the climate impact assessments as similar main points were observed as part of the broader review of technological and sustainability (i.e., economic, environmental, and social) aspects of (E)LFM (P6).

\subsection{Identified categories of assessment}

Sustainability assessments can be structured aiming to address different types of challenges and knowledge needs (Finnveden and Moberg, 2005; Swarr et al., 2011). From the literature review of previous assessments of (E)LFM, Figure 18 shows four categories of assessments (Categories A-D) based on their study object (case studyspecific or generic) and extent of analysis (decision-oriented or learning-oriented). Each of the categories are explained with a particular highlight on category D (generic and learning-oriented) in which the factor-based method belongs.

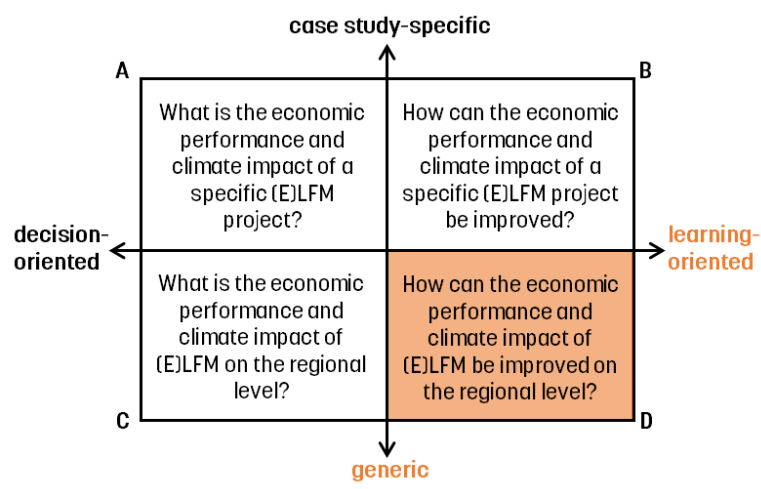

Figure 18. The categorization of assessments (Categories A-D) in terms of study object (case studyspecific or generic) and extent of analysis (decision-oriented or learning-oriented). The factor-based method (highlighted in orange) is categorized as generic and learning-oriented (Category D).

Most of the previous assessments on (E)LFM fall under Category A (decision-oriented and case study-specific). These assessments aim to obtain an estimate of the net economic performance and climate impact of a specific (E)LFM project (Hermann et al., 2016; Wolfsberger et al., 2016; Zanetti and Godio, 2006; Zhou et al., 2015). Such aggregated assessments forecast whether the realization of a planned project will end up with a net profit or net deficit and net climate savings or net climate burden, which 
can be useful to support the go or no-go decisions of a certain landfill owner or project manager. Dealing with a defined landfill site and under a specific system and regional condition, more scenario variations on the project-level are expected; that is, to provide decision support for the landfill practitioner in selecting alternatives considering various technology choices (e.g., a conventional or advanced process) and project organizational setup (e.g., an internal or external process, and different financing and business models). Like Category A, assessment studies under Category $\mathrm{C}$ (decisionoriented and generic) also aim to forecast the net economic performance and climate impact of (E)LFM but for the realization of multiple projects within a broader geographical scope such as national (Ford et al., 2013) and continental scopes (Van Vossen and Prent, 2011). Similar scenario variations in Category A are expected for studies under Category B (generic and decision-oriented) but much more by also considering the variations at the site-specific settings as well as the system conditions within the addressed region in question; that is, to provide decision support for (E)LFM investor in prioritizing landfill sites as well as for policymakers in implementing policy instruments to enable regional LFM development.

Beyond knowing the net economic performance and climate impact, there are also assessments that extend the analysis towards identifying its constituent drivers and their interrelations. The conducted assessments under Category B (learning-oriented and case study-specific) extend the analysis towards the identification of factors that build up the results for a specific (E)LFM project. Such information can be used to facilitate strategic guidance on how the results can be improved (i.e., How can a specific (E)LFM project be technically and organizationally set up to improve its economic performance and climate impact? How influential are the given conditions in terms of the chosen landfill site and the surrounding policy and market conditions?) (Danthurebandara et al., 2015c; Kieckhäfer et al., 2017; Van Passel et al., 2013; Winterstetter et al., 2015). Akin to Category B, the conducted assessments under Category D (learning-oriented and case study-specific) also extend the analysis towards the identification of economic drivers that build up the results, but in this case, for multiple projects within a broader geographical scope. Such results can be useful for various actors interested in investing in (E)LFM as a new line of business (i.e., Given the surrounding policy and market conditions, which landfill sites should be prioritized for (E)LFM?) or for supporting landfill management policymaking (i.e., What policy and market interventions can enable realization of (E)LFM?).

Virtually all categories of assessments for (E)LFM are faced with large knowledge deficits because of the limited implementation of real-life and large-scale projects. As they are ex-ante assessments, the modeling of (E)LFM is expected to involve many assumptions regarding both the selection and settings of the entire process chain and the use and treatment of underlying input data. These assumptions translate as the uncertainties of the assessments, respectively, which must be addressed when performing assessments. However, different assessments are done for different purposes according to the presented categories of assessments, and the importance of addressing these uncertainties and the implications of doing so could thus vary 
between different types of studies. Especially for Category D, with extended study object (from case study-specific to generic) and analysis (decision-oriented to learningoriented), these uncertainties propagate significantly as more (E)LFM scenario possibilities are expected, and subsequent systematic analyses are required (Clavreul et al., 2012; Hellweg and Milà i Canals, 2014; Martinez-Sanchez et al., 2015).

\subsection{Generic and learning-oriented assessment and the factor-based method}

Generic and learning-oriented assessment has seldom been conducted on (E)LFM and those that have suffered from several unaddressed uncertainties. In addition, the identification of economic drivers is only made on a highly aggregated level in terms of main processes and without the granular understanding of the underlying factors and their interactions. The identified shortcomings of this category of assessment $\left(P_{5}\right)$ led to the development and application of the factor-based method ( $P_{1}$ to $P_{4}$ ). Its main feature includes exploratory scenario development accounting for multiple scenario possibilities, and global sensitivity analysis is performed to systematically identify the underlying critical factors and their interrelations (Ferretti et al., 2016; Saltelli and Annoni, 2010). Here, these features of the factor-based method are contrasted with related studies, especially with a synthesis of presented results in the literature review (P5 and $P 6)$.

With a generic study object, large degrees of freedom are expected due to varying factors at the site, project, and system levels that define (E)LFM scenario possibilities. Such multiple degrees of freedom represent the characteristic complexity of modeling the development of emerging concepts such as (E)LFM, which can be aided through participatory scenario development with various experts along the value chain (Voinov et al., 2016; Wender et al., 2014). In Figure 19, selected results on the net economic performance of LFM from different generic assessments are presented to illustrate the differences in information they convey.

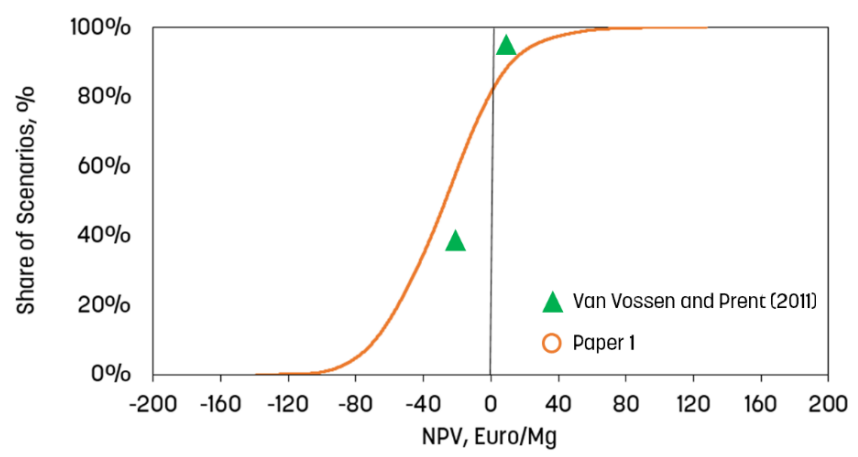

Figure 19. The net economic performance (in Euro/Mg waste) of landfill mining in Europe as presented in selected generic assessments with few scenarios (2 green triangles) in Van Vossen and Prent (2011) and multiple scenarios (531,441 orange circles) in P1 representing the use of the factor-based method in this thesis. 
As exemplified by the study of Van Vossen and Prent (2011), the objective of assessing the economic feasibility of (E)LFM in the entire European region is here addressed by only considering two scenarios involving different sorting technologies, and the obtained results are thus presented as two single values (green triangles in Figure 19). Such few scenarios limit the usefulness of the results in terms of their applicability by missing out on other possibilities for setting up a project, especially for a wider region. This poses specific concerns about to what extent this assessment manages to account for the presumably large variations and multiple possibilities of implementing (E)LFM in Europe with varying site-specific settings and policy and market conditions. Hence, it fails to provide decision support for (E)LFM investors in prioritizing landfill sites as well as for policymakers in implementing policy instruments to enable regional (E)LFM development. The use of such result of limited scenario possibilities can either lead to a bad investment and end up accruing economic liabilities (faulty profitability claim) or hinder further upscaling of the project (faulty non-profitability claim), which can both inhibit the development of emerging concepts that are still at an early phase of development.

As demonstrated in $P_{1}$ to $P_{3}$ under Category $D$ (generic and learning-oriented) using the factor-based method, the economic performance of (E)LFM in Europe can vary widely considering multiple discrete variations of factors (Fo-F11) at the site, project, and system levels, each with three alternatives $\left(3^{12}\right)$. For each project organizational setup, dedicated to understanding the economic drivers $\left(P_{1}\right)$, exploring possibilities for further materials valorization ( $\left.P_{2}\right)$, and the use of advanced technologies $\left(P_{3}\right)$, each model generated 531,441 unique (E)LFM scenario possibilities and presented them as a cumulative distribution plot (orange circles representing $P 1$, Figure 19). It becomes apparent that the knowledge contribution in this case is much broader, which provides more information by showing how much the economic performance and climate impact can vary within Europe as well as showing the corresponding influence of different factors at site, project, and system levels. Without such an explorative approach in scenario development, the results can be of limited usefulness as decision support for landfill investors who need insights on site selection as well as for policymakers who require insights on necessary policy instruments that can drive better economic performance and climate impact of (E)LFM in a region. With a broader view through the explorative scenario development, more information can lead to increased possibilities of how (E)LFM can be developed and specify the roles of landfill investors and policymakers, which is especially needed at this early stage of (E)LFM development.

Furthermore, with an in-depth extent of analysis, a more rigorous and systematic approach is expected in identifying what the important underlying factors are and how they build up the economic performance and climate impact of (E)LFM. Based on such information, improvement strategies can be developed. However, the identification of economic drivers is made in different ways compared to the approach of global sensitivity analysis used in the factor-based method. The studies often just use hotspot analysis, which only specifies how much some selected main processes contribute to 
the net result, while there are also such studies that aim for a more granular understanding through assessing the importance of underlying factors. Local sensitivity analysis is typically used, but it is unsystematic in revealing the critical factors, primarily because of its subjectivity. In addition, it is unable to address the interrelations among the input values that can be between different processes or specific parameters (Ferretti et al., 2016; Saltelli and Annoni, 2010). This concerns the identified important factors and their interrelations, which may affect the subsequent improvement strategies. To exemplify, previous economic assessments (mainly under Categories A and B) analyze and present economic drivers on different levels of aggregation, from the process and sub-process level to specific input parameters, making it difficult to synthesize their results and come up with generic knowledge of re-occurring economic drivers of (E)LFM. Figure 20 shows the economic drivers in terms of main cost and revenue items derived through an attempt to conduct such a synthesis of previous economic assessment of (E)LFM $\left(P_{5}\right)$. In $P_{5}$, different items are quantified based on the reported results, while in $P 6$, different items are only discussed on the same level without any attempt to highlight which among the factors are more relevant.

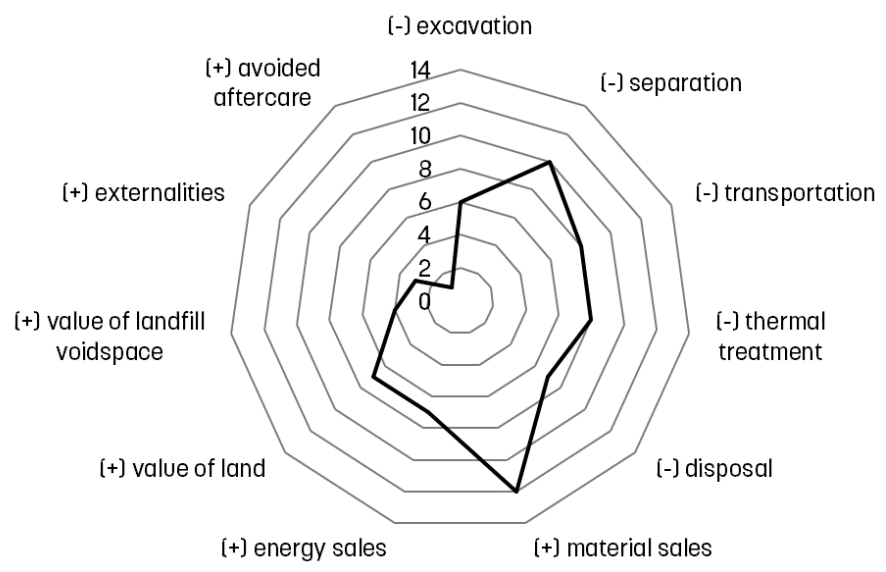

Figure 20. The economic drivers of landfill mining in terms of the main constituent costs and revenue items derived from the collective studies based on the systematic literature review $\left(P_{5}\right)$.

Most of the reviewed studies report that sales from recovered materials (which are almost exclusively related to metals) are an important revenue, while the value of reclaimed land and landfill void space or avoided landfill aftercare costs are less frequently identified as main drivers. Here, however, it is important to understand that this does not mean that such revenue items are not important for the economic outcome of an LFM project, but rather that the thus far conducted case studies have involved landfills with no or low aftercare costs situated in locations with relatively low land values and needs for new landfill void space. This inability to address the importance of case study-specific conditions (e.g., material composition and aftercare needs) and other local settings (e.g., needs and values for land and landfill void space) 
for the economy of (E)LFM projects is an inherent characteristic of the reviewed assessments due to their focus on assessing only one case. Such an approach for the synthesis of results partly undermines the usefulness of the literature reviews of different case studies to elicit generic economic drivers. Hence, in Papers 5 and 6, the identified main process contributors can therefore only serve as hints with respect to a more general understanding.

In contrast, the factor-based method, in a way, normalizes the differences among the individual case studies by pooling in the possible variations of (E)LFM within a region. For instance, in LFM (P2), with the considered site-specific settings as well as regulatory and market conditions, the revenue from the avoided aftercare costs is reported as more important than the sales from recovered materials. The difference in the relative importance of these revenue streams influences the understanding of the economics of LFM. In improving the economics, the focus is not just to improve the quantity, quality, and marketability of recovered materials but also strongly related to the selection of landfills with the potential for avoiding aftercare costs and prospects for other benefits due to reclaimed land and landfill void space. In terms of concerned stakeholders, such an understanding also shifts the focus from the (E)LFM practitioners to also considering policymakers. For instance, policymakers can influence the values of such revenue items by setting the requirements and costs for aftercare as well as the criteria for what is an effective and sustainable use of urban land resources. Furthermore, the identification of important factors through global sensitivity analysis provides a more systematic understanding of what factors throughout the (E)LFM process chain jointly contribute to the economic outcome. For instance, the total-order sensitivity index identifies what factors build up the economy, while its component indices identify how, either in terms of direct effect by individual factors (first-order sensitivity index) or combinational effect due to interrelations among different factors (higher-order sensitivity index). Such information is important for developing subsequent improvement strategies. 
9. Recommendations and reflections on using a generic and learning-oriented assessment 
This section puts into perspective how a generic and learning-oriented assessment can provide guidance for applied research to address inherently large knowledge deficits when dealing with emerging concepts. In addition, the limitations and corresponding improvements for the presented factor-based method are also discussed as further development for future work.

\subsection{Provision of guidance for applied research}

Due to the emerging character of (E)LFM, extensive and applied research is needed to address key knowledge deficits such as the lack of information about the individual processes of the (E)LFM value chain and a lack of know-how about how (E)LFM could be realized. Information regarding the (E)LFM value chain includes what resources can be extracted from landfills, at what quality levels, and under what conditions they will be accepted on existing markets. In gathering such information, there is a need for well-planned pilot projects in which the efficiency, capacities, and performance of different material and energy recovery technologies are developed and monitored on a large scale. The (E)LFM know-how, in contrast, refers to the facilitation of developing a cost-efficient and climate-beneficial (E)LFM project. For instance, $P_{1}$ and $P_{2}$ identified that the most critical factors that drive the economy of LFM are at the system level, such as the costs for waste disposal, treatment, and transport, the imposed alternative landfill management that dictates the indirect revenue, and the background material and energy systems. In particular, knowing that high alternative landfill management costs drive cost-efficiency ( $P_{1}$ and $\left.P_{2}\right)$ and a fossil-based background material and energy system drives climate savings $\left(P_{3}\right)$, it pinpoints the prioritization of selecting promising landfills sites as platforms for learning about how to extract resources from deposited waste. Moreover, for a specific process improvement (P4), a gasifying agent turned out as the most important process parameter for plasma gasification. Through a generic and learning-oriented assessment, the future of (E)LFM research can be guided towards addressing key challenges and potential solutions for improvement (Fleischer et al., 2005; Wender et al., 2014). As in the factor-based method, it is done by considering the available knowledge from previous studies as well as the knowledge of experts on how future scenario developments would look (van der Giesen et al., 2020; Villares et al., 2017).

In consideration of (E)LFM as an investment-intensive undertaking, it is necessary to assure the usefulness of assessments in terms of their applicability for facilitating the strategic development of future projects. As mentioned, with the emerging character of (E)LFM, simply knowing the net economic performance and climate impact (decision-oriented studies, Categories A and C) may hinder its further upscaling and adaptation as an alternative approach for landfill management, especially knowing that (E)LFM can result to a wide range of results from net profit to net deficit and from net climate savings to net climate burden. Above all, the current large knowledge deficits must be first addressed. Learning-oriented studies can work as complementary assessment approaches to today's often-seen decision-oriented studies. As more extensive and applied research must be carried out to increase the empirical support, 
one fundamental question is which landfill site must be prioritized to exemplify economic and climate-preferable projects. Selection of site primarily depends on the system setting answering which are the favorable policy and market conditions. In this regard, generic and learning-oriented studies (Category D) can be used to determine strategic locations for future pilot-scale and (eventually) large-scale project implementations. Then, to direct individual (E)LFM projects in terms of technological choices and project organizational setup, case study-specific and learning-oriented studies (Category B) can be used. In this way, more practical knowledge and primarysourced data will become available, feeding into the generic studies and hence improving its results. With widely accepted conclusions that reveal the economic performance and climate impact of (E)LFM in a more systematic way, further development of favorable policy and market conditions can be advised for more costefficient and climate-preferable (E)LFM projects and provision of guidance for key research areas. In this manner, early discrimination of (E)LFM, just like other emerging concepts and technologies, can be avoided and their responsible innovation promoted (Hetherington et al., 2014; Wender et al., 2014).

\subsection{Limitations and possible improvements of the factor-based method}

The factor-based method uses multiple scenario development and global sensitivity analysis to address the breadth and depth of the assessment essential for a generic and learning-oriented assessment. However, there are some criticalities when using the factor-based method including the plausibility of full factorial combinations, selection of factors, and inclusion of parametric uncertainties.

As previously mentioned, the advantage of the full factorial combination is that it allows exploratory scenario development enabling the determination of (E)LFM project possibilities that are preferable in terms of economy and climate. However, it is also a limitation as there is a difficulty in checking the plausible scenario upon allowing all factor combinations, considering the current system conditions. As an approach to it, specific regional archetypes are simulated to narrow down the factor combinations and elicit more specific insights in terms of tailored project setups (Section 7.2). Another approach is to add another set of factors, modifying factors, which correspond to the plausibility of such a factor combination to happen and assess its influence on the overall result.

The selection of factors is tricky as it can be in different levels of aggregation, like from process level to sub-process level. It should be clear that the selection of factors should depend on the purpose of the study. In the case of how it is used, it is about identifying the important factors of the economic performance ( $P 1$ and $P 2)$ and climate impact $\left(P_{3}\right)$ of (E)LFM in Europe. Thus, the level of aggregation of factors depends on the investigated scenario considerations in previous studies as well as the input of experts through the working group on LFM within the COST-Action MINEA. Hence, the selected factors encompass covering possible variations in the site-specific settings, project setup, policy and market conditions, and background material and energy systems. In contrast, for understanding a specific process such as plasma gasification 
alone $\left(P_{4}\right)$, the selected factors refer to the input and output of the sub-processes. This can later be a guide for selecting fewer factors for plasma gasification as used in multiprocess concept such as (E)LFM. For instance, it is the use of $P_{4}$ that led to the selection of steam and $\mathrm{O}_{2}$ as the fixed gasifying agent for the assessment of ELFM in $P_{3}$.

Regarding parametric uncertainties, they are often unaccounted for by using single input values instead of a range of values. Such a range covers both the stochastic uncertainties due to natural variations in the efficiency and performance of the (E)LFM processes as well as epistemic uncertainties caused by the lack of practical experiences about these processes and is usually substituted by proxy data, which in itself is uncertain. Accounting for parametric uncertainties is expected for all the categories of assessment to properly account for the variation of data values and the extent of their effect on the spread of the study results. For now, this is addressed in the factor-based method as discreet alternatives (average value per alternative). However, some factor alternatives, especially for ELFM, refer to different technologies, such as the different valorization routes of syngas and slag, which may also have wide process variations. In this case, what is missed is the specific parameter improvement beyond just pinpointing its importance. Such methodological rigor has some major implications on how to execute data collection. For better empirical support in all categories of studies, the collection of data for different processes and parameters should aim to cover the range of possible variation rather than to obtain, as in many cases, a single (but highly uncertain) value. In practice, this means having a detailed data collection among various experts along the (E)LFM value chain, specifying the range of possible values accounting for both stochastic and epistemic uncertainties.

Furthermore, extensions of the assessment in terms of the broader sustainability perspective can be done. The environmental perspective is only represented here through a single impact category, which is climate change, although several impact categories were also included in $\mathrm{P}_{4}$, but not for all the papers, to allow in-depth comparative analysis rather than broader analysis. In addition, the inclusion of local impact categories such as human toxicity would require further elemental and substance flow analysis following the input and output of the entire (E)LFM process chain. Similarly, the impact of the "do nothing" reference case can also be improved by accounting for probabilities of design failure, especially when covering a longer lifespan of about 100 years (Sauve et al., 2021). The extension in terms of social perspective can also be done, accounting for possible societal costs and benefits. One way to do this is through monetization, just like the climate savings here. However, monetization of societal costs and benefits would be more meaningful when dealing with smaller regions (Damigos et al., 2016; Einhäupl et al., 2021) and hence could be an additional step after a certain priority region or site is identified from the prior economic and environmental assessment. 
10. Conclusions 
In this thesis, a factor-based method was developed and applied to assess the economic performance and climate impact of (E)LFM in Europe. It is a generic method that allows multiple scenario development accounting for varying factors at the site, project, and system levels, which can be encountered within the broad European scope. It is also a learning-oriented method that allows aggregated to granular understanding-net results, important underlying factors, and interrelations among factors, which aids in the development of strategies for achieving beneficial (E)LFM projects in terms of economy and climate. In consideration of varying site and system conditions, three of the appended papers were used to contrast the varying technological and organizational setups such as traditional LFM with external WtE treatment, traditional LFM with internal incineration and extended utilization of fines residue, and ELFM with plasma gasification and valorization of syngas and slag.

Across the varying technological and organizational setups, it was shown that (E)LFM is a challenging business venture with an average net deficit, while more promising in terms of climate with average net climate savings. Apart from the average scenario results, the characteristic wide range-from net deficit to net profit and from net climate burdens to net climate savings-highlighted the importance of site and system conditions. That is, the varying technological and organizational setups at the project level must be in coordination with other factors occurring on the site and system levels to improve the economic performance and reduce the climate impact of (E)LFM. In general, multiple resource recovery should be aimed for accounting for the associated economic and climate benefits directly from recovered materials and energy, reclaimed land, or landfill void space, and indirectly from the reference landfill management in terms of avoided costs and avoided landfill gas emission, respectively. Moreover, the importance of these aspects varies depending on the specific technological and organizational setups, which has implications for the selection of priority sites.

In terms of economic performance, traditional LFM is driven by the avoided costs from the reference landfill management and the costs for waste handling for fines residue. Hence, sites with high costs for the reference case and with low costs for treatment and disposal are preferred for improved economic performance. On the other hand, ELFM is more driven by the revenues from recovered material and energy. Hence, it should be implemented in regions where market acceptance at a competitive price is assured. Otherwise, the revenues will not be able to compensate for the expensive costs of the advanced and extended technologies for processing. In terms of climate impact, both traditional LFM and ELFM are driven by the reference case. That is, sites with no landfill gas collection and treatment should be prioritized for climate savings in terms of avoided landfill gas emission. In addition, sites with a high fossil share for background material and energy systems lead to a higher climate savings due to higher avoided climate burden from the substituted primary production of material and energy. These particular pre-conditions are especially relevant for ELFM to compensate for the high climate burden from material and energy input for advanced and extended technologies for processing. 
However, it is notable that the abovementioned strategies for site selection (i.e., low costs for waste handling, high avoided costs for reference case, high market prices, and background system with high-fossil share) can be of arguable plausibility considering the incumbent policy and market conditions. Hence, the development of projects also depends on the specific situation that is relevant for landfill practitioners in specific regional settings. By narrowing down the factor combinations through regional archetype analysis, more specific insights on site selection and project setup were elicited. For instance, whereas cost-efficient projects can mainly be achieved by minimizing expenditures for treatment and disposal of waste in the case of high waste management costs, maximizing revenues by intensive sorting and upgrading of materials is more important than minimizing costs for managing waste in regions with low waste management costs. In the former case, material revenues are of minor importance for the project economy, whereas they are the main drivers in the latter case.

Indeed, the incumbent policy and market conditions make it difficult to develop beneficial (E)LFM projects, but it also can lead to significant change considering the influence of the policymakers. Several policy instruments were shown to be relevant in improving the economics of (E)LFM. Instruments in the form of remediation subsidies and green energy certificates were shown to be more effective than a reduction in landfill tax and GWP incentives through the monetary valuation of climate savings. Furthermore, it should be emphasized that such policy instruments must be complemented by climate assessments or broader environmental assessments to avoid unreasonable incentives for (E)LFM projects that are not climate or environmentally beneficial. In particular, it is known that (E)LFM projects can also result in climate burdens. Furthermore, before such policy interventions can come into question, the (E)LFM knowledge area needs to mature further by taking the current knowledge levels of such process and value chains beyond the laboratory and small-scale trials to full-scale operations in which the technical feasibility, as well as the economic and climate implications, are demonstrated in practice.

In sum, the use of a generic and learning-oriented type of assessment, such as the factor-based method in this thesis, was shown to be relevant for understanding and guiding the future implementation of an emerging concept such as (E)LFM. This can also be applied to a wide range of emerging sustainable solutions and circular economy strategies, go beyond a case study approach and guide future research, support strategic decision making, and facilitate project implementation under a variety of boundary conditions and settings. With respect to the developed model, an extension to integrate more environmental impact categories apart from climate, as well as the social dimensions in the assessment, should be envisaged to provide a single tool for well-informed decision-making on (E)LFM. Furthermore, this thesis highlights the important role of assessments, which is not only limited for the assessment of net performance but also for learning and guiding the development of emerging concepts. 


\section{References}


Ahlroth, S., Nilsson, M., Finnveden, G., Hjelm, O., Hochschorner, E., 2011. Weighting and valuation in selected environmental systems analysis tools e suggestions for further developments. J Clean Prod 19, 145-156.

https://doi.org/10.1016/j.jclepro.2010.04.016

Bosmans, A., Vanderreydt, I., Geysen, D., Helsen, L., 2013. The crucial role of Wasteto-Energy technologies in enhanced landfill mining: A technology review. J Clean Prod 55, 10-23. https://doi.org/10.1016/j.jclepro.2012.05.032

Brandão, M., Heath, G., Cooper, J., 2012. What Can Meta-Analyses Tell Us About the Reliability of Life Cycle Assessment for Decision Support? J Ind Ecol 16, 3-7. https://doi.org/10.1111/j.1530-9290.2012.00477.x

Brealy, R.A., Myers, S.C., Allen, F., 2011. Net Present Value and Other Investment Criteria, in: Principles of Corporate Finance. The McGraw-Hill/Irwin, New York, pp. 101-115.

Brennan, R.B., Healy, M.G., Morrison, L., Hynes, S., Norton, D., Clifford, E., 2016. Management of landfill leachate: The legacy of European Union Directives. Waste Manag 55, 355-363. https://doi.org/10.1016/j.wasman.2015.10.010

Burlakovs, J., Kriipsalu, M., Klavins, M., Bhatnagar, A., Vincevica-Gaile, Z., Stenis, J., Jani, Y., Mykhaylenko, V., Denafas, G., Turkadze, T., Hogland, M., Rudovica, V., Kaczala, F., Rosendal, R.M., Hogland, W., 2017. Paradigms on landfill mining: From dump site scavenging to ecosystem services revitalization. Resour Conserv Recycl 123, 73-84. https://doi.org/10.1016/j.resconrec.2016.07.007

Burlakovs, J., Jani, Y., Kriipsalu, M., Vincevica-Gaile, Z., Kaczala, F., Celma, G., Ozola, R., Rozina, L., Rudovica, V., Hogland, M., Viksna, A., Pehme, K.M., Hogland, W., Klavins, M., 2018. On the way to "zero waste" management: Recovery potential of elements, including rare earth elements, from fine fraction of waste. J Clean Prod 186, 81-90. https://doi.org/10.1016/j.jclepro.2018.03.102 Calderón Márquez, A.J., Cassettari Filho, P.C., Rutkowski, E.W., de Lima Isaac, R., 2019. Landfill mining as a strategic tool towards global sustainable development. J Clean Prod 226, 1102-1115. https://doi.org/10.1016/J.JCLEPRO.2019.04.057

Ciuffo, B., Miola, A., Punzo, V., Sala, S., 2012. Report on the application of different sensitivity analysis techniques to field-specific simulation models Dealing with uncertainty in sustainability assessment. Ispra, Italy.

https://doi.org/10.2788/57452

Clavreul, J., Guyonnet, D., Christensen, T.H., 2012. Quantifying uncertainty in LCAmodelling of waste management systems. Waste Manag 32, 2482-2495. https://doi.org/10.1016/J.WASMAN.2012.07.008

Clavreul, J., Guyonnet, D., Tonini, D., Christensen, T.H., 2013. Stochastic and epistemic uncertainty propagation in LCA. Int $J$ Life Cycle Assess 18, 1393-1403. https://doi.org/10.1007/s11367-013-0572-6

Confederation of European Waste-to-Energy Plants, 2017. Landfill taxes and bans [WWW Document]. URL http://www.cewep.eu/wpcontent/uploads/2017/12/Landfill-taxes-and-bans-overview.pdf (accessed 3.1.19).

Cossu, R., Williams, I.D., 2015. Urban mining: Concepts, terminology, challenges. 
Waste Manag 45, 1-3. https://doi.org/10.1016/j.wasman.2015.09.040

Cucurachi, S., Giesen, C. Van Der, Guinée, J., 2018. Ex-ante LCA of emerging

technologies. Procedia CIRP 69, 463-468.

https://doi.org/10.1016/j.procir.2017.11.005

Damigos, D., Menegaki, M., Kaliampakos, D., 2016. Monetizing the social benefits of landfill mining: Evidence from a Contingent Valuation survey in a rural area in Greece. Waste Manag 51, 119-129.

https://doi.org/10.1016/j.wasman.2015.12.012

Danthurebandara, M., Van Passel, S., Machiels, L., Van Acker, K., 2015a. Valorization of thermal treatment residues in Enhanced Landfill Mining: Environmental and economic evaluation. J Clean Prod 99, 275-285.

https://doi.org/10.1016/j.jclepro.2015.03.021

Danthurebandara, M., Van Passel, S., Van Acker, K., 2015b. Environmental and economic assessment of “open waste dump” mining in Sri Lanka. Resour Conserv Recycl 102, 67-79. https://doi.org/10.1016/j.resconrec.2015.07.004

Danthurebandara, M., Van Passel, S., Vanderreydt, I., Van Acker, K., 2015c. Assessment of environmental and economic feasibility of Enhanced Landfill Mining. Waste Manag 45, 434-447. https://doi.org/10.1016/j.wasman.2015.01.041

Danthurebandara, M., Van Passel, S., Vanderreydt, I., Van Acker, K., 2015d. Environmental and economic performance of plasma gasification in Enhanced Landfill Mining. Waste Manag 45, 458-467.

https://doi.org/10.1016/j.wasman.2015.06.022

Einhäupl, P., Krook, J., Svensson, N., Van Acker, K., \& Van Passel, S. (2019). Eliciting stakeholder needs - An anticipatory approach assessing enhanced landfill mining. Waste Manag 98, 113-125.

El-Fadel, M., Findikakis, A.N., Leckie, J.O., 1997. Environmental Impacts of Solid Waste Landfilling. J Environ Manage 50, 1-25.

https://doi.org/10.1006/JEMA.1995.0131

Ellen MacArthur Foundation, 2013. Towards the Circular Economy [WWW Document]. URL http://circularfoundation.org/sites/default/files/tce_report1_2012.pdf (accessed 12.7.18).

European Enhanced Landfill Mining Consortium, 2019. EURELCO - EU Funded Landfill Mining Projects [WWW Document]. URL https://eurelco.org/projects/ (accessed 4.7.19).

European Parliament, 2018. Answer to Question No E-003580/18 [WWW Document]. URL http://www.europarl.europa.eu/doceo/document/E-8-2018o03580-ASW_EN.html?redirect\#ref2 (accessed 3.15.19).

Eurostat, 2019. Municipal waste statistics - Statistics Explained [WWW Document]. URL https://ec.europa.eu/eurostat/statisticsexplained/index.php?title=Municipal_waste_statistics (accessed 2.20.20).

Ferretti, F., Saltelli, A., Tarantola, S., 2016. Trends in sensitivity analysis practice in the last decade. Sci Total Environ 568, 666-670. 
https://doi.org/10.1016/j.scitotenv.2016.02.133

Finnveden, G., Moberg, Å., 2005. Environmental systems analysis tools - an overview. J Clean Prod 13, 1165-1173.

https://doi.org/10.1016/J.JCLEPRO.2004.06.004

Fleischer, T., Decker, M., Fiedeler, U., 2005. Assessing emerging technologiesMethodological challenges and the case of nanotechnologies. Technol Forecast Soc Change, New Horizons and Challenges for Future-Oriented Technology Analysis: The 2004 EU-US Seminar 72, 1112-1121. https://doi.org/10.1016/j.techfore.2004.10.005

Ford, S., Warren, K., Lorton, C., Smithers, R., Read, A., Hudgins, M., 2013. Feasibility and Viability of Landfill Mining and Reclamation in Scotland.

Frändegård, P., Krook, J., Svensson, N., 2015. Integrating remediation and resource recovery: On the economic conditions of landfill mining. Waste Manag 42, 137147. https://doi.org/10.1016/j.wasman.2015.04.008

Frändegård, P., Krook, J., Svensson, N., Eklund, M., 2013. Resource and climate implications of landfill mining: A case study of Sweden. J Ind Ecol 17, 742-755. https://doi.org/10.1111/jiec.12039

Glass, G. V, 1976. Primary, Secondary, and Meta-Analysis of Research'. Educ Res 5, 3-8.

Guinée, J., 2016. Life Cycle Sustainability Assessment: What Is It and What Are Its Challenges?, in: Taking Stock of Industrial Ecology. Springer International Publishing, Cham, pp. 45-68. https://doi.org/10.1007/978-3-319-20571-7_3

Gutiérrez-Gutiérrez, S.C., Coulon, F., Jiang, Y., Wagland, S., 2015. Rare earth elements and critical metal content of extracted landfilled material and potential recovery opportunities. Waste Manag 42, 128-136.

https://doi.org/10.1016/j.wasman.2015.04.024

Hellweg, S., Milà i Canals, L., 2014. Emerging approaches, challenges and opportunities in life cycle assessment. Science 344, 1109-13. https://doi.org/10.1126/science.1248361

Hermann, R., Baumgartner, R.J., Sarc, R., Ragossnig, A., Wolfsberger, T., Eisenberger, M., Budischowsky, A., Pomberger, R., 2014. Landfill mining in Austria: foundations for an integrated ecological and economic assessment. Waste Manag Res 32, 48-58. https://doi.org/10.1177/o734242X14541168

Hermann, R., Baumgartner, R.J., Vorbach, S., Wolfsberger, T., Ragossnig, A., Pomberger, R., 2016. Holistic assessment of a landfill mining pilot project in Austria: Methodology and application. Waste Manag Res 34, 646-657. https://doi.org/10.1177/0734242X16644517

Hernandez Parrodi, J.C., Hollen, D., Pomberger, R., 2018. Fine fractions from landfill mining : Potential and main challenges to overcome. Detritus 19-29. https://doi.org/10.31025/2611-4135/2018.13689

Hernández Parrodi, J.C., Höllen, D., Pomberger, R., 2018. Characterization of fine fractions from landfill: A review of previous investigations. Detritus 2, 46. https://doi.org/10.31025/2611-4135/2018.13663

Hetherington, A.C., Borrion, A.L., Griffiths, O.G., McManus, M.C., 2014. Use of LCA 
as a development tool within early research: challenges and issues across different sectors. Int J Life Cycle Assess 19, 130-143.

https://doi.org/10.1007/s11367-013-0627-8

Hogland, M., Āriņa, D., Kriipsalu, M., Jani, Y., Kaczala, F., Luís de Sá Salomão, A., Orupõld, K., Pehme, K.-M., Rudoviča, V., Denafas, G., Burlakovs, J., VincēvičaGaile, Z., Hogland, W., Hogland williamhogland, W., 2018. Remarks on four novel landfill mining case studies in Estonia and Sweden. J Mater Cycles Waste Manag 20, 1355-1363. https://doi.org/10.1007/s10163-017-0683-4

Hogland, W., Hogland, M., Marques, M., 2010. Enhanced landfill mining: material recovery, energy utilisation and economics in the EU (Directive) perspective. ELFM Symp landfill Min Transit to Sustain Mater Manag 209-222.

Hölzle, I., 2019. Analysing material flows of landfill mining in a regional context. J Clean Prod 207, 317-328. https://doi.org/10.1016/j.jclepro.2018.10.002

Hoogmartens, R., Van Passel, S., Van Acker, K., Dubois, M., 2014. Bridging the gap between LCA, LCC and CBA as sustainability assessment tools. Environ Impact Assess Rev 48, 27-33. https://doi.org/10.1016/J.EIAR.2014.05.001

Huijbregts, M.A.J., Gilijamse, W., Ad M. J. Ragas, Reijnders †, L., 2003. Evaluating Uncertainty in Environmental Life-Cycle Assessment. A Case Study Comparing Two Insulation Options for a Dutch One-Family Dwelling. https://doi.org/10.1021/ESo20971+

Huppes, G., Ciroth, A., Lichtenvort, K., Rebitzer, G., Schmidt, W.-P., Seuring, S., 2008. Modelling for Life Cycle Costing, in: Hunkeler, D., Lichtenvort, K., Rebitzer, G., Ciroth, A. (Eds.), Environmental Life Cycle Costing. SETAC, pp. 1731.

ISO, 2006a. International standard ISO 14040:2006 - Environmental management -Life cycle assessment -- Principles and framework.

ISO, 2006b. International standard ISO 14044:2006 - Environmental management -Life cycle assessment -- Requirements and guidelines.

Jain, P., Powell, J.T., Smith, J.L., Townsend, T.G., Tolaymat, T., 2014. Life-Cycle Inventory and Impact Evaluation of Mining Municipal Solid Waste Landfills. Environ Sci Technol 48, 2920-2927. https://doi.org/10.1021/es404382s

Johansson, N., Krook, J., Eklund, M., 2012. Transforming dumps into gold mines. Experiences from Swedish case studies. Environ Innov Soc Transitions 5, 33-48. https://doi.org/10.1016/j.eist.2012.10.004

Johansson, N., Krook, J., Frändegård, P., 2017. A new dawn for buried garbage? An investigation of the marketability of previously disposed shredder waste. Waste Manag 6o, 417-427. https://doi.org/10.1016/j.wasman.2016.05.015

Jones, P.T., Geysen, D., Tielemans, Y., Passel, S. Van, Pontikes, Y., Blanpain, B., Quaghebeur, M., Hoekstra, N., 2013. Enhanced Landfill Mining in view of multiple resource recovery: a critical review. J Clean Prod 55, 45-55. https://doi.org/10.1016/j.jclepro.2012.05.021

Jones, P.T., Wille, J.E., Krook, J., 2018. 2nd ELFM Seminar in the European Parliament: 5 Lessons Learned Why we need to develop a broad Dynamic Landfill Management strategy and vision for Europe’s 500,00o landfills. Policy 
Brief, EU Training Network for Resource Recovery through Enhanced Landfill [WWW Document]. URL https://kuleuven.sim2.be/wpcontent/uploads/2018/12/NEW-MINE-Policy-Brief-December-2018.pdf (accessed 3.24.19).

Kapur, A., Graedel, T.E., 2006. Copper mines above and below the ground. Environ

Sci Technol. https://doi.org/10.1021/eso626887

Kaza, S., Yao, L., Bhada-Tata, P., Van Woerden, F., 2018. What a Waste 2.0: A Global Snapshot of Solid Waste Management to 2050, What a Waste 2.0: A Global Snapshot of Solid Waste Management to 2050. The World Bank.

https://doi.org/10.1596/978-1-4648-1329-0

Kieckhäfer, K., Breitenstein, A., Spengler, T.S., 2017. Material flow-based economic assessment of landfill mining processes. Waste Manag 60, 748-764.

https://doi.org/10.1016/j.wasman.2016.06.012

Krook, J., Baas, L., 2013. Getting serious about mining the technosphere: a review of recent landfill mining and urban mining research.

https://doi.org/10.1016/j.jclepro.2013.04.043

Krook, J., Johansson, N., Frändegård, P., 2015. Landfill Mining: On the Potential and Multifaceted Challenges for Implementation, in: Taherzadeh, Mohammad Richards, T. (Ed.), . CRC Press, pp. 313-330. https://doi.org/10.1201/b18680-15 Krook, J., Jones, P.T., Van Passel, S., 2018. Why Enhanced Landfill Mining (ELFM) needs to be politically acknowledged to facilitate sustainable management of European landfills. Policy Brief, EU Training Network for Resource Recovery through Enhanced Landfill Mining (NEW-MINE) [WWW Document]. URL https://kuleuven.sim2.be/wp-content/uploads/2018/11/NEW-MINE-pdf-PBNov-2018.pdf (accessed 3.24.19).

Krook, J., Svensson, N., Eklund, M., 2012. Landfill mining: A critical review of two decades of research. Waste Manag 32, 513-520.

https://doi.org/10.1016/j.wasman.2011.10.015

Krook, J., Svensson, N., Van Passel, S., Van Acker, K., 2019. What do Recent Assessments Tell Us About the Potential and Challenges of Landfill Mining? Sustain Resour Recover Zero Waste Approaches 267-281. https://doi.org/10.1016/B978-0-444-64200-4.00018-9

Laner, D., Cencic, O., Svensson, N., Krook, J., 2016. Quantitative Analysis of Critical Factors for the Climate Impact of Landfill Mining. Environ Sci Technol 50, 6882-6891. https://doi.org/10.1021/acs.est.6bo1275

Laner, D., Crest, M., Scharff, H., Morris, J.W.F., Barlaz, M.A., 2012. A review of approaches for the long-term management of municipal solid waste landfills. Waste Manag 32, 498-512. https://doi.org/10.1016/j.wasman.2011.11.010 Laner, D., Fellner, J., Brunner, P.H., 2009. Flooding of municipal solid waste landfills - An environmental hazard? Sci Total Environ 407, 3674-3680. https://doi.org/10.1016/j.scitotenv.2009.03.006

Lifset, R., 2012. Toward Meta-Analysis in Life Cycle Assessment. J Ind Ecol 16, S1S2. https://doi.org/10.1111/j.1530-9290.2012.00473.x

Machiels, L., Arnout, L., Yan, P., Tom, P., 2016. Transforming Enhanced Landfill 
Mining Derived Gasification / Vitrification Glass into Low-Carbon Inorganic Polymer Binders and Building Products. J Sustain Metall. https://doi.org/10.1007/s40831-016-0105-1

Machiels, L., Bernardo, E., Jones, P.T., 2019. Enhanced landfill mining, the missing link to a circular economy 2.0? Detritus 2019 - Vol 1-4. https://doi.org/10.31025/2611-4135/2019.13874

Marella, G., Raga, R., 2014. Use of the Contingent Valuation Method in the assessment of a landfill mining project. Waste Manag 34, 1199-1205. https://doi.org/10.1016/j.wasman.2014.03.018

Martinez-Sanchez, V., Kromann, M.A., Astrup, T.F., 2015. Life cycle costing of waste management systems: Overview, calculation principles and case studies. https://doi.org/10.1016/j.wasman.2014.10.033

Monich, P., Rincon, A., Daniel, H., Bernardo, E., 2018. Porous glass-ceramics from alkali activation and sinter-crystallization of mixtures of waste glass and residues from plasma processing of municipal solid waste $188,871-878$. https://doi.org/10.1016/j.jclepro.2018.03.167

Mönkäre, T., Palmroth, M.R.T., Sormunen, K., Rintala, J., 2019. Scaling up the treatment of the fine fraction from landfill mining: Mass balance and cost structure. Waste Manag 87, 464-471.

https://doi.org/10.1016/j.wasman.2019.02.032

Müller, D.B., Wang, T., Duval, B., Graedel, T.E., 2006. Exploring the engine of anthropogenic iron cycles. Proc Natl Acad Sci U S A 103, 16111-16116. https://doi.org/10.1073/pnas.0603375103

NIST/SEMATECH, 2012. NIST/SEMATECH e-Handbook of Statistical Methods.

Pastre, G., Griffiths, Z., Val, J., Tasiu, A.M., Camacho-Dominguez, E.V., Wagland, S., Coulon, F., 2018. A Decision Support Tool for Enhanced Landfill Mining. Detritus 1, 91-101. https://doi.org/10.26403/detritus/2018.5

Pianosi, F., Beven, K., Freer, J., Hall, J.W., Rougier, J., Stephenson, D.B., Wagener, T., 2016. Sensitivity analysis of environmental models: A systematic review with practical workflow. Environ Model Softw.

https://doi.org/10.1016/j.envsoft.2016.02.008

Porta, D., Milani, S., Lazzarino, A.I., Perucci, C.A., Forastiere, F., 2009. Systematic review of epidemiological studies on health effects associated with management of solid waste. Environ Heal 8, 6o. https://doi.org/10.1186/1476-069X-8-6o

Purvis, B., Mao, Y., Robinson, D., 2019. Three pillars of sustainability: in search of conceptual origins. Sustain Sci 14, 681-695. https://doi.org/10.1007/s11625018-0627-5

Quaghebeur, M., Laenen, B., Geysen, D., Nielsen, P., Pontikes, Y., Van Gerven, T., Spooren, J., 2013. Characterization of landfilled materials: Screening of the enhanced landfill mining potential. J Clean Prod 55, 72-83.

https://doi.org/10.1016/j.jclepro.2012.06.012

Rosendal, R., 2015. The economics of landfill mining - focus on the legth of aftercare, in: Proceedings Sardinia 2015, 15th International Waste Management and Landfill Symposium, S. Margherita Di Pula, Cagliari, Italy. Sardinia. 
Rotheut, M., Quicker, P., 2017. Energetic utilisation of refuse derived fuels from landfill mining. Waste Manag 62, 101-117.

https://doi.org/10.1016/j.wasman.2017.02.002

Saavedra, Y.M.B., Iritani, D.R., Pavan, A.L.R., Ometto, A.R., 2018. Theoretical contribution of industrial ecology to circular economy. J Clean Prod. https://doi.org/10.1016/j.jclepro.2017.09.260

Saltelli, A., Aleksankina, K., Becker, W., Fennell, P., Ferretti, F., Holst, N., Li, S., Wu, Q., 2019. Why so many published sensitivity analyses are false: A systematic review of sensitivity analysis practices. Environ Model Softw 114, 29-39. https://doi.org/10.1016/j.envsoft.2019.01.012

Saltelli, A., Annoni, P., 2010. How to avoid a perfunctory sensitivity analysis. Environ Model Softw 25, 1508-1517. https://doi.org/10.1016/j.envsoft.2010.04.012

Saltelli, A., Annoni, P., Azzini, I., Campolongo, F., Ratto, M., Tarantola, S., 2010. Variance based sensitivity analysis of model output. Design and estimator for the total sensitivity index. Comput Phys Commun 181, 259-270. https://doi.org/10.1016/j.cpc.2009.09.018

Saltelli, A., Ratto, M., Andres, T., Campolongo, F., Cariboni, J., Gatelli, D., Saisana, M., Tarantola, S., 2008. Global Sensitivity Analysis: The Primer. John Wiley \& Sons Ltd., Chichester, England.

Shelby, L.B., Vaske, J., 2008. Understanding meta-analysis: A review of the methodological literature. Leis Sci. https://doi.org/10.1080/01490400701881366

Swarr, T., Hunkeler, D., Klopffer, W., Pesonen, H.-L., Ciroth, A., Brent, A., Pagan, R., 2011. Environmental life cycle costing : a code of practice. Society of Environmental Toxicology and Chemistry, Pensacola.

UN Economic Commission for Europe, 2018. Specifications for the application of the United Nations Framework Classification for Resources to Anthropogenic Resources. Geneva.

UNEP/SETAC Life Cycle Initiative, 2011. Towards a life Cycle Sustainability Assessment: Making informed choices on products. UNEP/SETAC Life Cycle Initiative.

van der Giesen, C., Cucurachi, S., Guinée, J., Kramer, G.J., Tukker, A., 2020. A critical view on the current application of LCA for new technologies and recommendations for improved practice. J Clean Prod 259, 120904. https://doi.org/10.1016/j.jclepro.2020.120904

Van Der Zee, D.J., Achterkamp, M.C., De Visser, B.J., 2004. Assessing the market opportunities of landfill mining. Waste Manag 24, 795-804. https://doi.org/10.1016/j.wasman.2004.05.004

Van Passel, S., Dubois, M., Eyckmans, J., De Gheldere, S., Ang, F., Tom Jones, P., Van Acker, K., 2013. The economics of enhanced landfill mining: Private and societal performance drivers. J Clean Prod 55, 92-102. https://doi.org/10.1016/j.jclepro.2012.03.024

Van Vossen, W.J., Prent, O.J., 2011. Feasibility study of sustainable material and energy recovery from landfills in EU, in: Proceedings Sardinia 2011, 13th 
International Waste Management and Landfill Symposium S. Margherita Di Pula, Cagliari, Italy. Sardinia.

Villares, M., Işıldar, A., van der Giesen, C., Guinée, J., 2017. Does ex ante application enhance the usefulness of LCA? A case study on an emerging technology for metal recovery from e-waste. Int $J$ Life Cycle Assess 22, 1618-1633. https://doi.org/10.1007/s11367-017-1270-6

Voinov, A., Kolagani, N., Mccall, M.K., Glynn, P.D., Kragt, M.E., Ostermann, F.O., Pierce, S.A., Ramu, P., 2016. Modelling with stakeholders e Next generation. https://doi.org/10.1016/j.envsoft.2015.11.016

Wagner, T.P., Raymond, T., 2015. Landfill mining: Case study of a successful metals recovery project. Waste Manag 45, 448-457. https://doi.org/10.1016/j.wasman.2015.06.034

Wender, B.A., Foley, R.W., Hottle, T.A., Sadowski, J., Prado-Lopez, V., Eisenberg, D.A., Laurin, L., Seager, T.P., 2014. Anticipatory life-cycle assessment for responsible research and innovation. J Responsible Innov 0. https://doi.org/10.1080/23299460.2014.920121

Wille, E. (2018). Flooding risks at old landfill sites: Linear economy meets climate change. Proceedings of the 4th International Symposium on Enhanced Landfill Mining, 361-365. Mechelen, Belgium.

Winterstetter, A., Laner, D., Rechberger, H., Fellner, J., 2016. Integrating anthropogenic material stocks and flows into a modern resource classification framework: Challenges and potentials. https://doi.org/10.1016/j.jclepro.2016.06.069

Winterstetter, A., Laner, D., Rechberger, H., Fellner, J., 2015. Framework for the evaluation of anthropogenic resources: A landfill mining case study - Resource or reserve? Resour Conserv Recycl 96, 19-30. https://doi.org/10.1016/j.resconrec.2015.01.004

Winterstetter, A., Wille, E., Nagels, P., Fellner, J., 2018. Decision making guidelines for mining historic landfill sites in Flanders. Waste Manag. https://doi.org/10.1016/j.wasman.2018.03.049

Wolfsberger, T., Aldrian, A., Sarc, R., Hermann, R., Höllen, D., Budischowsky, A., Zöscher, A., Ragoßnig, A., Pomberger, R., 2015. Landfill mining: Resource potential of Austrian landfills - Evaluation and quality assessment of recovered municipal solid waste by chemical analyses. Waste Manag Res 33, 962-974. https://doi.org/10.1177/0734242X15600051

Wolfsberger, T., Pinkel, M., Polansek, S., Sarc, R., Hermann, R., Pomberger, R., 2016. Landfill mining: Development of a cost simulation model. Waste Manag Res 34, 356-367. https://doi.org/10.1177/0734242X16628980

Zhang, L., Zhong, Y., Geng, Y., 2019. A bibliometric and visual study on urban mining. J Clean Prod 239, 118067. https://doi.org/10.1016/J.JCLEPRO.2019.118067

Zhou, C., Gong, Z., Hu, J., Cao, A., Liang, H., 2015. A cost-benefit analysis of landfill mining and material recycling in China. Waste Manag 35, 191-198. https://doi.org/10.1016/j.wasman.2014.09.029 
Appended papers 



\section{Papers}

The papers associated with this thesis have been removed for copyright reasons. For more details about these see:

https://doi.org/10.3384/9789179290559 


\section{FACULTY OF SCIENCE AND ENGINEERING}

Linköping Studies in Science and Technology, Dissertation No. 2180, 2021 Department of Management and Engineering

Linköping University

SE-581 83 Linköping, Sweden

wWw.liu.se 